\title{
On-Site Measurement of the Water-Cementitious Ratio and Heat of Hydration of Delivered Concrete
}

\author{
Seyednavid Mardmomen \\ WVU, semardmomen@mix.wvu.edu
}

Follow this and additional works at: https://researchrepository.wvu.edu/etd

Part of the Civil Engineering Commons, Construction Engineering and Management Commons, Structural Engineering Commons, and the Transportation Engineering Commons

\section{Recommended Citation}

Mardmomen, Seyednavid, "On-Site Measurement of the Water-Cementitious Ratio and Heat of Hydration of Delivered Concrete" (2020). Graduate Theses, Dissertations, and Problem Reports. 7562.

https://researchrepository.wvu.edu/etd/7562

This Thesis is protected by copyright and/or related rights. It has been brought to you by the The Research Repository @ WVU with permission from the rights-holder(s). You are free to use this Thesis in any way that is permitted by the copyright and related rights legislation that applies to your use. For other uses you must obtain permission from the rights-holder(s) directly, unless additional rights are indicated by a Creative Commons license in the record and/ or on the work itself. This Thesis has been accepted for inclusion in WVU Graduate Theses, Dissertations, and Problem Reports collection by an authorized administrator of The Research Repository @ WVU. For more information, please contact researchrepository@mail.wvu.edu. 
On-Site Measurement of the Water-Cementitious Ratio and Heat of Hydration of Delivered Concrete

Seyednavid Mardmomen

Thesis submitted to

the Benjamin M. Statler College of Engineering and Mineral Resources at West Virginia University
in partial fulfillment of the requirements for the degree of
Master of Science
in

Civil and Environmental Engineering

Roger H.L. Chen, Ph.D., Chair

Fei Dai, Ph.D.

Hailin Li, Ph.D.

Department of Civil and Environmental Engineering

\author{
Morgantown, West Virginia
}

2020

Keywords: On-site testing; Water-cementitious ratio; Adiabatic temperature rise; Semiadiabatic calorimetry; Adiabatic calorimetry; Isothermal calorimetry; Mass concrete; Ground granulated blast furnace slag; Class F fly ash 


\begin{abstract}
On-site Measurement of the Water-Cementitious Ratio and Heat of Hydration of Delivered

Concrete
\end{abstract}

Seyednavid Mardmomen

In this study, AASHTO T318-15 was adopted to estimate the water content of fresh concrete mixes and then revised to have better precision. The additional step required sieving out the coarse aggregate after drying the sample in a microwave oven, and it was then used in the calculation of the absorbed water and cementitious material content. Several laboratory batches, as well as onsite water-cementitious $(\mathrm{w} / \mathrm{cm})$ ratio tests, were performed on concrete mixes containing ordinary Portland cement, ground granulated blast furnace slag, and Class F fly ash. The results of the experiments indicated that the accuracy of the revised method was increased to an average percentage error of $2.16 \%$ from the actual $\mathrm{w} / \mathrm{cm}$ ratio, while the method based on AASHTO T318 was $6.2 \%$. For cases with high chemical admixtures dosages, washing vinegar was used to wash out the particles around the dried sieved coarse aggregate to calculate the $\mathrm{w} / \mathrm{cm}$ ratio with a more precise mass for each sample.

A simple on-site measurement for the heat of hydration of fresh concrete was conducted using an insulated 1-meter cube. The cube was designed to be well insulated with $8-\mathrm{cm}$ of insulation material on each side. It acted as a semi-adiabatic calorimetry since the heat loss was small. The temperature-time history at the center was used to calculate the adiabatic temperature rise (ATR) of the concrete. An average heat loss characteristic parameter was obtained for each delivered batch using the measured concrete temperature-time history after five days of curing. A finite element model (FEM) was developed to analyze the cube at different ambient environmental conditions. A table with the required insulation for various ambient conditions with a range between -10 to $30^{\circ} \mathrm{C}$ ambient temperatures was also provided so that the setup can accurately estimate the ATR using only the temperature measurement at the center of the cube.

The $w / \mathrm{cm}$ ratio and the heat of hydration test methods were evaluated in three on-site castings in the state of West Virginia. Two of the on-site castings contained Grade 100 ground granulated blast furnace slag. The third on-site casting used Class F fly ash concrete. Several compressive strength cylinders were made and cured at a temperature of $23{ }^{\circ} \mathrm{C}$. The materials used in each onsite casting were also collected to perform compressive strength, adiabatic, and isothermal heat of hydration tests in laboratory conditions. The compressive strength measured on-site was lower than the laboratory batches which indicates a higher $\mathrm{w} / \mathrm{cm}$ ratio was received on-site. The adiabatic temperature rises calculated from the cube's center temperature compared well with the results from both the adiabatic and isothermal calorimetry. Results show that the on-site temperature measurement using the 1-m cube can be considered as a simple and accurate approach to measure the heat of hydration of a delivered concrete batch. 


\section{ACKNOWLEDGEMENTS}

I would like to spread my appreciation to all those who have guided me throughout this journey, prepared me to be a better civil engineer, and made this study possible.

I would like to first thank my advisor, Dr. Roger Chen, for his valuable insights and guidance throughout my entire graduate studies. Aside from your passion and knowledge, your hard-working habits have been an incredible encouragement for knowing more about my potential and working towards bigger goals. Certainly, this study would not be possible without your continuous supports.

Besides my advisor, I would like to also thank my Thesis Committee, Dr. Fei Dai and Dr. Hailin Li, for their encouragement and efforts.

I would also like to acknowledge the support from the West Virginia Department of Transportation (WVDOT) Division of Highways and FHWA for the research project WVDOH RP\#312. Also, the District (4,5 and 10) engineers of WVDOT.

Secondly, I would like to thank my great colleges Guadalupe Leon, Tadamon Mohammed, Amelia Riley, Nawaf Alsulami, Bekir Erdem Bas, Yun Lin, Zhanxiao Ma, and Jared Hershberger. Especially Guadalupe Leon who has been incredibly supportive since the day we started working together with his bright visions and permanent patience.

Finally, I would like to express my deepest gratitude to my beloved family: my parents and my sister for assisting me throughout my graduate educations and for teaching me how to be vulnerable in learning new information each day. 


\section{TABLE OF CONTENTS}

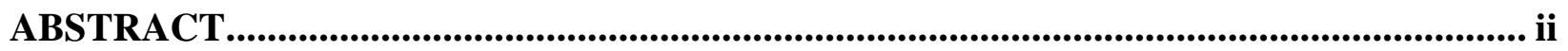

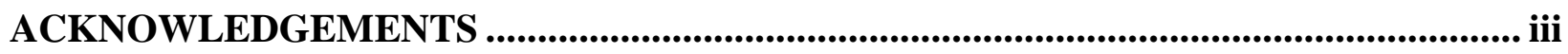

LIST OF TABLES ........................................................................................................................ vi

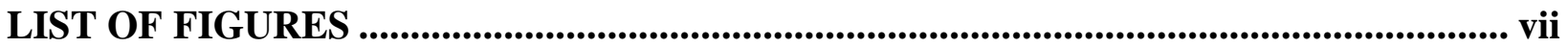

Chapter 1 : Introduction...............................................................................................................................1

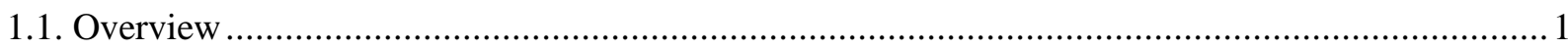

1.1.1. Revised Method for Rapid Determination of On-Site Water-Cementitious Ratio Using

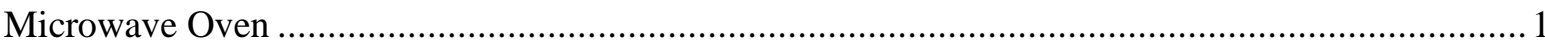

1.1.2. On-Site Measurement of the Adiabatic Temperature Rise of Delivered Concrete ................... 1

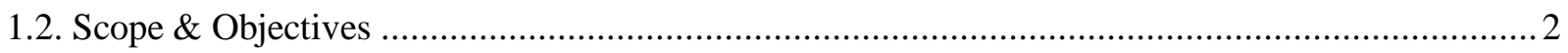

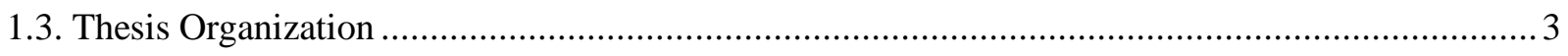

Chapter 2 : Literature Review ...............................................................................5

2.1. Revised Method for Rapid Determination of On-Site Water-cementitious Ratio Using Microwave Oven 5

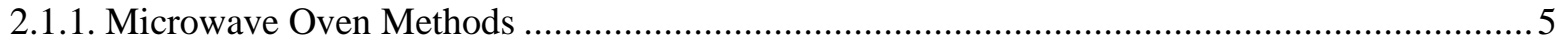

2.1.2. Other w/cm Ratio Measurement Techniques.................................................................. 7

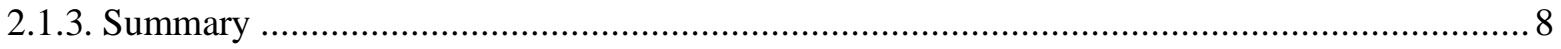

2.2. On-Site Measurement of Adiabatic Temperature Rise of Delivered Concrete ….........................8

2.2.1. Isothermal \& Adiabatic Calorimetry …........................................................................... 9

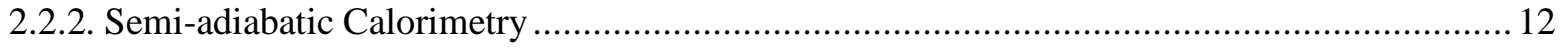

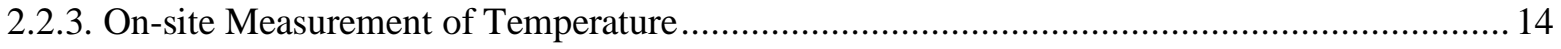

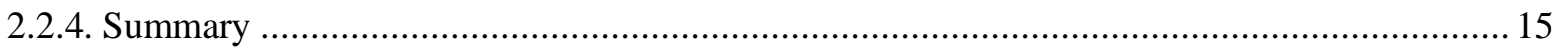

Chapter 3 : Revised Method for the Rapid Determination of On-Site Water-Cementitious Ratio Using Microwave Oven ..........................................................................................................16

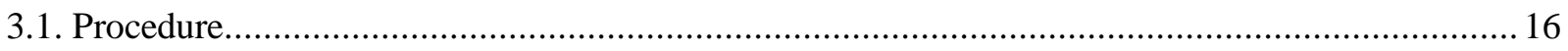

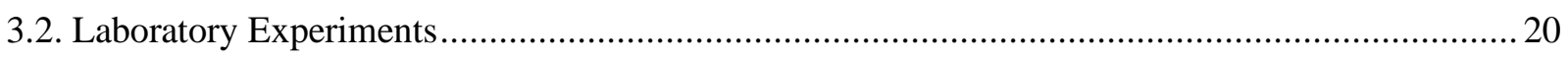

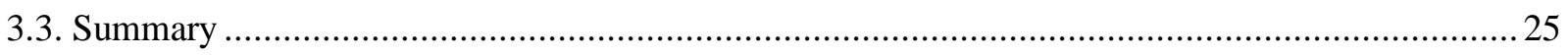

Chapter 4 : On-site Measurement of Adiabatic Temperature Rise of Concrete ...................27

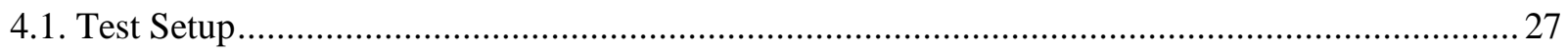

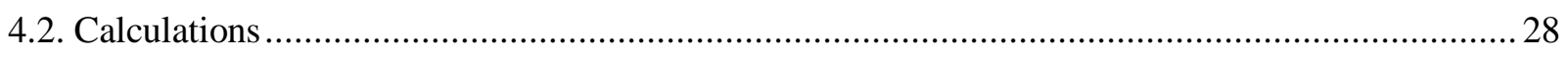

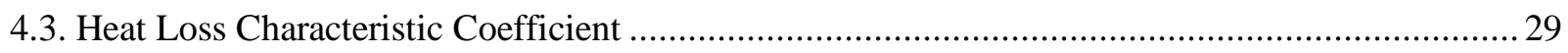




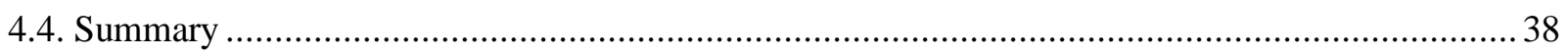

Chapter 5 : On-site testing......................................................................................40

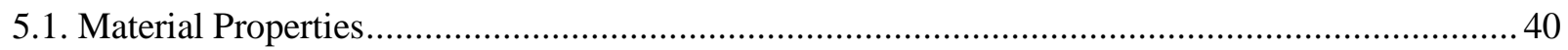

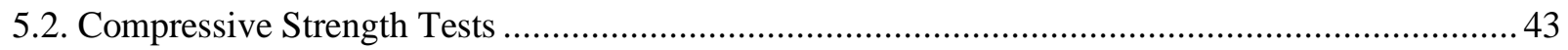

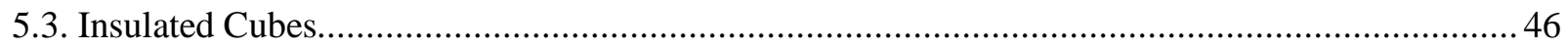

Chapter 6 : Laboratory Tests, Analysis and Comparison of Results ......................................49

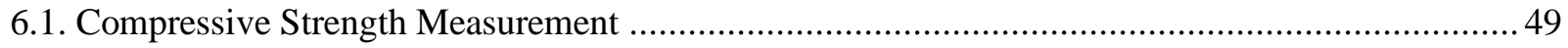

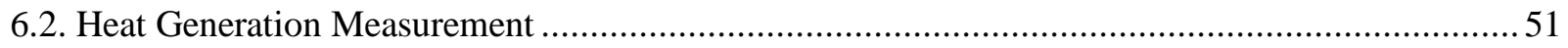

6.3. Adiabatic Temperature Rise Measurement …........................................................................5

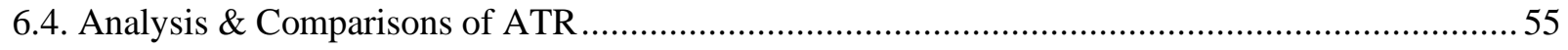

Chapter 7 : Conclusions \& Recommendations .......................................................................64

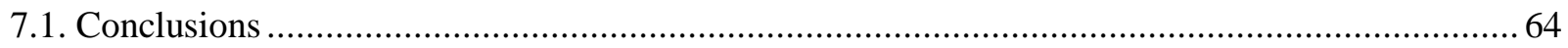

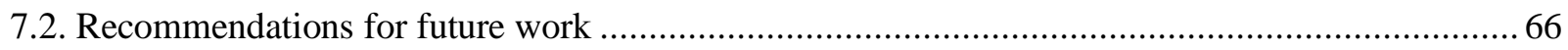

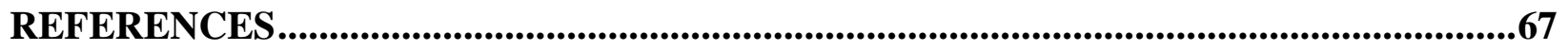

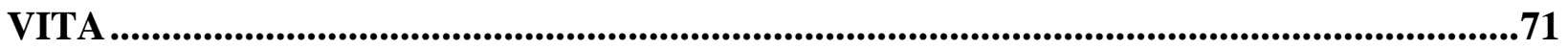




\section{LIST OF TABLES}

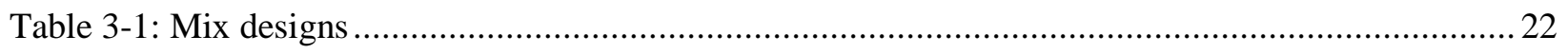

Table 3-2: W/cm ratio results with different mix designs ............................................................ 24

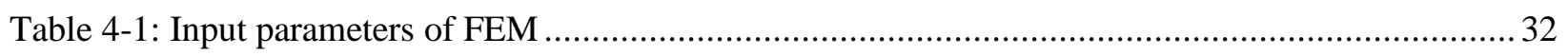

Table 4-2: Required insulation for different ambient temperature .................................................. 35

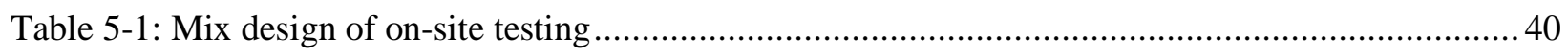

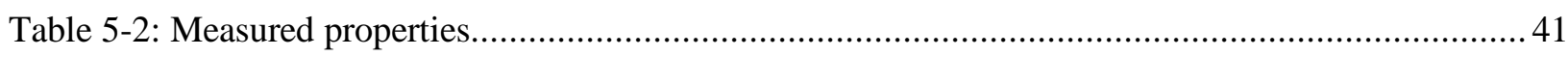

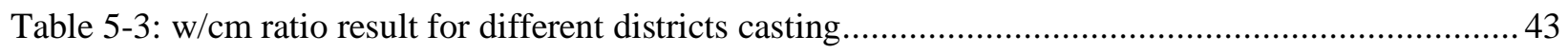

Table 5-4: Comparison of compressive strength 1-day and 28-days................................................. 45

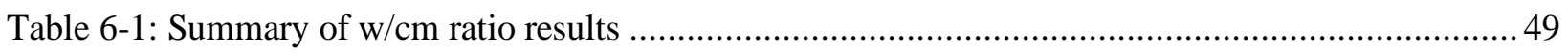

Table 6-2: Calculated heat loss characteristic coefficient for each cube ...............................................56

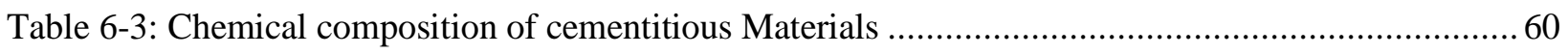

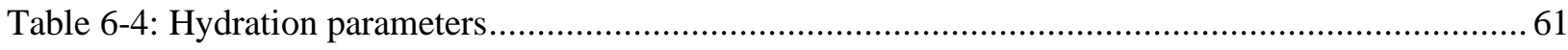




\section{LIST OF FIGURES}

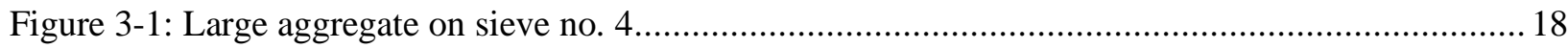

Figure 3-2: (a) Before washing with vinegar, (b) After washing with vinegar ..................................... 19

Figure 3-3: Water loss of cement paste in microwave vs. time ........................................................2 21

Figure 3-4: Water loss trend for different types of mixes............................................................... 23

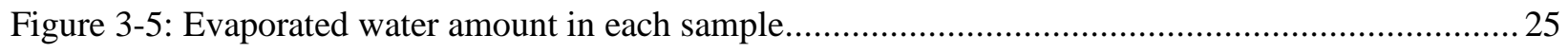

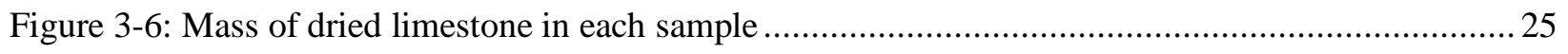

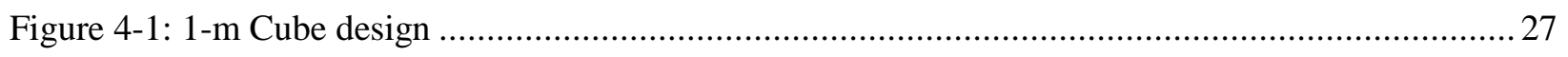

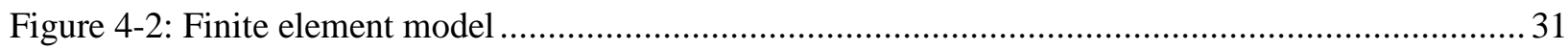

Figure 4-3: The effect of ambient temperature on the temperature of the center location ...................... 33

Figure 4-4: Heat loss characteristic coefficient vs. ambient temperature ............................................ 34

Figure 4-5: ATR error at 7-days due to ambient temperature ....................................................... 34

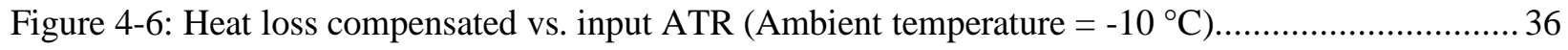

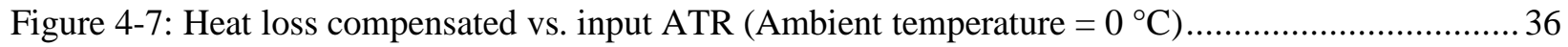

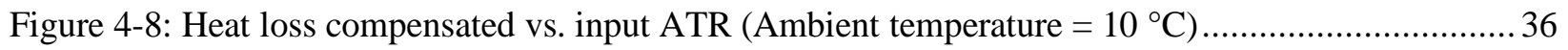

Figure 4-9: Heat loss compensated vs. input ATR (Ambient temperature $=20{ }^{\circ} \mathrm{C}$ ) ........................... 37

Figure 4-10: Heat loss compensated vs. input ATR (Ambient temperature $=30{ }^{\circ} \mathrm{C}$ ) .......................... 37

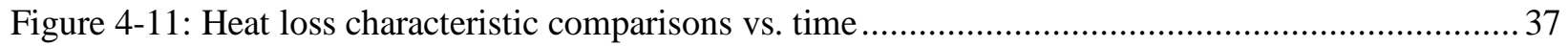

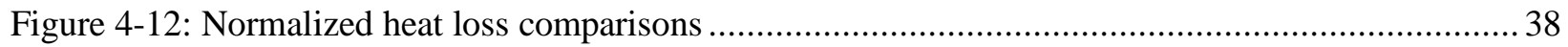

Figure 4-13: Heat loss characteristic coefficient vs. ambient temperature .......................................... 38

Figure 5-1: Onsite testing: (a) slump, (b) air content and (c) temperature measurement ........................ 41

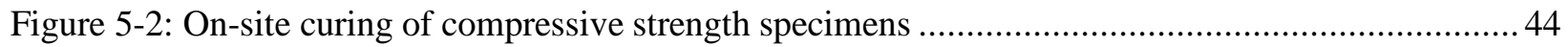

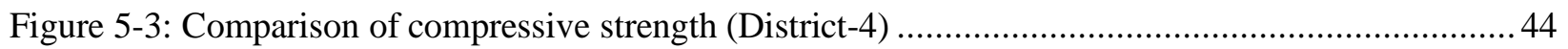

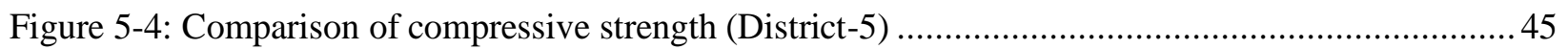

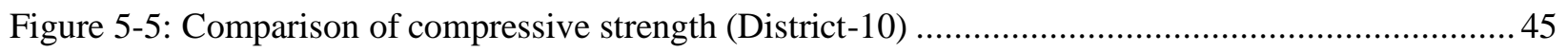

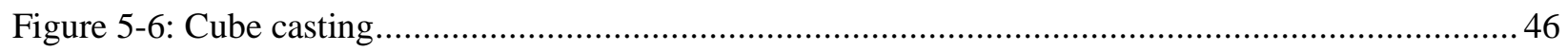

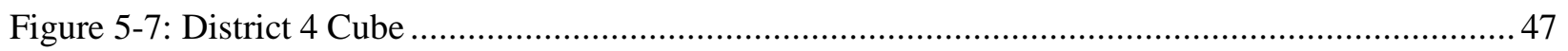

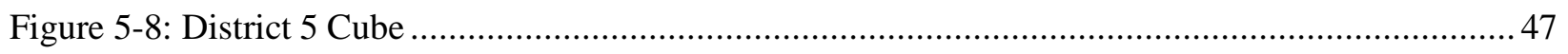

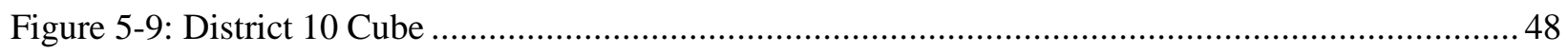

Figure 6-1: The compressive strength comparison of District-4 mix .................................................50

Figure 6-2: The compressive strength comparison of District-5 mix ..............................................50

Figure 6-3: The compressive strength comparison of District-10 mix ............................................ 51

Figure 6-4: Isothermal heat of hydration measurement of District-4 mix ..........................................52 
Figure 6-5: Isothermal heat of hydration measurement of District-5 mix

Figure 6-6: Isothermal heat of hydration measurement of District-10 mix

Figure 6-7: ATR of District-4 mix

Figure 6-8: ATR of District-5 mix .54

Figure 6-9: ATR of District-10 mix .55

Figure 6-10: Cube's heat loss characteristic coefficients vs. reference. .57

Figure 6-11: District 4 adiabatic temperature rise comparison .57

Figure 6-12: District 5 adiabatic temperature rise comparison .58

Figure 6-13: District 10 adiabatic temperature rise comparison .58

Figure 6-14: Comparison of slag materials heat of hydration... 60

Figure 6-15: Heat ratios of slag materials........ 61

Figure 6-16: Analysis vs. experiment (District-4)... 62

Figure 6-17: Analysis vs. experiment (District-5).. .63

Figure 6-18: Analysis vs. experiment (District-10) 63 


\section{Chapter 1 : Introduction}

\subsection{Overview}

\subsubsection{Revised Method for Rapid Determination of On-Site Water-Cementitious Ratio Using Microwave Oven}

The determination of the amount of water in a concrete mix is an important factor to ensure the concrete has good quality and performance. In the past, before the use of water-reducing admixtures, extra water was added to increase the workability of the concrete; concrete was usually ordered within a specific slump range to allow for proper placement and workability. However, adding water to a concrete mix increases the capillary pores and reduces the strength. Researchers have shown that an increment of the water cementitious $(w / \mathrm{cm})$ ratio of 0.01 will cause a strength decrease of approximately 0.86 MPa (Nantung 1998). Neville (Neville 2011) denoted that when the w/cm ratio increased from 0.4 to 0.5 , the compressive strength of the concrete would reduce; the compressive strength reduction at one-day is about $38 \%$, and the strength reduction at one-year is about $17 \%$. Since in modern construction, the concrete's strength is highly important, an accurate and consistent method that can measure the $\mathrm{w} / \mathrm{cm}$ ratio within a short period of time and can be applied in field conditions would be a very useful tool.

\subsubsection{On-Site Measurement of the Adiabatic Temperature Rise of Delivered Concrete}

The curing process of concrete is an exothermic chemical reaction between the cementitious material and the mixing water. The adiabatic temperature rise (ATR) could be significant, depending on the mix proportions and cementitious chemical compositions. High ATRs increase the possibility of thermal cracking in mass concrete structures since the surface of 
the concrete tends to cool down much faster than the inside layers. A precise estimation of the ATR is vital to model the thermal and mechanical behavior of concrete at an early age. Several test methods are available to determine the heat of hydration of concrete. Isothermal, semiadiabatic, and adiabatic calorimetry are the standard test methods that have been used by many researchers. Reaching an exact adiabatic condition is a difficult task. Therefore, semi-adiabatic calorimeters are a more practical way to measure the heat of hydration and needs a less complicated controlling unit. For a semi-adiabatic calorimeter, the heat loss due to the ambient conditions needs to be estimated and added back to calculate the ATR. Building a calorimetry at a job site with various ambient environmental conditions is not an easy task and requires expensive equipment and sophisticated testing procedures. Therefore, an alternative method is needed to measure the unknown ATR of a fresh concrete mix.

\subsection{Scope \& Objectives}

The scope of this thesis was to develop an accurate method for the on-site measurements of the water-cementitious ratio and heat of hydration of a delivered concrete batch. These objectives were completed in the thesis:

$\checkmark$ Development of a revised AASHTO T318-15 method for on-site measurement of w/cm ratio.

$\checkmark$ Laboratory w/cm ratio measurements for different types of concrete mixes and discussions about the accuracy of the method.

$\checkmark$ Development of a simple and accurate method of an on-site heat of hydration measurement of a concrete batch using a 1-m insulated cube.

$\checkmark$ Development of guidelines for using the on-site heat of hydration method at different ambient conditions. 
$\checkmark$ Evaluation of the revised w/cm ratio and on-site heat of hydration measurement in real field castings.

$\checkmark$ Calculation of the adiabatic temperature rise (ATR) using the temperature measurement at the center location after five days of curing.

$\checkmark$ Evaluation of the accuracy of the calculated ATR with adiabatic and isothermal calorimetry.

\subsection{Thesis Organization}

An overview of the organization is as follows:

\section{* Chapter 2:}

This chapter contains different studies for the determination of the watercementitious ratio and heat of hydration of concrete. Literature studies related to both laboratory and on-site measurement techniques are discussed in this chapter.

\section{* Chapter 3:}

This chapter provides the revised method of on-site determination of the water cementitious ratio using microwave oven. The technique is discussed in detail, and the laboratory results are presented.

\section{* Chapter 4:}

The chapter presents the on-site measurement setup for the determination of heat of hydration and adiabatic temperature rise of fresh concrete batch. A table is provided to be used when the setup is used in cold ambient temperatures. 


\section{* Chapter 5:}

This chapter contains the details and the results obtained from three field castings. The on-site water-cementitious ratio testing results, as well as the temperature data obtained from different locations in the cubes, are provided.

\section{* Chapter 6:}

This chapter presents discussions and comparisons between the results provided in Chapter 5 with some laboratory measurements of compressive strength and the heat of hydration. The laboratory compressive strengths were compared to the compressive strengths obtained from the delivered batches. The adiabatic temperature rise obtained from the 1-m cube was compared to isothermal and adiabatic calorimetry measurements.

\section{* Chapter 7:}

This chapter includes a summary of the work that has been done in this study including the conclusions and recommendations for future studies on the same topics. 


\section{Chapter 2 : Literature Review}

\subsection{Revised Method for Rapid Determination of On-Site Water-cementitious Ratio Using Microwave Oven}

Many methods have been reported for measuring w/cm ratio of concrete (Roshore 1973; Naik and Ramme 1987; Nagi and Whiting 1994; Leung and Pheeraphan 1995; Hershberger 2015; Dowell and Cramer 2002; Fox, Trost, and Hellman 2007; Hossain et al. 1996; Chen, Shen, and Shui 2012; Mancio et al. 2010). Since the early 1970s, there have been many research studies that have improved the testing procedure using the microwave oven (Roshore 1973; Naik and Ramme 1987; Nagi and Whiting 1994; Leung and Pheeraphan 1995; Hershberger 2015; Dowell and Cramer 2002; Fox, Trost, and Hellman 2007). The researchers focused on the accuracy, time consumption, cost, and, most importantly, the replicability of two or three samples. Other w/cm ratio measurement techniques were also investigated by the researchers such as the nuclear gauge (Center 1996), chemical titration method (Williamson 1985), flotation method (Nägele and Hilsdorf 1980), electrical resistivity method (K. A. MacDonald and D. O. Northwood 1999), reflectometer apparatus (N. T. Ali et al. 2010), and buoyancy method (Tarun R. Naik and Bruce W. Ramme 1989).

\subsubsection{Microwave Oven Methods}

A study by Naik et al. (Naik and Ramme 1987) considered the microwave method as a fast, simple, inexpensive, and accurate way of determining the water content of a fresh mix and the moisture content of aggregates. The study presents a rapid (15 minutes or less) method for determining the water content of the mix. Approximately 1000-grams of a concrete sample were placed in a microwave oven. The microwave oven was also used to establish natural moisture 
content, absorption, and bulk specific gravity in aggregates in a short period. It was recommended by the authors to test the method in a job-site condition. The authors also had up to $27.8 \%$ error for their laboratory mixes.

Nagi and Whiting (Nagi and Whiting 1994) used a 900-W microwave oven to measure the water content of three different mixes containing fly ash and silica fume, and it was found to be applicable to all the mixes. Approximately 1500-grams were used for each sample. The method was verified to be applicable under actual field conditions at the placements of bridge deck overlays and full-depth pavement repair sections. The measured unit weight of fresh concrete was used to calculate the water content of the mix in this method. It was concluded that the test is simple, requires little skill to perform, and applies to both laboratory and field testing. The accuracy of the method was verified by testing it under actual field conditions with deviations up to $7 \%$.

Leung and Pheeraphan (Leung and Pheeraphan 1995) used a method to increase the curing process by placing the sample inside a microwave oven. Relatively high early strengths were obtained within 4.5 hours for w/cm ratios ranging from 0.40 to 0.55 compared to the 7 -day compressive strength of samples cured at room temperature. The procedure was used to determine the w/cm based upon the strength gain of a sample after a given period in a microwave oven at relatively low power.

Microwave oven method AASHTO T318-15 (“Standard Method of Test for Water Content of Freshly Mixed Concrete Using Microwave Oven Drying” 2015) involves heating a fresh concrete sample at specific intervals using a 900-watt or higher capacity microwave. By recording the mass of the sample, the total water content can be obtained. Hershberger (Hershberger 2015) and Dowell et al. (Dowell and Cramer 2002) investigations showed that this test could be performed under 30 minutes and still result in a reasonable accuracy. 
A study by Fox et al. (Fox, Trost, and Hellman 2007) attempted to improve the w/cm ratio measurement accuracy by using a 55-micron filter bag to separate the cementitious powder and the fine aggregate after microwave drying. The method was not found to be precise due to the loss of sand in the process of forcing the particles through the filter bag.

The benefits of the microwave methods are low cost, accessible, high speed, and small sample size compared to other methods. However, later tests revealed that the accuracy of the method would deviate because of the non-homogenous nature of concrete, which causes a different amount of large aggregate in each sample taken from the mix.

\subsubsection{Other w/cm Ratio Measurement Techniques}

Niak and Ramme (Tarun R. Naik and Bruce W. Ramme 1989) used the buoyancy method to measure the water content of fresh concrete mixes. In this method, it is mentioned that by adding water to a 22-pound concrete sample, the underwater weight of the material could be calculated. By knowing the density of each aggregate and cement based on the mix design ratios, the amount of water can be obtained with the average error of $4.1 \%$.

Hossain et al. (Hossain et al. 1996) developed a tool for measuring the w/cm ratio, which involved a principle measurement of turbidity and pressure sieving of concrete to separate the cement-water slurry phase from the aggregate. Although the accuracy of the test was within 0.01 in terms of the w/cm ratio, the commercially available version of the device could be expensive compared to the other methods.

Chen et al. (Chen, Shen, and Shui 2012) used penetrating radar to measure the dielectric constant since the water content could alter this variable. The relative dielectric constant of the fresh mix was measured by calculating the propagation time of the electromagnetic impulse in the 
material. A hybrid capacitor model was used to correlate the composition of the fresh mix to its relative dielectric constant. The method could be strongly influenced by the temperature of freshly mixed concrete, and it has not been implemented at a job site to check its feasibility.

Mancio et al. (Mancio et al. 2010) developed an electrical resistivity probe for fresh concrete samples containing fly ash with varying $w / \mathrm{cm}$ ratios ranging from $0.3-0.6$. The results indicated the device could estimate the $\mathrm{w} / \mathrm{cm}$ ratio within a variation of 0.01 from the actual w/cm values; However, it is mentioned by the authors, the device has not been tested for mixes containing chemical admixtures and higher volume of mineral admixtures as well as the need for evaluation of the method in actual field testing.

\subsubsection{Summary}

Among all the studies, the most recent AASHTO T318-15 guideline was adopted and improved to have better precision in estimating the water amount of an on-site delivered concrete mix. AASHTO T318-15 recommends using the measured density to calculate the absorbed amount of water. However, since the coarse aggregate amount in each sample could vary, the method proposed requires sieving the coarse aggregate from the dried sample and separating the mass of the fine aggregate and cementitious material based on the mix design ratios. The details are explained in Chapter 3.

\subsection{On-Site Measurement of Adiabatic Temperature Rise of Delivered Concrete}

The heat generation of concrete due to the exothermic reaction between the cementitious materials and water has been measured by many researchers using isothermal or adiabatic calorimeters (De Schutter and Taerwe 1995; Broda, Wirquin, and Duthoit 2002; Pane and Hansen

2005; L. Poole et al. 2007; Gruyaert, Robeyst, and De Belie 2010; Poole Jonathan L. et al. 2011; 
Pang, Cuello Jimenez, and Iverson 2013; Pang et al. 2013; C. T. Tam 1994; Gibbon, Ballim, and Grieve 1997; Lin and Chen 2015). Creating an isothermal or adiabatic environment is not an easy task. Therefore, more straightforward methods have been used for the determination of the heat and adiabatic temperature rise. As an alternative approach, the semi-adiabatic curing test has been popular among researchers (Zhang, Sun, and Liu 2002; Schindler and Folliard 2005; Kyle A. Riding 2006; P. L. Ng 2008; Ng and Kwan 2012; Eddhahak et al. 2014; Klemczak and Batog 2016). A semi-adiabatic method does not require complex procedures or equipment and can be as easy as implanting thermal couples in a concrete sample surrounded by insulation. The accuracy of the semi-adiabatic heat measurement is closely related to the determination of the heat loss to the ambient environment. Besides the calorimetry methods, on-site temperature measurements have also been performed by other researchers (Tia et al. 2010; Do 2013; T. Yikici and Chen 2015) to determine the concrete's early-age heat of hydration.

\subsubsection{Isothermal \& Adiabatic Calorimetry}

De Shutter et al. (De Schutter and Taerwe 1995) measured the evolution of the heat of hydration of hardening concrete for several mixes, including partial replacement of blast furnace slag using isothermal and adiabatic calorimetry. The isothermal calorimetry was developed based on the conduction method of Belgian standard NBN B12-213. The adiabatic condition was obtained by controlling the temperature of a water-ring surrounding the concrete using a differential thermostat. A hydration model was developed, for both cement and blast furnace slag, based on the heat measurements. A water-cementitious ratio of 0.5 was used in the isothermal measurements with curing temperatures of 5, 20, and $35^{\circ} \mathrm{C}$. Broda et al. (Broda, Wirquin, and Duthoit 2002) designed an isothermal calorimeter to measure the heat of hydration of a cylindrical sample with an 11-cm diameter and $22 \mathrm{~cm}$ height in different curing temperatures $(10,20,30$ and 
$\left.40{ }^{\circ} \mathrm{C}\right)$. The isothermal heat measurements were then used to determine the activation energy of mixes using two methods of "rates" and "superposition." Pane et al. (Pane and Hansen 2005) investigated the hydration of Portland cement pastes containing fly ash, ground-granulated slag, and silica fume using differential thermal analysis (DTA), thermogravimetric (TGA) and isothermal calorimetry. The isothermal calorimetry was used to measure the heat of the cement paste specimens at curing temperatures of 15,23 and $34{ }^{\circ} \mathrm{C}$ for about 3 weeks. It was shown that the chemically bound water obtained using DTA/TGA was proportional to the heat of hydration. Poole et al. (L. Poole et al. 2007) studied three different computational methods to obtain activation energy based on isothermal heat measurement and compressive strength tests at different curing temperatures. In their study, isothermal calorimetry was performed on various cementitious pastes with the curing temperatures of $5,15,23,38$, and $60{ }^{\circ} \mathrm{C}$. The tests were performed for a duration of 44 hours at $60{ }^{\circ} \mathrm{C}$ to over 100 hours at $5{ }^{\circ} \mathrm{C}$. Class I Portland cement, two types of Class F fly ash, two types of Class C fly ashes, silica fume, and Grade 120 ground-granulated blast furnace slag were used by the authors to produce the mixes. Gruyaert et al. (Gruyaert, Robeyst, and De Belie 2010) investigated the hydration process of blast furnace slag and Portland cement mixes in which 0 to $85 \%$ of the Portland cement was replaced by the blast furnace slag. At an early age, the isothermal, semi-adiabatic, and adiabatic calorimetry measurements were performed to measure the heat produced by the cementitious materials. At the later ages, thermogravimetric (TG) analyses were performed to detect the hydration behavior of the mixes using the amount of bonded water content. Using both heat and chemically bonded water, the reaction degrees were determined and compared well to the results of the backscattered electron microscopy's image analyses. Poole et al. (Poole Jonathan L. et al. 2011) studied the effect of different types of mineral and chemical admixtures on the hydration of concrete mixes using isothermal calorimetry at five different curing 
temperatures between 5 to $60{ }^{\circ} \mathrm{C}$. The paper examined the effects of set-accelerating, waterreducing, water set retarding, and air entraining admixtures on the apparent activation energy for the mixes with or without mineral admixtures. Pang et al. (Pang, Cuello Jimenez, and Iverson 2013; Pang et al. 2013) examined the heat evolution of different classes of oil-well cement under different curing temperatures $\left(25\right.$ to $60{ }^{\circ} \mathrm{C}$ ) and pressures $(2$ to $45 \mathrm{MPa})$ using isothermal calorimetry. The results were used to develop the scaling factor which is related to the activation energy and activation volume of the mix. Tam et al. (C. T. Tam 1994) used a computer controlled cell as an adiabatic calorimeter to measure the ATR of different concrete mixes with replacement up to $70 \%$ slag of the total cementitious materials. The samples were cast inside a thin-walled cylindrical steel container $(15-\mathrm{cm}$ diameter by $15-\mathrm{cm}$ height $)$ with a thermal couple located at the center of the sample. It was found that the increment of slag will result in the reduction of temperature rise in the concrete mix. The effect of higher fineness and placing temperature were also investigated using the adiabatic calorimetry. Gibbon et al. (Gibbon, Ballim, and Grieve 1997) designed a low-cost adiabatic calorimeter that was controlled using a computer system. The calorimetry was surrounded by water and the water was heated up to have the same temperature as the concrete sample. Two stirrers were used to homogenize the 50-liter water tank. A similar temperature between the concrete specimen and the surrounding water will lead to no loss of heat. Therefore, the measured temperature is from heat production in adiabatic conditions. Lin and Chen (Lin and Chen 2015) developed adiabatic calorimetry based on Gibbon et al.'s design. A control unit with a solid-state relay was designed to control the heating unit using an electrical switch based on the temperature of the sample and the surrounding water. RTD sensors with an accuracy of $0.1{ }^{\circ} \mathrm{C}$ were used in the study. A light-weight high porosity foam layer was added between the concrete sample and the surrounding water to delay the heat loss from the sample to the 
surrounding water. The ATRs measured by the calorimeter were used in a finite element analysis to calculate the temperature distribution of mass concrete elements.

\subsubsection{Semi-adiabatic Calorimetry}

RILEM TC 119-TCE (TC Members 1997) document introduced a semi adiabatic calorimeter to be made up of an insulating vessel filled with foam rubber and an external shell. Based on this document, the coefficient of heat loss shall not exceed $100 \mathrm{~J} / \mathrm{hr} / \mathrm{K}$ in a fixed ambient temperature of $20^{\circ} \mathrm{C}$. Zhang et al. (Zhang, Sun, and Liu 2002) evaluated the effect of w/cm ratio, superplasticizer, and mineral admixtures on the hydration heat of high-performance concrete using semi-adiabatic calorimetry. In this method, a cylindrical container with a $10-\mathrm{cm}$ diameter by $200-$ $\mathrm{mm}$ height was placed inside a large insulated box. The temperature was recorded using a thermocouple located at the center of the cylinder, and the amount of liberated heat was calculated using a heat-dissipating coefficient that was measured before the concrete's heat measurements. Schindler et al. (Schindler and Folliard 2005) used semi-adiabatic calorimetry to quantify the hydration development of different concrete mixes containing various amount of ground granulated blast furnace slag (30 and 50\%), Class C and Class F fly ash (15 to 45\%). The calorimeter consisted of an insulated 3.8-liter steel drum with a $15.24-\mathrm{cm}$ diameter by $30.48-\mathrm{cm}$ height concrete specimen. In this setup, the temperature sensors were used to record the temperature, heat loss through the calorimeter wall, and ambient air temperature. The calorimeter's heat loss was determined using a hot water calibration before the heat of hydration testing. The measured heat of hydration was used to develop a general hydration model of cementitious materials. Ng et al. (P. L. Ng 2008; Ng and Kwan 2012) compared an adiabatic versus two semiadiabatic curing test setups. A $25-\mathrm{cm}$ cubic specimen surrounded by $5-\mathrm{cm}$ phenolic polymer boards and $18-\mathrm{mm}$ thick plywood was used as an adiabatic calorimeter. A $0.5-\mathrm{m}$ cube specimen 
surrounded by $10-\mathrm{cm}$ thick phenolic polymer boards and 18-mm thick plywood in every direction was used to build the first semi-adiabatic test setup. To evaluate the effect of the specimen size, another 1-m cube with an 18-mm plywood framework was created, which was insulated with a 50-mm air gap outside of the wooden formwork and braced with steel. A computer-controlled environmental chamber was used to reach an adiabatic condition in the first setup. The system was able to keep the air temperature inside the room within $0.2{ }^{\circ} \mathrm{C}$. Heat loss characteristic coefficients were calculated using four measurements: the center, side center, center of the edge, and corner. A fourth-order parabolic function was used to represent the concrete temperature at every location. Two empirical equations were developed to calculate the volumetric and surface mean temperatures for each test. Eddhahak et al. (Eddhahak et al. 2014) used a Langavant type semiadiabatic test to measure the heat generated by fresh PCM-mortars specimens. Four cylindrical mortar bottles closed with an insulating stopper were inserted at the center of four calorimeters formed by a high vacuum Dewar flask (made of silvered Pyrex glass). The thermal insulation used in the calorimeter minimized the heat loss. Temperature sensors were used in every calorimeter to measure the temperature evolution over time. A hardened mortar specimen was also used as a reference specimen. The temperature deviation between the fresh mortar and hardened specimens was used to calculate the total thermal conduction losses. Klemczak et al. (Klemczak and Batog 2016) used isothermal and semi-adiabatic calorimetry to test several mixes with Portland cement (95.7\%), limestone (4.3\%), ground granulated blast furnace slag and siliceous fly ash (10, 30, 50 and $70 \%$ as replacements of Portland cement). The isothermal measurement at two curing temperatures of 20 and $50{ }^{\circ} \mathrm{C}$ was carried out using a commercially available device, TAM Air. The TAM Air has eight-channels to measure the heat flow. Additionally, a six-channel semi adiabatic calorimeter was used to measure the heat evolution of $800-\mathrm{mL}$ mortar samples. The 
temperature difference between the fresh mortar sample and the reference was used to calculate the heat loss. Riding et al. (Kyle A. Riding 2006) used semi-adiabatic calorimetry devices at several construction sites under controlled ambient temperature. Multiple semi-adiabatic tests were also performed in the laboratory using the material collected from each on-site test. The semiadiabatic calorimeter was an insulated steel drum with a $15-\mathrm{cm}$ diameter by a $30-\mathrm{cm}$ height concrete cylinder. The temperature of the concrete and heat flux in the calorimeter were recorded. An energy balance finite difference method was used to calculate the heat of hydration of the concrete using the data collected from each semi-adiabatic test.

\subsubsection{On-site Measurement of Temperature}

A 1-m concrete cube was used by Tia et al. (Tia et al. 2010) to measure the temperature of the delivered concrete on-site. The side faces and the base of the block were surrounded by 19$\mathrm{mm}$ plywood and 76-mm polystyrene foam insulations. Type $\mathrm{K}$ thermal couples were used to monitor the early-age temperature of several concrete mixes. The recorded data was used to validate the ability and the correctness of hydration parameters using finite element analysis. Do (Do 2013) monitored the temperature development of three different bridge pier footings cast in Florida. The temperature measurements were then compared with the results obtained from the finite element modeling. In his study, a preprocessing method was used by DIANA finite element software, and the adiabatic temperature rise was calculated and input from an isothermal measurement of heat. Lin and Chen (Lin and Chen 2015) monitored two 1.2-m concrete cubes with embedded temperature sensors. The cubes were constructed using steel formworks. Temperature sensors with an accuracy of $1^{\circ} \mathrm{C}$ were placed using a rebar cage to be sure of the location of each sensor. Then, the measured temperature-time histories were compared to the predicted values from a finite element analysis. Yikici and Chen (T. Yikici and Chen 2015) 
constructed four 2-m concrete cubes in various locations throughout West Virginia. The delivered concrete had ground granulated blast furnace slag, and Class F fly ash. The blocks were instrumented using temperature loggers at various locations. The materials used in each batch were collected and used to produce semi-adiabatic and adiabatic (Lin and Chen 2015) specimens to measure the heat of hydration of each mix.

\subsubsection{Summary}

In this study, a 1-m cube with a similar design to $\mathrm{Ng}$ et al.'s was used as an on-site semiadiabatic calorimetry. Since the setup can be used in ambient weather conditions with variations more significant than laboratory conditions, the setup was analyzed in a finite element model, and a table was provided for the required insulations in different ambient temperatures. On-site measurements of heat of hydration using a cube located beside the real structure can be a useful, accurate, and straightforward practice. 


\section{Chapter 3 : Revised Method for the Rapid Determination of}

\section{On-Site Water-Cementitious Ratio Using Microwave Oven}

AASHTO T318-15 is a standard method to measure the amount of water in a freshly mix concrete using microwave oven. AASHTO T318-15 recommends using the measured density to calculate the absorbed amount of water. However, since the large aggregate amount in each sample could vary, a significant error would possibly happen. A revised method using a similar procedure as AASHTO T318-15 guideline was studied to have less measurement error.

\subsection{Procedure}

The required tools for the method include a microwave oven with a strength higher than 900-watts, a microwavable glass container which can hold about 1600 grams of concrete, a balance with an accuracy of at least 0.1 gram, a grinding pestle, a \#4 sieve, and a plate. The steps needed to define the amount of water in a mix are mentioned below and are based on AASHTO T318-15 (the mass determination for all procedures must be nearest to $0.1 \mathrm{~g}$ ):

1. Determine the mass of the dry and clean glass tray and record it as WS.

2. Leave tray on the scale and zero it. Place $1500 \pm 100$ (g) fresh specimen to be tested. Record the sample mass.

3. Measure the mass of the tray and the freshly mixed concrete specimen in total and record its mass as WF.

4. Place the tray and specimen on the turntable microwave oven and turn the microwave on at the 900 -watt power setting for $5.0 \pm 0.5 \mathrm{~min}$ for the first interval.

5. At the end of the first drying cycle, the specimen shall be removed for a short period. During this time, the large aggregate should be debonded from the mortar using the grinding pestle, 
and the mortar should be grounded to break up any big clumps. Then record the mass of the tray and specimen.

6. The specimen is then returned to the microwave for an additional $5.0 \pm 0.5 \mathrm{~min}$ at the 900watt power setting. Remove the tray and specimen and record the mass.

7. Return to microwave for $2.0 \pm 0.5 \mathrm{~min}$ at the 900 -watt setting.

8. Remove the tray and specimen, lightly stir the specimen to expose mortar. Record the mass of the tray and specimen.

9. Keep track of the mass, if the change in the mass of the tray is greater than $1.0 \mathrm{~g}$, repeat steps 7-9. If the change in the recorded mass is less than $1.0 \mathrm{~g}$, record the mass of dry sample and glass tray as WD and end the experiment.

The water content of the sample is determined below:

$W T_{M}=\frac{W F-W D}{W F-W S} * U W$

Where, $\mathrm{WT}_{\mathrm{M}}$, is the total measured water content $\left(\mathrm{kg} / \mathrm{m}^{3}\right), \mathrm{WF}$, is the mass of the tray + fresh test specimen (g), WD, is the mass of the tray + dry test specimen (g), WS, is the mass of the tray $(\mathrm{g})$, and UW is the density of the fresh concrete $\left(\mathrm{kg} / \mathrm{m}^{3}\right)$. To calculate the $\mathrm{w} / \mathrm{cm}$ ratio, the amount of free water needs to be calculated. To estimate the free water amount, the absorbed water of the aggregates must be deducted from the total water content of the mix. In this step, the AASHTO guideline suggests using the dry densities of the aggregates in the delivered concrete. The absorbed water can be calculated using the saturated surface dried (SSD) amounts and the mix design ratio of each aggregate which as follows:

$$
W T_{A}=\frac{\sum\left(A_{C} * W_{C A}\right)+\sum\left(A_{F} * W_{F A}\right)}{100 * V}, \quad M W=W T_{M}-W T_{A}
$$


Where, $\mathrm{WT}_{\mathrm{A}}$, is the estimated absorbed water content $\left(\mathrm{kg} / \mathrm{m}^{3}\right), \mathrm{A}_{\mathrm{C}}$, is the coarse aggregate absorption (SSD of coarse aggregate-\%), $\mathrm{A}_{\mathrm{F}}$, is the fine aggregate absorption (SSD of fine aggregate-\%), $\mathrm{W}_{\mathrm{CA}}$, is the dry mass of coarse aggregate in test specimen based on mix design (kg), $\mathrm{W}_{\mathrm{FA}}$, is the dry mass of fine aggregate in test specimen based on mix design (kg), $\mathrm{V}$, is the batch volume, $\mathrm{m}^{3}$ and $\mathrm{MW}$ is the estimated mixing of water content $\left(\mathrm{kg} / \mathrm{m}^{3}\right) . \mathrm{W}_{\mathrm{Cem}}$, is the dry mass of cementitious material in the sample based on mix design $(\mathrm{kg})$. The $\mathrm{w} / \mathrm{cm}$ ratio can then be estimated using MW/W $\mathrm{W}_{\mathrm{Cem}}$ (Hershberger 2015; Dowell and Cramer 2002). However, due to the variability of the large aggregate mass in every sample taken as well as the amount of water absorbed in the large aggregate, which is proportional to the mass, in some cases, the above equations will not be accurate. Sieving the large aggregate from the dried specimen and properly separating the dried fine aggregate and cementitious powder by forcing the sample on the top of a \#4 sieve (shown in Figure 3-1) with reasonable force is helpful at this point. Considering that one piece of large aggregate could alter the calculation of free water and cementitious materials.

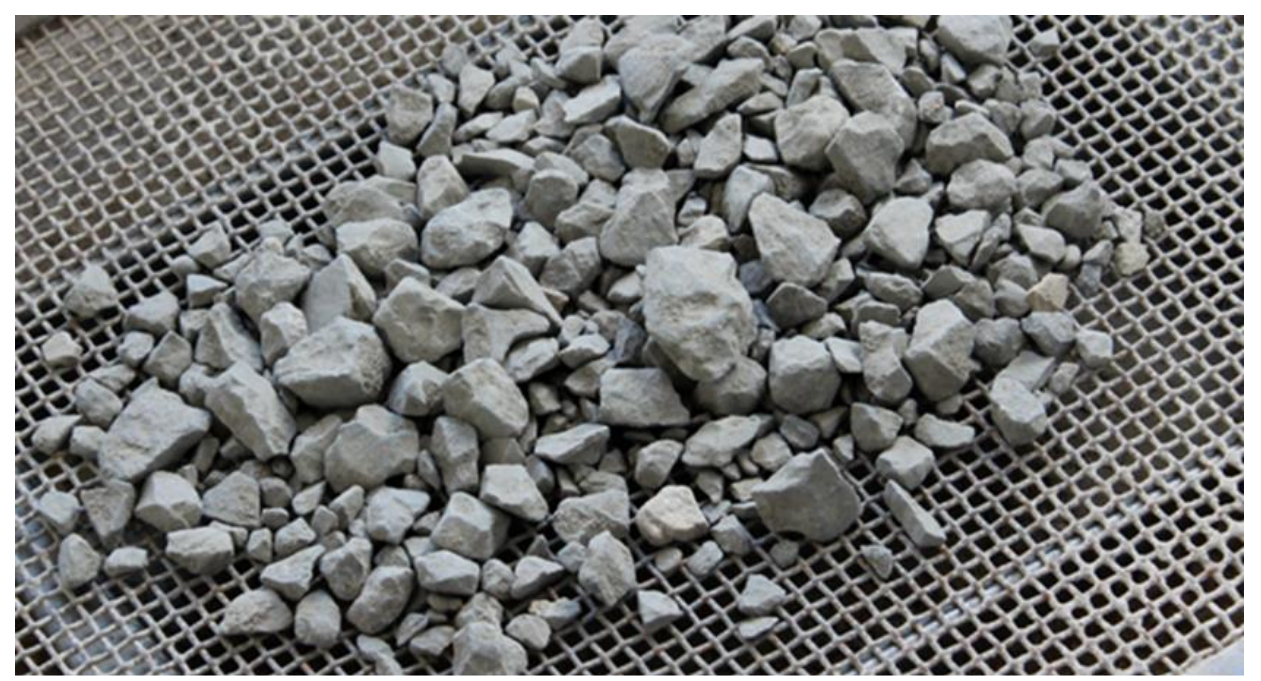

Figure 3-1: Large aggregate on sieve no. 4 
Consequently, knowing the precise amount in each sample would reduce the error caused by sampling. As an additional consideration, if powder is observed bonded around the large aggregate (as shown in Figure 3-2), especially when there is a large amount of chemical admixture in the mix or more extended period of heating, washing vinegar can be used to wash out the remaining particles after the drying cycle. However, vinegar's acetic acid can dissolve the limestone aggregates at the time of mixing; therefore, this loss of mass needs to be added to the cleaned large aggregate mass.

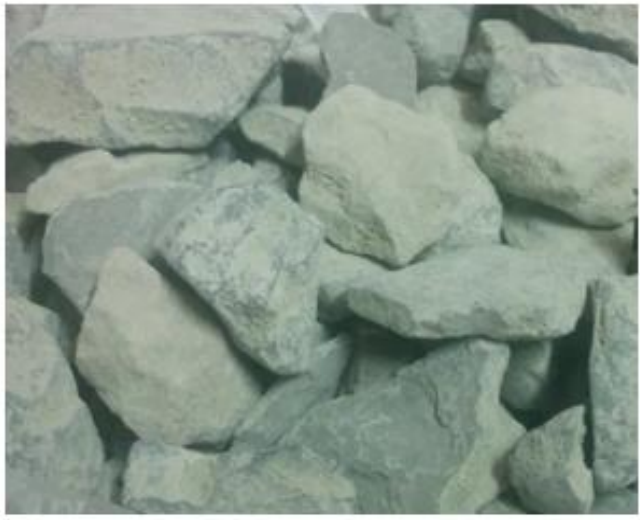

(a)

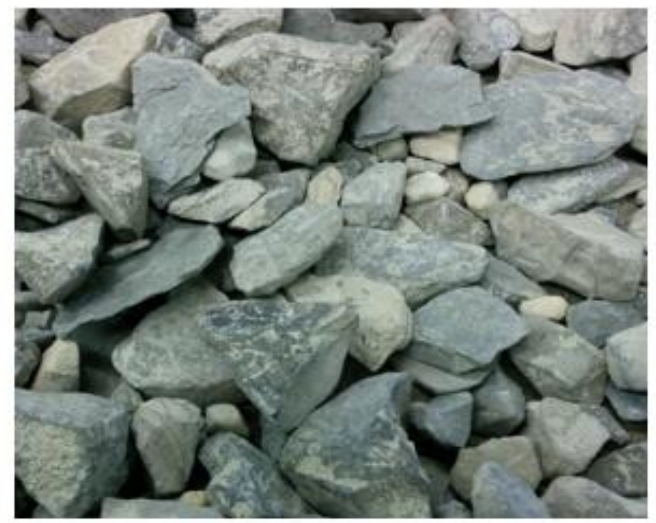

(b)

\section{Figure 3-2: (a) Before washing with vinegar, (b) After washing with vinegar}

For limestone aggregate, the amount of loss can be calculated using the stoichiometric equation of lime and acetic acid, the following equation was used to determine the loss of limestone.

$\mathrm{CaCO}_{3}($ Lime $)+2 \mathrm{CH}_{3} \mathrm{COOH}($ Washing Vinegar $) \rightarrow\left(\mathrm{CH}_{3} \mathrm{COO}\right)_{2} \mathrm{Ca}($ Solid $)+\mathrm{CO}_{2}+\mathrm{H}_{2} \mathrm{O}$

The loss is dependent on the concentration of acetic acid and the amount of collected, dried limestone. Finally, by measuring the remaining mass of large aggregate, two unknowns (water and 
large aggregate masses) from the total weight of the mix can be determined. Therefore, the combined weight of cementitious material and fine aggregate can be estimated in each sample. Separation of these two materials is not practical with simple methods. Therefore, the remaining weight on the tray is distributed using the mix design ratio to the cementitious materials and fine aggregate. This will give a reasonable approximation of the dry mass of cementitious material in the sample. The revised $w / \mathrm{cm}$ ratio can now be calculated using the revised equations:

$$
\begin{aligned}
& W_{F A}^{\prime}=\left(W D-W S-W_{C A}^{\prime}\right) *\left[\frac{W_{F A}}{W_{C e m}+W_{F A}}\right] \\
& W_{C e m}^{\prime}=W D-W S-W_{C A}^{\prime}-W_{F A}^{\prime} \\
& M W^{\prime}=(W F-W D)-\left[A_{C} * W_{C A}^{\prime}+A_{F} * W_{F A}^{\prime}\right]
\end{aligned}
$$

$$
\text { The revised } \frac{w}{\mathrm{~cm}} \text { ratio }=\frac{M W^{\prime}}{W^{\prime}{ }_{\mathrm{Cem}}}
$$

Where, $\mathrm{W}_{\mathrm{CA}}^{\prime}$, is the dry mass of coarse aggregate in the sample (measured, $\mathrm{g}$ ), $\mathrm{W}_{\mathrm{FA}}^{\prime}$, is the dry mass of fine aggregate in the sample (calculated, $\mathrm{g}$ ) $\mathrm{W}^{\prime} \mathrm{Cem}$, is the dry mass of cementitious material in the sample (calculated, g) and, MW' is the mixing water content in the sample (g).

\subsection{Laboratory Experiments}

Several sets of experiments were performed to test the ability of the microwave oven in drying the concrete ingredients. The limestone aggregate and sand were tested first. After two heating periods of 5 minutes, the microwave oven could evaporate over $99 \%$ of the added water amount in both types of aggregate. Another experiment was conducted on a cement paste with a w/cm ratio of 0.415 . As Figure 3-3 shows, after heating for several 2 minutes intervals, a loss of 
about $98.2 \%$ of the added water was recorded. Although the heat from the microwave oven accelerates the chemical reaction between the cement and water, as the results indicate, there was not enough time for the water to be chemically bonded with the cement particles during the first few minutes of heating, and almost all the added water could be retracted from the mix. Thus, the microwave oven is proven to be capable of evaporating almost all the water added to each material used in concrete mixes.

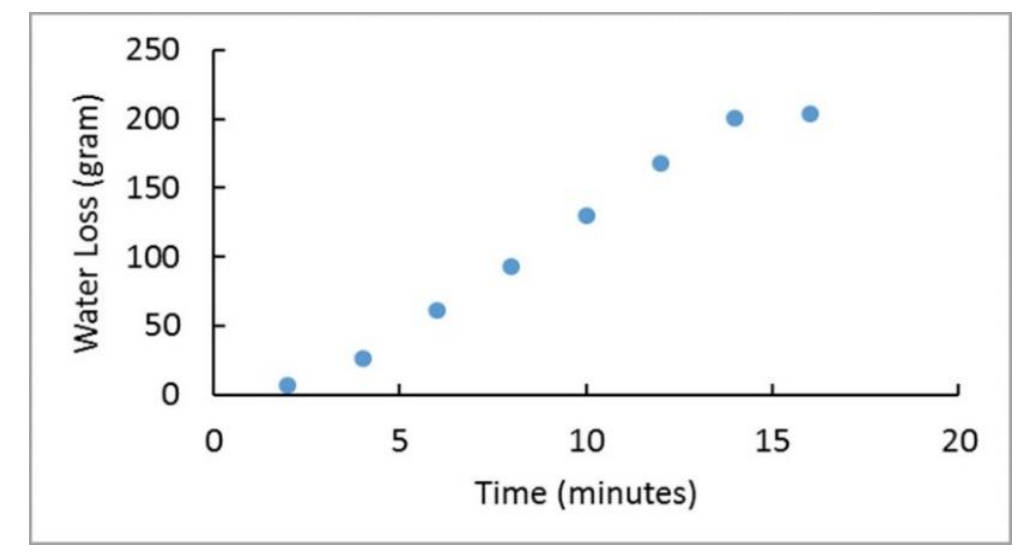

Figure 3-3: Water loss of cement paste in microwave vs. time

The mix designs of all the laboratory batches are shown in Table 3-1. These mix designs contained Type I/II ordinary Portland cement as well as a 50\% slag mix using Grade 100 groundgranulated blast-furnace slag (GGBFS) and a 30\% fly-ash mix using Class F fly ash as supplementary cementitious materials. The measured SSD of the coarse aggregate (limestone) was $0.5 \%$, and the SSD of sand was $1.4 \%$ based on ASTM C127 ("Standard Test Method for Relative Density (Specific Gravity) and Absorption of Coarse Aggregate" 15) and ASTM C128 ("Standard Test Method for Relative Density (Specific Gravity) and Absorption of Fine Aggregate" 15). In every experiment, two to three samples were taken from each batch of concrete after testing the slump and air content. 


\section{Table 3-1: Mix designs}

\begin{tabular}{lccc}
\hline Material & OPC & 50\% slag & 30\% fly ash \\
\hline Cement $\left(\mathbf{k g} / \mathbf{m}^{\mathbf{3}}\right)$ & 335.2 & 150.6 & 201.71 \\
\hline Slag $\left(\mathbf{k g} / \mathbf{m}^{\mathbf{3}}\right)$ & - & 150.6 & - \\
\hline Fly Ash $\left(\mathbf{k g} / \mathbf{m}^{\mathbf{3}}\right)$ & - & - & 99.67 \\
\hline Water $\left(\mathbf{k g} / \mathbf{m}^{\mathbf{3}}\right)$ & 139.4 & 135.6 & 127.55 \\
\hline Limestone $(\# \mathbf{5 7}) \mathbf{S S D}\left(\mathbf{k g} / \mathbf{m}^{\mathbf{3}}\right)$ & 968.8 & 1064.93 & 1056.03 \\
\hline Sand SSD $\left(\mathbf{k g} / \mathbf{m}^{\mathbf{3}}\right)$ & 844.2 & 809.22 & 806.85 \\
\hline w/cm ratio & 0.417 & 0.445 & 0.423 \\
\hline
\end{tabular}

The amount of water in the slag mixes (Test 1-1, 1-2, and 1-3) was $135.6 \mathrm{~kg} / \mathrm{m}^{3}$. A total of four ordinary Portland cement (w/cm ratio of 0.417 ), three slag (w/cm ratio of 0.45 ), another four slag (w/cm ratio of 0.423$)$, and seven fly ash (w/cm ratio of 0.423$)$ mix designs were tested. The evaporated water, sieved limestone mass, as well as the calculated w/cm ratio based on both AASHTO guideline and the revised method, are shown in Table 3-2. To control the moisture content and prevent any excessive moisture in the aggregates, some batches were prepared using dried aggregates such as three OPC samples (test 1-1, test 1-2, test 2), two fly ash samples (test 11, test 1-2), and three slag samples (test 1-1, test 1-2, test 1-3). Both limestone and sand were prepared in a $105{ }^{\circ} \mathrm{C}$ oven and dried for 24 hours as recommended by ASTM C127 and ASTM C128. The dried aggregate content and measured SSD could be the basis for the exactness of the added water amount to each mix. In addition, all the ingredients in the concrete were measured within a precision of 1.0-g before the mixing process. The average evaporated water measured from each $1500 \pm 100$-g sample was $94.67-\mathrm{g}$, with a range of 21.0 -g $(86.1-\mathrm{g}-107.1-\mathrm{g})$. As the percentage error columns show, the w/cm ratio calculated based on the T318 method varies up to a maximum error of $15.1 \%$, while the maximum error is within $3.9 \%$ using the revised method. The average percentage error between the target $w / \mathrm{cm}$ ratio and the measured $w / \mathrm{cm}$ ratio calculated by the T318 method was $6.2 \%$ in comparison to $2.16 \%$ with the revised method. Other 
than the reduction of overall error the revised method indicates a much better consistencies between the calculated results of the same concrete batch than the T318 method. As an example, by looking at 50\% Slag 1-1, 50\% Slag 1-2 and 50\% Slag 1-3 samples from the same concrete batch the w/cm ratio results using T318 were not consistent (with the deviation of 0.039 ); however, the revised method shows very consistent values (with the deviation of 0.01 ). The amount of water loss for the different mixes is shown in Figure 3-4, a similar trend was observed for all three mixes. The distribution of evaporated water and the limestone mass is shown in Figure 3-5 and Figure 3-6. The average sieved limestone mass was 727.15-g, with a range of 174.4-g (648.5-g - 822.9g). The range between the highest and the lowest amount of limestone reveals the impact of not sieving the aggregate. It can have an enormous influence on the results. For instance, based on the OPC mix design, 632-g of dried coarse aggregate should be available in 1500-g of the concrete sample, which is an aggregate ratio of 0.421 . However, the average aggregate ratio of the test results for OPC was calculated to be 0.444 . A lower amount of coarse aggregate ratio means if the density of the whole concrete batch (current T318 method) is used in the w/cm ratio calculation, the amount of cementitious material would be overestimated; therefore, it reduces the accuracy of the estimated $\mathrm{w} / \mathrm{cm}$ ratios.

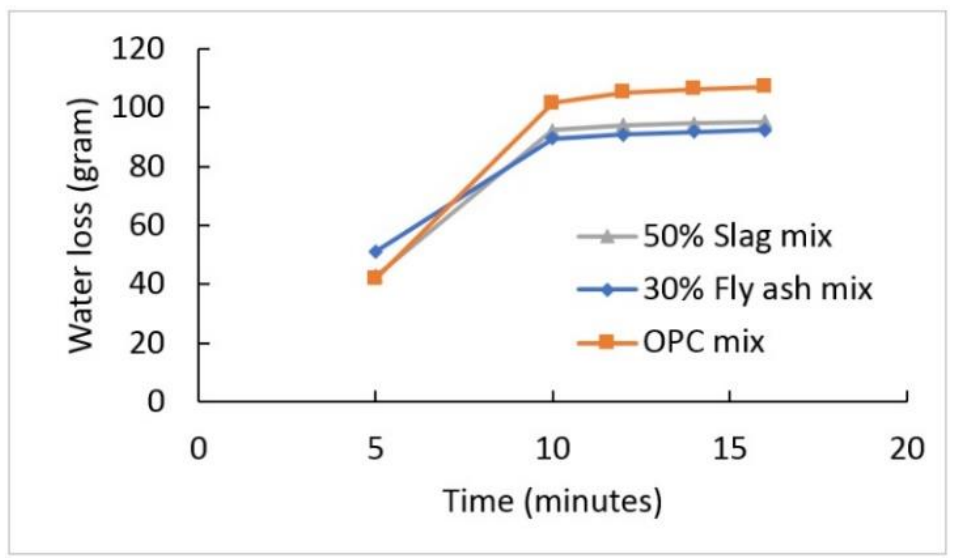

Figure 3-4: Water loss trend for different types of mixes 


\section{Table 3-2: W/cm ratio results with different mix designs}

\begin{tabular}{|c|c|c|c|c|c|c|c|c|}
\hline \multirow{2}{*}{ Description } & \multirow{2}{*}{$\underset{\text { (g) }}{\text { Sample }}$} & \multirow{2}{*}{$\begin{array}{c}\text { Evaporated } \\
\text { Water (g) }\end{array}$} & \multirow{2}{*}{$\begin{array}{c}\text { Coarse } \\
\text { Aggregate } \\
\text { (g) }\end{array}$} & \multirow{2}{*}{$\begin{array}{l}\text { Given } \\
\text { w/cm } \\
\text { ratio }\end{array}$} & \multicolumn{2}{|c|}{$\begin{array}{c}\text { AASHTO T-318 } \\
\text { Method }\end{array}$} & \multicolumn{2}{|c|}{ Revised Method } \\
\hline & & & & & $\begin{array}{l}\text { w/cm } \\
\text { ratio }\end{array}$ & $\begin{array}{l}\text { Percentage } \\
\text { Error }\end{array}$ & $\begin{array}{l}\text { w/cm } \\
\text { ratio }\end{array}$ & $\begin{array}{c}\text { Percentage } \\
\text { Error }\end{array}$ \\
\hline $\begin{array}{l}\text { OPC } \\
\text { (test 1-1) }\end{array}$ & 1534.8 & 107.1 & 653.3 & 0.417 & 0.427 & $2.3 \%$ & 0.432 & $3.5 \%$ \\
\hline $\begin{array}{l}\text { OPC } \\
\text { (test 1-2) }\end{array}$ & 1547.5 & 103.4 & 689.7 & 0.417 & 0.407 & $2.5 \%$ & 0.427 & $2.3 \%$ \\
\hline $\begin{array}{l}\text { OPC } \\
\text { (test 2) }\end{array}$ & 1516.7 & 95.2 & 726.1 & 0.417 & 0.379 & $10.0 \%$ & 0.424 & $1.7 \%$ \\
\hline $\begin{array}{l}\text { OPC } \\
\text { (test 3) }\end{array}$ & 1515.6 & 100.9 & 648.5 & 0.417 & 0.405 & $3.0 \%$ & 0.409 & $2.0 \%$ \\
\hline $\begin{array}{l}50 \% \text { slag } \\
\text { (test 1-1) }\end{array}$ & 1501.3 & 95.4 & 720.2 & 0.45 & 0.43 & $4.7 \%$ & 0.451 & $0.2 \%$ \\
\hline $\begin{array}{l}50 \% \text { slag } \\
\text { (test 1-2) }\end{array}$ & 1513.3 & 90.1 & 770.5 & 0.45 & 0.399 & $12.8 \%$ & 0.444 & $1.4 \%$ \\
\hline $\begin{array}{l}50 \% \text { slag } \\
\text { (test 1-3) }\end{array}$ & 1595.5 & 93.2 & 822.9 & 0.45 & 0.391 & $15.1 \%$ & 0.441 & $2.0 \%$ \\
\hline $\begin{array}{l}50 \% \text { slag } \\
\text { (test 2-1) }\end{array}$ & 1501.3 & 95.4 & 700.5 & 0.423 & 0.43 & $1.6 \%$ & 0.438 & $3.4 \%$ \\
\hline $\begin{array}{l}50 \% \text { slag } \\
\text { (test 2-2) }\end{array}$ & 1542.1 & 93 & 760 & 0.423 & 0.405 & $4.4 \%$ & 0.435 & $2.8 \%$ \\
\hline $\begin{array}{l}\text { 50\% slag } \\
\text { (test 3-1) }\end{array}$ & 1529.8 & 89.4 & 747.3 & 0.423 & 0.391 & $8.2 \%$ & 0.413 & $2.4 \%$ \\
\hline $\begin{array}{l}\text { 50\% slag } \\
\text { (test 3-2) }\end{array}$ & 1535.7 & 88 & 766.3 & 0.423 & 0.382 & $10.7 \%$ & 0.413 & $2.4 \%$ \\
\hline $\begin{array}{l}\text { 30\% fly ash } \\
\text { (test 1-1) }\end{array}$ & 1552.3 & 92.4 & 740 & 0.423 & 0.398 & $6.3 \%$ & 0.411 & $2.9 \%$ \\
\hline $\begin{array}{l}\text { 30\% fly ash } \\
\text { (test 1-2) }\end{array}$ & 1426.8 & 88.3 & 660.1 & 0.423 & 0.416 & $1.7 \%$ & 0.419 & $1.0 \%$ \\
\hline $\begin{array}{l}\text { 30\% fly ash } \\
\text { (test 2-1) }\end{array}$ & 1532.3 & 102.8 & 672 & 0.423 & 0.456 & $7.2 \%$ & 0.44 & $3.9 \%$ \\
\hline $\begin{array}{l}\text { 30\% fly ash } \\
\text { (test 2-2) }\end{array}$ & 1539.3 & 94.6 & 742.1 & 0.423 & 0.412 & $2.7 \%$ & 0.433 & $2.3 \%$ \\
\hline $\begin{array}{l}\text { 30\% fly ash } \\
\text { (test 2-3) }\end{array}$ & 1537.7 & 92.6 & 761.2 & 0.423 & 0.403 & $5.0 \%$ & 0.435 & $2.8 \%$ \\
\hline $\begin{array}{l}\text { 30\% fly ash } \\
\text { (test 2-4) }\end{array}$ & 1536.8 & 96.1 & 707.1 & 0.423 & 0.421 & $0.5 \%$ & 0.422 & $0.2 \%$ \\
\hline $\begin{array}{l}\text { 30\% fly ash } \\
\text { (test 3-1) }\end{array}$ & 1525.1 & 86.1 & 800.9 & 0.423 & 0.374 & $13.1 \%$ & 0.431 & $1.9 \%$ \\
\hline
\end{tabular}




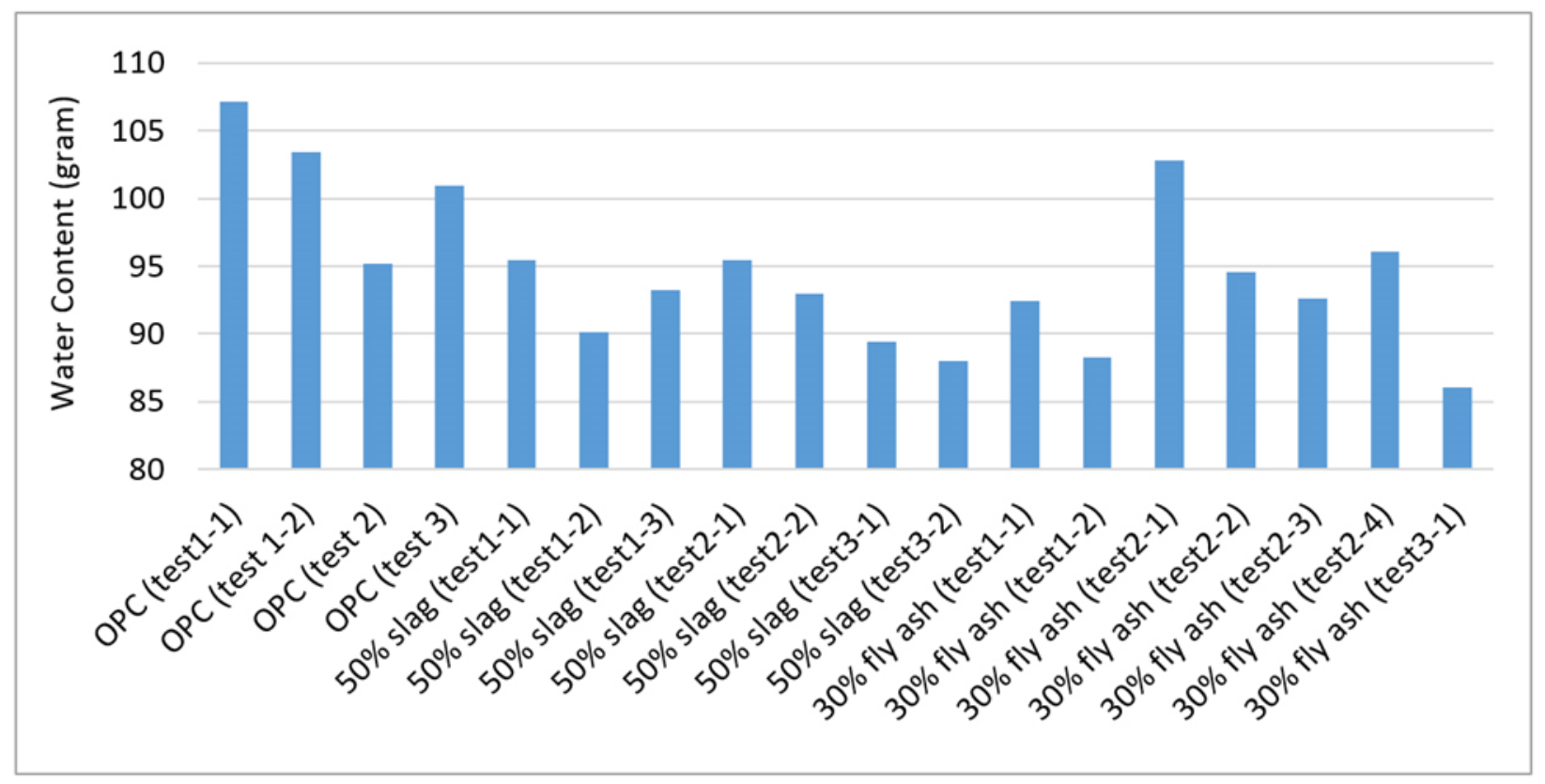

Figure 3-5: Evaporated water amount in each sample

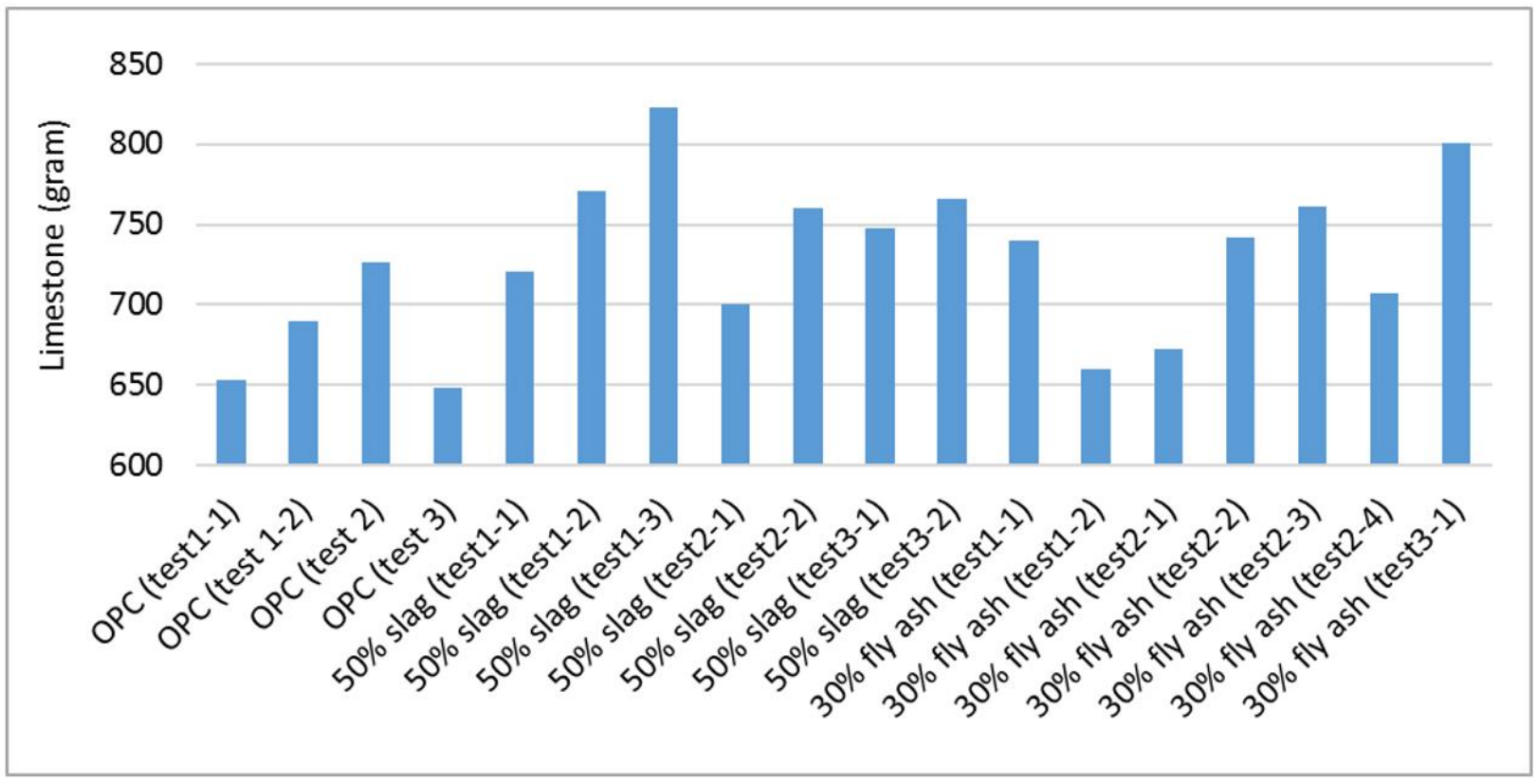

Figure 3-6: Mass of dried limestone in each sample

\subsection{Summary}

A revised method based on the AASHTO T318-15 standard for the determination of water content in fresh mixes of concrete was evaluated. The revised method considered the actual amount 
of coarse aggregates used in the calculation of the absorbed water and cementitious material content. Several laboratory batch tests were performed on concrete mixes containing various types of cementitious materials with slag and fly ash. The results of the experiments indicated the accuracy of the proposed method was increased to an average error of about $2.16 \%$ from the actual mix design w/cm ratio whereas the method based on AASHTO calculations had an error of $6.2 \%$. In the case of a higher amount of chemical admixture in the mixes, washing vinegar was used to wash out the particles around the dried aggregate which was dissolved by the vinegar's acid was calculated based on its stoichiometric reaction equation. Using the revised method, the results of laboratory tests were consistent among the samples from the same batch which also indicates the accuracy of the revised method when considering the actual mass of coarse aggregate for each sample. 


\section{Chapter 4 : On-site Measurement of Adiabatic Temperature}

\section{Rise of Concrete}

\subsection{Test Setup}

In this study, a 1-meter (1-m) cube with multiple layers of insulations (as shown in Figure 4-1) was built in a way that minimizes the amount of heat loss to the ambient environment. Plywood was used to create the structure of the cube, and polystyrene foam boards were cut into pieces and placed on each side of the cube. The 1-m cube specimen was chosen to act as a semiadiabatic calorimetry. Two temperature loggers are needed to measure the temperature-time history of the center and the ambient environment. The temperature-time history of the cube at the center was used to calculate the ATR of a delivered concrete batch. However, the amount of insulation provided may not be enough for all ambient conditions. Therefore, a practical method is needed to adjust the amount of insulation based on ambient conditions.
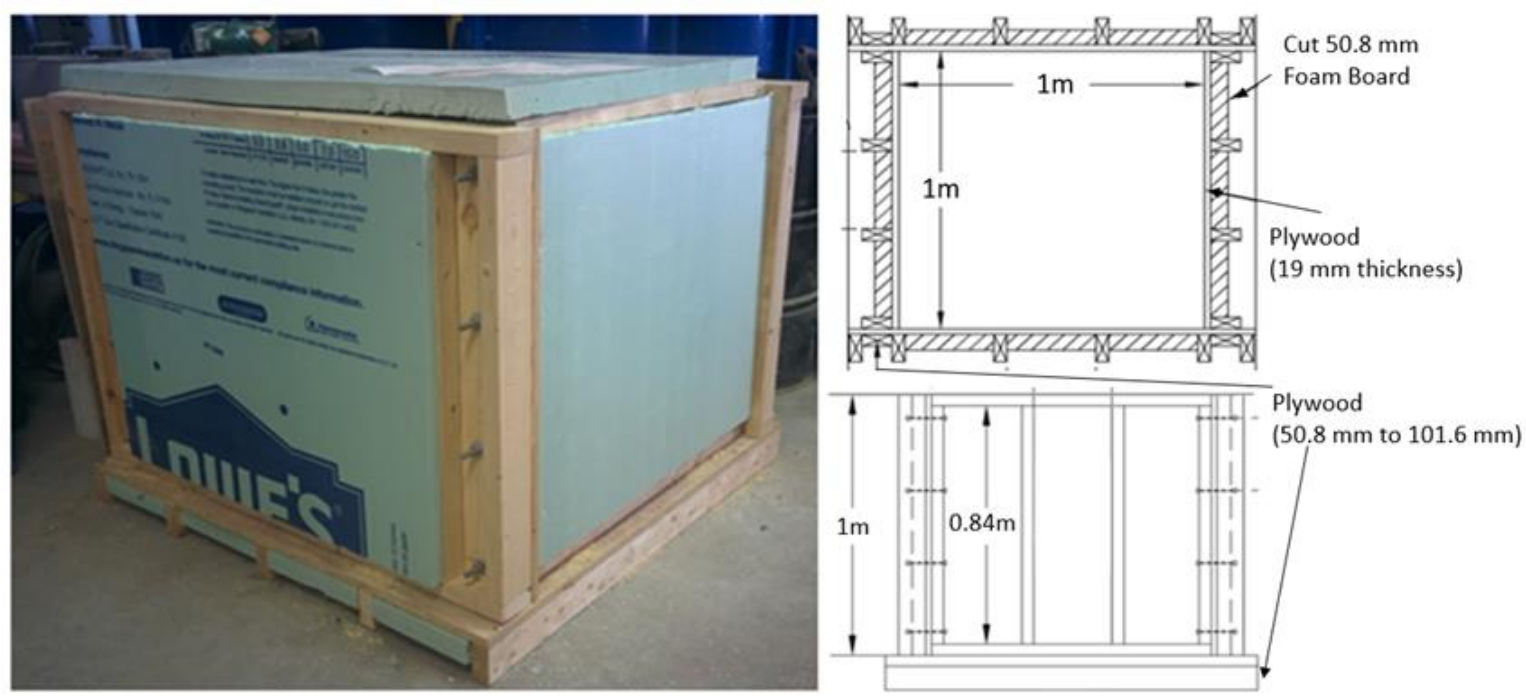

Figure 4-1: 1-m Cube design 


\subsection{Calculations}

For a concrete specimen subjected to a semi-adiabatic curing condition, the following equation can be expressed between the adiabatic temperature rise and the amount of heat loss:

$$
T_{V o l}-T_{i n i}=T_{a d}-\frac{H_{L o s S}}{\rho \cdot C_{p}}
$$

Where, $T_{V o l}, T_{\text {ini }}, T_{a d}, H_{\text {Loss }}, \rho, C_{p}$ are measured volumetric mean temperature, initial temperature, adiabatic temperature rise, the amount of heat loss, density, and specific heat of concrete. According to the heat conduction law (Fourier's Law), the rate of the heat loss vs. time $\partial H_{L o s s} / \partial t$ between the specimen and the ambient environment is proportional to the average thermal conductivity of the system $\left(K_{a v g}\right)$ multiplied by the temperature difference between the surface of the concrete and ambient temperature. $K_{a v g}$ is highly dependent on the surroundings, including the formwork, insulation foam, or blanket which all have different thermal resistance. The overall heat loss can be determined using the following relationship:

$$
H_{\text {Loss }}=K_{\text {avg }} \int_{0}^{t}\left(T_{\text {Surf }}-T_{A m b}\right) d t
$$

Where the $T_{\text {Surf }}$ and $T_{A m b}$ are the surface mean temperature of the concrete and ambient temperature. By substituting Equation (4-2) into Equation (4-1), the adiabatic temperature rise of the concrete can be calculated with the following equation:

$$
T_{a d}=T_{\text {Vol }}-T_{\text {ini }}+\lambda \int_{0}^{t}\left(T_{\text {Surf }}-T_{A m b}\right) d t
$$

Where, $\lambda=K_{\text {avg }} / \rho \cdot C_{p}$ represents the heat loss characteristic coefficient of the curing test setup. By taking a derivative of Equation (4-3), the following expression will be obtained: 
$\frac{\partial T_{a d}}{\partial t}=\frac{\partial T_{V o l}}{\partial t}+\lambda\left(T_{\text {Surf }}-T_{A m b}\right)$

Where $T_{V o l}$ and $T_{\text {Surf }}$ are:

$$
T_{V o l}=\frac{1}{V} \int_{V} T(x, y, z) d V \quad, \quad T_{\text {Surf }}=\frac{1}{A} \int_{A} T(x, y, z) d A
$$

Where $V$ and $A$ are the volume and surface area of the concrete. After a long period of time, the concrete, which cured at a high temperature, will have a sufficiently small amount of heat production. Therefore, $\partial T_{a d}$ will be approximately equal to zero (constant adiabatic temperature). $\mathrm{Ng}$ et al. (Ng and Kwan 2012) proposed 120 hours after placement of the concrete to be enough time based on several experiments. Therefore, the heat loss characteristic coefficient can be obtained using the following equation:

$$
\lambda=-\frac{\frac{\partial T_{V o l}}{\partial t}}{\left(T_{\text {Surf }}-T_{A m b}\right)}
$$

Since the estimation of the spatial temperature profile, $T(x, y, z)$, within the concrete volume, is not simple and needs a heat conduction model, a practical method is required in order to simplify the calculation process. In this study, it was assumed that both $T_{V o l}$ and $T_{S u r f}$ are equal to the measured center temperature. Therefore, enough insulation is needed to satisfy this condition for any ambient temperatures.

\subsection{Heat Loss Characteristic Coefficient}

To assume that $T_{V o l}$ and $T_{\text {Surf }}$ are equal to the temperature measured at the center location of the cube, a minimum amount of insulation is required. The minimum amount depends on the different ambient environmental conditions. A finite element model (FEM) with a user subroutine (Lin and Chen 2015) in ABAQUS program was used to find the minimum insulation needed for 
using a one-point measurement to calculate the ATR accurately. As shown in Figure 4-2, a 1-m cube of concrete surrounded by $1.9-\mathrm{cm}$ plywood and $2.54-\mathrm{cm}$ thickness of insulation was modeled in the program. To be conservative, tie constraints were used between the plywood, insulation material, and concrete. Hexahedral (linear) type mesh (DC3D8) with a size of 1.9-cm were found to be enough for convergence. The mass densities of the concrete, plywood, and insulation foam were $2286.6,672.8$, and $30.4\left(\mathrm{~kg} / \mathrm{m}^{3}\right)$, respectively. The specific heat of 1256 and $2261\left(\mathrm{~J} / \mathrm{kg} /{ }^{\circ} \mathrm{C}\right)$ were used for the insulation and plywood material. The thermal conductivity of the plywood was assumed to be $0.13 \mathrm{~W} / \mathrm{m} / \mathrm{K}$. The specific heat $\left(C_{p}\right)$ and thermal conductivity $\left(K_{c}\right)$ of the concrete was considered to be a degree of hydration dependent. They were calculated in a user subroutine with the following equations (Van Breugel 1980; Meeks and Folliard 2013):

$C_{p}\left(\alpha_{r}, T(t)\right)=\frac{1}{\rho}\left(W_{c} \alpha_{r}(8.4 T(t)+339)+740 W_{c}\left(1-\alpha_{r}\right)+710 W_{s}+840 W_{a}+4184 W_{w}\right)$

$$
K_{c}\left(\alpha_{r}\right)=K_{u c}\left(1.33-0.33\left(\alpha_{r}(t)\right)\right.
$$

Where $\alpha_{r}=\alpha / \alpha_{u}, \alpha$ is the degree of hydration of the concrete, $\alpha_{u}$ is the ultimate degree of hydration, $\rho$ is the mass density of concrete, $W_{c}, W_{s}, W_{a}$ and $W_{w}$ are the mass of cementitious materials, sand, large aggregate and water per unit volume of concrete $\left(\mathrm{Kg} / \mathrm{m}^{3}\right), \mathrm{T}(t)$ is the temperature of concrete $\left({ }^{\circ} \mathrm{C}\right)$ and $K_{u c}$ is the thermal conductivity of the mature concrete (measured after 28 days of curing). 


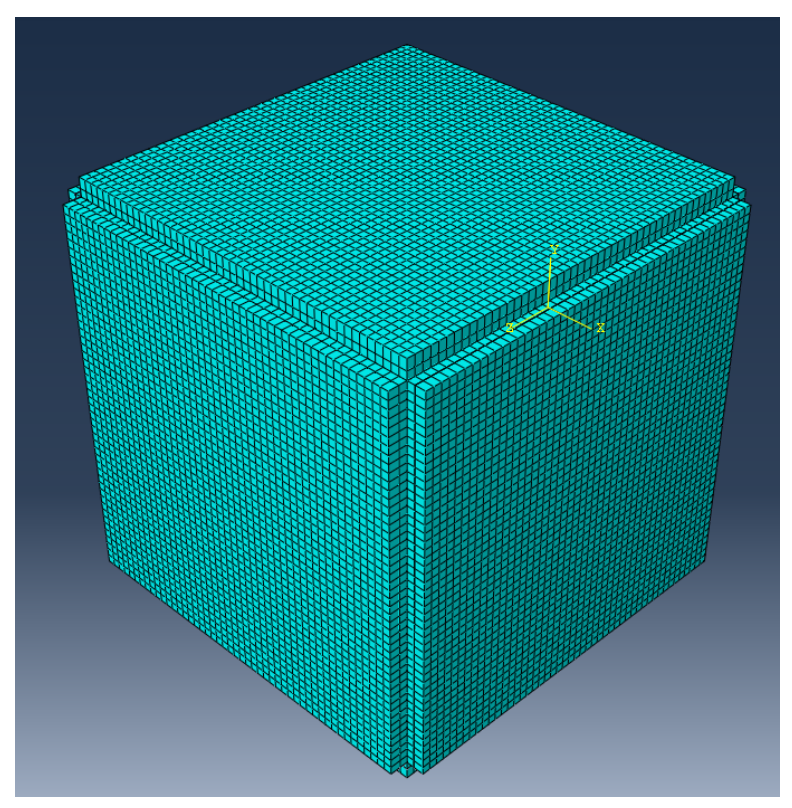

Figure 4-2: Finite element model

In the FEM, the heat release, $H\left(t_{e}\right)$, is fundamentally based on an exponential function with two empirical hydration parameters $(\tau$ and $\beta$ ) shown in Equation (4-9). The degree of hydration can be obtained using the heat release of concrete divided by the ultimate heat of hydration $\left(H_{u}\right)$. The ultimate heat of hydration is a quantity dependent on the chemical properties of the cementitious materials. Since the temperature of the concrete can affect the chemical reaction between the cementitious materials and water, the time shift is considered by Arrhenius law of chemical reaction using the equivalent age concept $\left(t_{e}\right)$. In the Arrhenius equation, the reference temperature was assumed to be $23^{\circ} \mathrm{C}$. Therefore, the heat generation (q) of each element can be calculated using the following equations:

$$
\begin{aligned}
& H\left(t_{e}\right)=H_{u} \alpha_{u} \exp \left(-\left[\frac{\tau}{t_{e}}\right]^{\beta}\right), \quad \alpha\left(t_{e}\right)=\frac{H\left(t_{e}\right)}{H_{u}} \\
& t_{e}=\int_{0}^{t} \exp \left(\frac{E_{a}}{R}\left(\frac{1}{T(t)+273}-\frac{1}{23+273}\right)\right) d t
\end{aligned}
$$




$$
q(t)=H_{u} W_{c} \alpha_{u} \exp \left(-\left[\frac{\tau}{t_{e}}\right]^{\beta}\right)\left[\frac{\tau}{t_{e}}\right]^{\beta} \frac{\beta}{t_{e}} \exp \left(\frac{E_{a}}{R}\left(\frac{1}{T(t)+273}-\frac{1}{23+273}\right)\right)
$$

Where $\tau, \beta$ are the hydration parameters, $t$ is the current time, $T$ is the temperature $\left({ }^{\circ} \mathrm{C}\right)$ and $E_{a}$ is the activation energy of concrete. In all the analyses, the initial temperature of the concrete was assumed to be $30^{\circ} \mathrm{C}$. The parameters used in the ABAQUS model are shown in Table 4-1. The ultimate thermal conductivity was measured following the CRD-C standard for the concrete (Lin and Chen 2015; US Army Corps of Engineers 1973). The activation energy was tested following ASTM C-1074 (T. A. Yikici and Chen 2015).

Table 4-1: Input parameters of FEM

\begin{tabular}{lc}
\hline $\mathbf{H}_{\mathbf{u}}(\mathbf{J} / \mathbf{g})$ & 498,970 \\
\hline $\boldsymbol{\alpha}_{\mathbf{u}}$ & 0.703 \\
\hline $\mathbf{E}_{\mathbf{a}}(\mathbf{J} / \mathbf{m o l})$ & 41,841 \\
\hline$\tau$ & 14 \\
\hline $\boldsymbol{\beta}$ & 0.94 \\
\hline $\boldsymbol{K}_{\mathbf{u c}}(\boldsymbol{W} / \mathbf{m} / \mathbf{K})$ & 1.765 \\
\hline $\mathbf{W}_{\mathbf{c}}\left(\mathbf{K g} / \mathbf{m}^{\mathbf{3}}\right)$ & 334.6 \\
\hline $\mathbf{W}_{\mathbf{s}}\left(\mathbf{K g} / \mathbf{m}^{\mathbf{3}}\right)$ & 843.63 \\
\hline $\mathbf{W}_{\mathbf{a}}\left(\mathbf{K g} / \mathbf{m}^{\mathbf{3}}\right)$ & 969.11 \\
\hline $\mathbf{W}_{\mathbf{w}}\left(\mathbf{K g} / \mathbf{m}^{\mathbf{3}}\right)$ & 139.41 \\
\hline
\end{tabular}

A convection film coefficient of $7.9 \mathrm{~W} / \mathrm{m}^{2} / \mathrm{K}$ (free convection) was assumed for the surface convection heat transfer between the ambient air and the surface of the insulation materials. A constant 7-day ambient temperature of 0 to $35^{\circ} \mathrm{C}$ with an increment of $5{ }^{\circ} \mathrm{C}$ was used in the model. The thermal conductivity of the foam was assumed to be $0.0289(\mathrm{~W} / \mathrm{m} / \mathrm{K})$ or RSI value of 0.88 $\left(\mathrm{m}^{2} . \mathrm{K} / \mathrm{W}\right)$ for the 25.4-mm insulation board. Figure 4-3 shows the change in the center temperature 
due to the variation of the ambient temperature. It is evident that by lowering the ambient temperature, the cube loses more heat to the environment; therefore, the heat loss characteristic coefficient will be higher at lower ambient temperatures. The temperature-time history of the center location was chosen to calculate the ATR for each ambient temperature, by using Equation (4-6) and assuming $\mathrm{T}_{\mathrm{surf}}=\mathrm{T}_{\mathrm{vol}}=\mathrm{T}$ at center location. As shown in Figure 4-4, a linear relationship was found between the ambient temperature and the heat loss characteristic coefficient when keeping the thermal conductivity of the insulation as a constant value. The percent difference between the calculated ATR using the temperature history of the center location and the ATR from the input parameters (Table 4-1) at 7 days is shown in Figure 4-5. Figure 4-5 indicates that the error from the one-point measurement (center temperature) calculation increases as the heat loss increases (due to a reduction of the ambient temperature). This error is mainly due to insufficient insulation needed at lower ambient temperature.

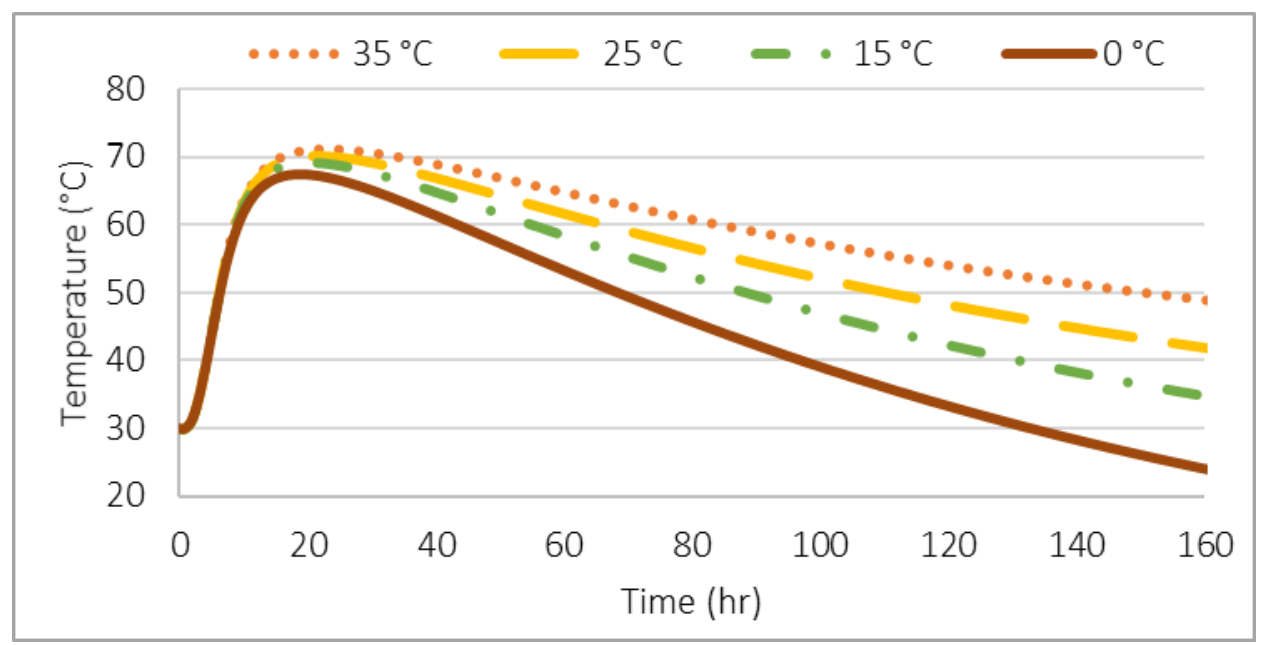

Figure 4-3: The effect of ambient temperature on the temperature of the center location 


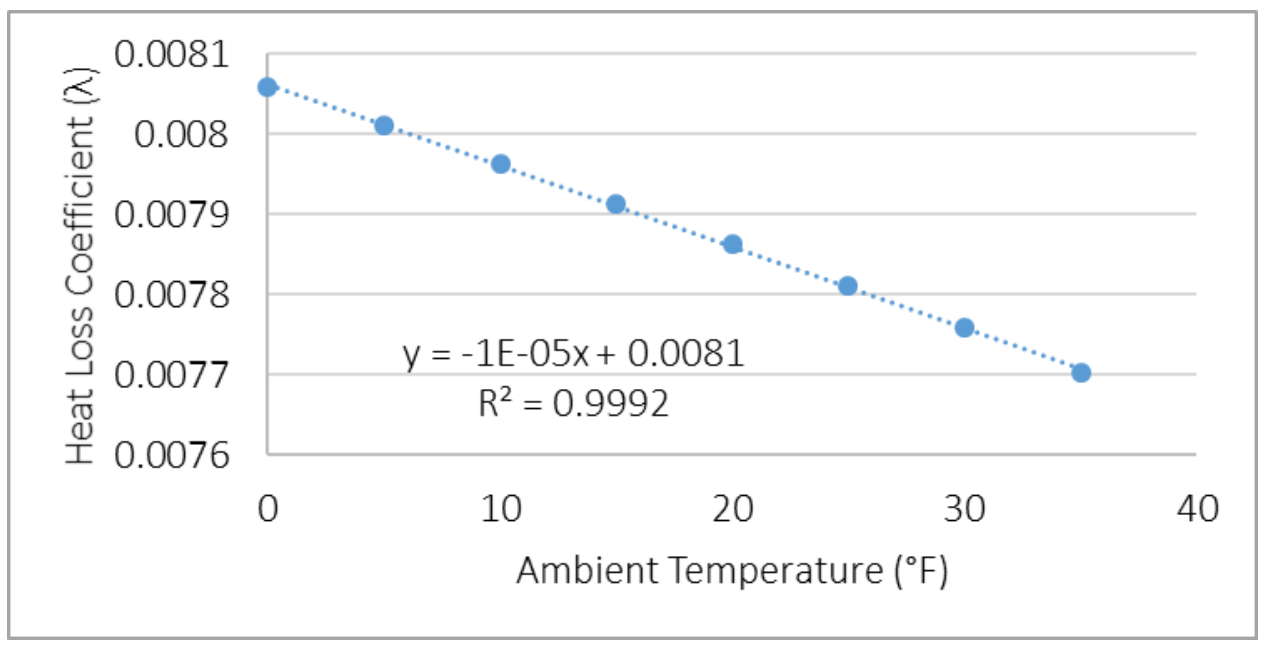

Figure 4-4: Heat loss characteristic coefficient vs. ambient temperature

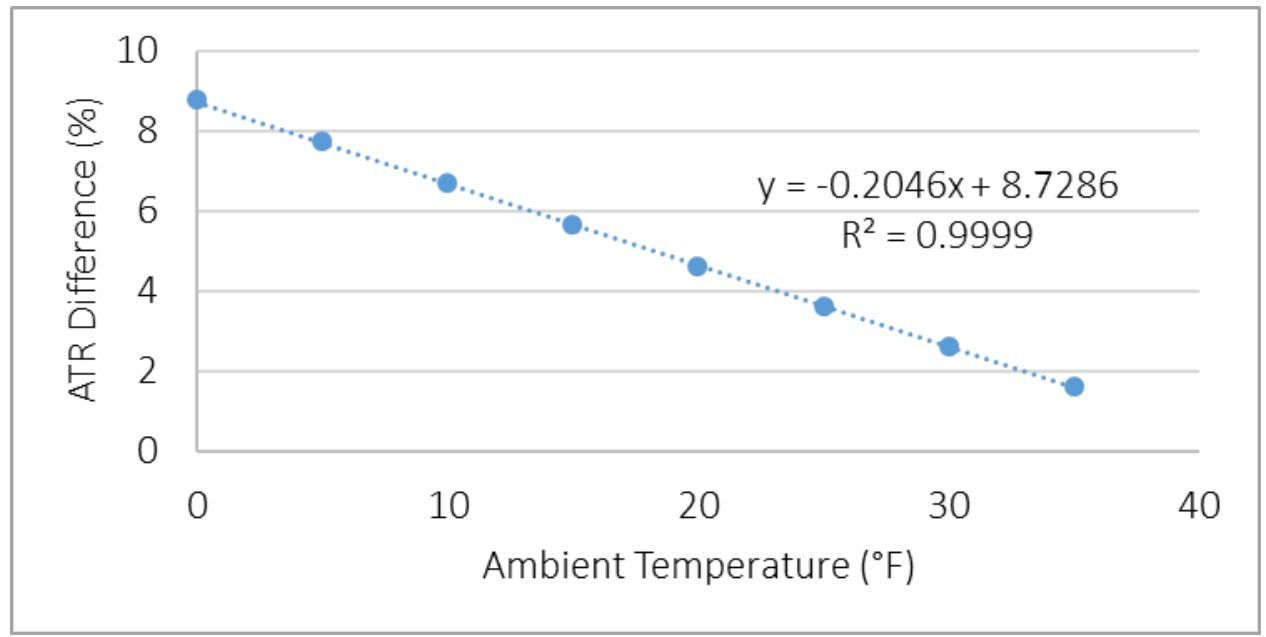

Figure 4-5: ATR error at 7-days due to ambient temperature

Using the FEM model, the amount of insulation was estimated so that the calculated ATR using the one-point measurement is close to the actual ATR of the mix. The thermal conductivity of the 25.4-mm insulation was modified until the calculated ATR using the center temperature was within $1{ }^{\circ} \mathrm{C}(2 \%)$ of the actual ATR at 7 days $\left(49.38{ }^{\circ} \mathrm{C}\right)$. Finally, the amount of insulation needed for each different ambient temperature, the calculated heat loss characteristic coefficient and the percentage difference between the calculated ATR and the input ATR are shown in Table 4-2. The comparison between the ATRs obtained by the heat loss compensation and the input ATR are 
shown in Figure 4-6, Figure 4-7, Figure 4-8, Figure 4-9 and Figure 4-10. These Figures represent that the amount of insulation in Table 4-2 is enough for each ambient condition, and the ATRs calculated using the center temperature compare very well with the actual ATR input. The heat loss characteristic coefficient versus time is shown in Figure 4-11 for each case. It is obvious that the $\lambda$ coefficients approached to constant values after 120 hours in any cases which is a validation for the usage of average $\lambda$ after approximately 5 days of curing. As shown in Table 4-2, Figure 4-11 and Figure 4-12 the heat loss characteristic coefficient decreases as the amount of insulation due to lower ambient temperature increases; however, similar heat loss behavior can be obtained for all the cases. The normalized heat loss by the density and specific heat of the concrete is compared closely and shown in Figure 4-12. Therefore, the method can be applied in various ambient conditions as long as the insulation requirements shown in Table 4-2 are met. The number of minimum insulation layers with RSI value of $0.88\left(\mathrm{~m}^{2} . \mathrm{K} / \mathrm{W}\right)$ with the thickness of 25.4-mm for each layer are shown in Table 4-2. The average calculated heat loss characteristic based on Table 4-2 is plot versus the ambient temperature in Figure 4-13. Since the heat loss characteristics shown in Table 4-2 are based on the minimum required insulations; therefore, Figure 4-13 can be used as the upper bound for the heat loss characteristic coefficient so that the ATR can be accurately calculated.

Table 4-2: Required insulation for different ambient temperature

\begin{tabular}{ccccc}
\hline Ambient $\left({ }^{\circ} \mathbf{C}\right)$ & $\begin{array}{c}\text { Thermal } \\
\text { Conductivity of } \\
\text { insulation }(\mathbf{W} / \mathbf{m} / \mathbf{K})\end{array}$ & $\begin{array}{c}\text { RSI value of insulation } \\
\left(\mathbf{m}^{\mathbf{2}} \mathbf{. K} / \mathbf{W}\right) \\
\left(\text { Each Layer } \mathbf{0 . 8 8} \mathbf{~ m}^{\mathbf{2}} \mathbf{. K} / \mathbf{W}\right)\end{array}$ & $\boldsymbol{\lambda}\left(\mathbf{h r}^{-\mathbf{1}}\right)$ & $\begin{array}{c}\text { ATR difference } \\
\text { at 7-days }(\boldsymbol{\%})\end{array}$ \\
\hline $\mathbf{- 1 0}$ & 0.0103 & 2.448 (3 Layers) & 0.00350 & 1.06 \\
\hline $\mathbf{0}$ & 0.0121 & 2.098 (3 Layers) & 0.00400 & 1.21 \\
\hline $\mathbf{1 0}$ & 0.0147 & 1.728 (2 Layers) & 0.00471 & 1.39 \\
\hline $\mathbf{2 0}$ & 0.0207 & 1.224 (2 Layers) & 0.00559 & 1.41 \\
\hline $\mathbf{3 0}$ & 0.0242 & 1.049 (2 Layers) & 0.00699 & 1.70 \\
\hline
\end{tabular}




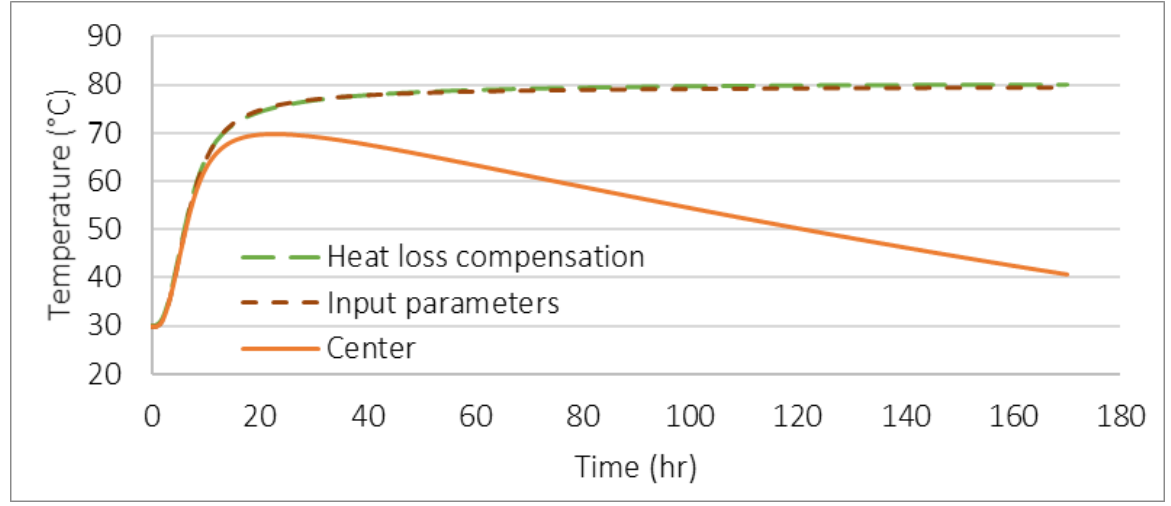

Figure 4-6: Heat loss compensated vs. input ATR (Ambient temperature $\left.=-10{ }^{\circ} \mathrm{C}\right)$

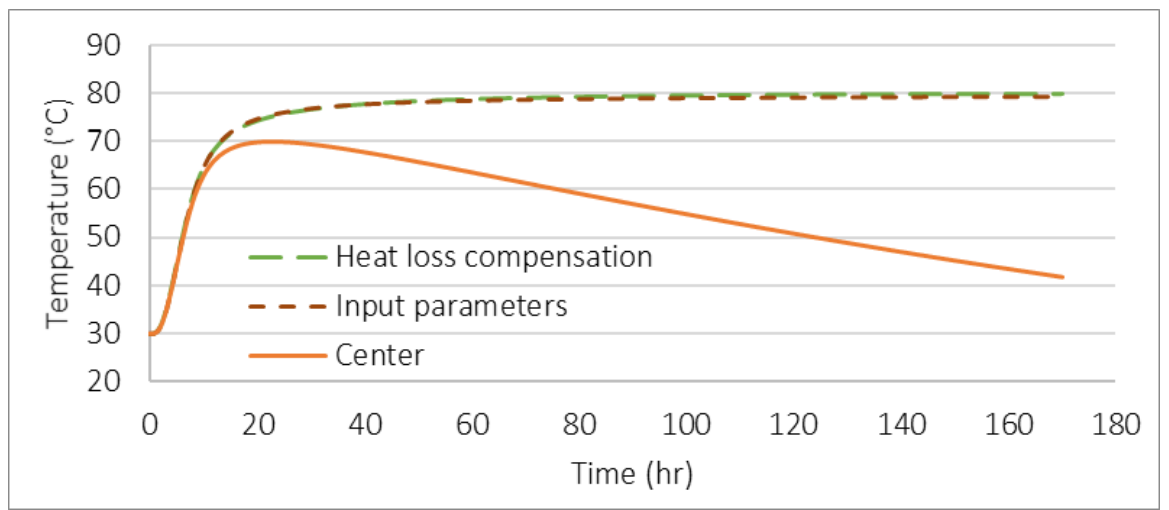

Figure 4-7: Heat loss compensated vs. input ATR (Ambient temperature $\left.=0{ }^{\circ} \mathrm{C}\right)$

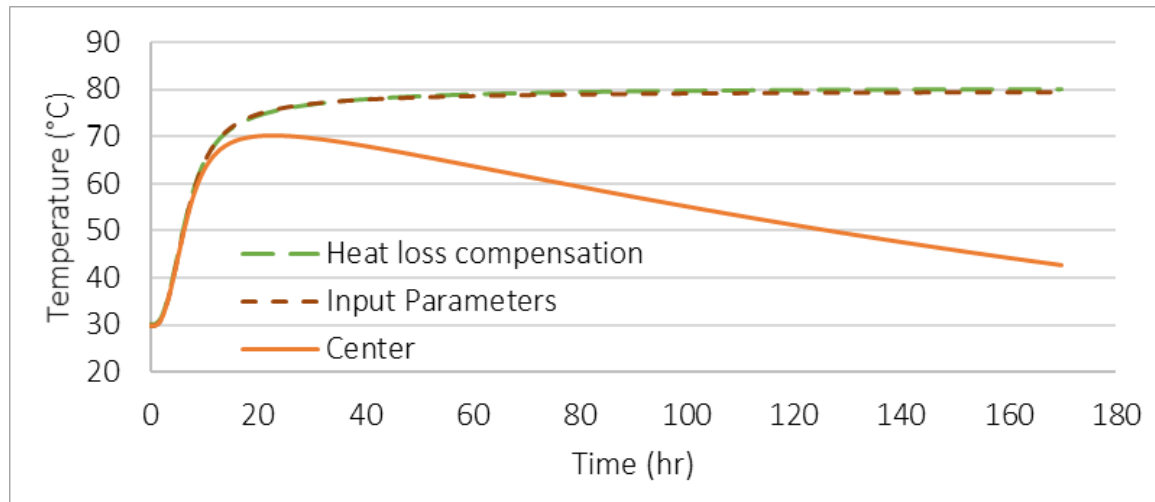

Figure 4-8: Heat loss compensated vs. input ATR (Ambient temperature $=10{ }^{\circ} \mathrm{C}$ ) 


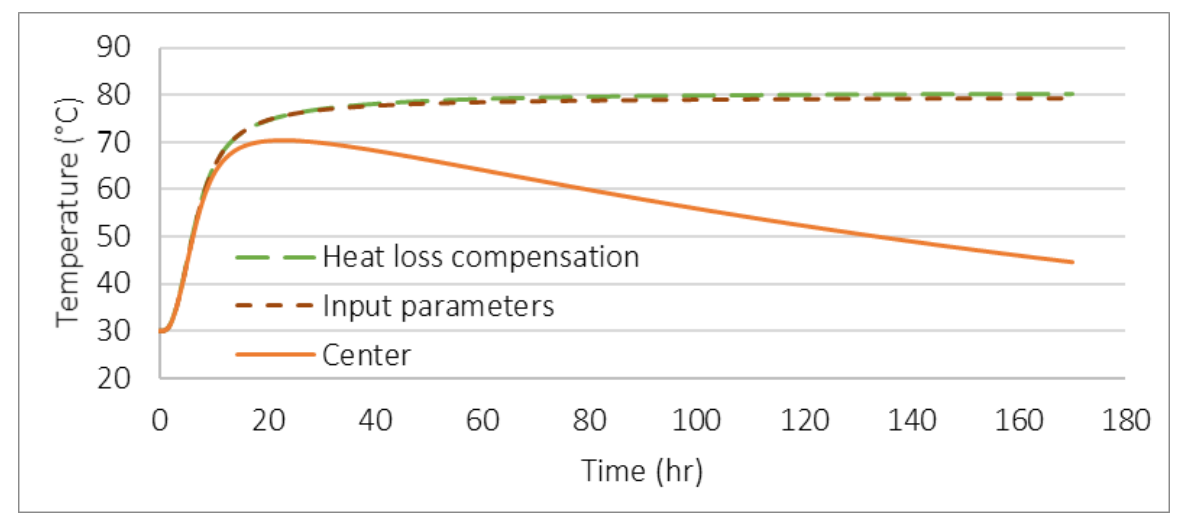

Figure 4-9: Heat loss compensated vs. input ATR (Ambient temperature $=20^{\circ} \mathrm{C}$ )

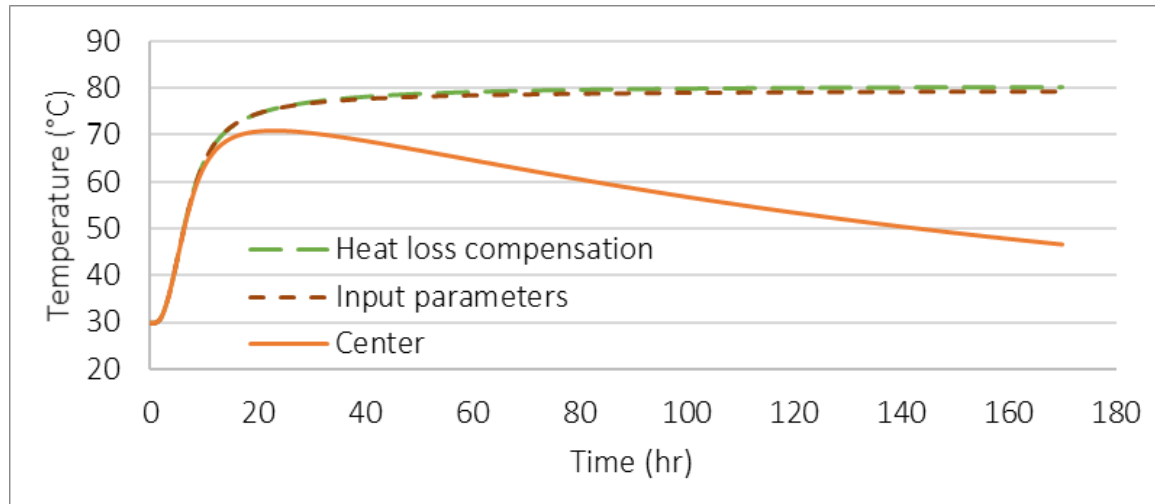

Figure 4-10: Heat loss compensated vs. input ATR (Ambient temperature $\left.=30^{\circ} \mathrm{C}\right)$

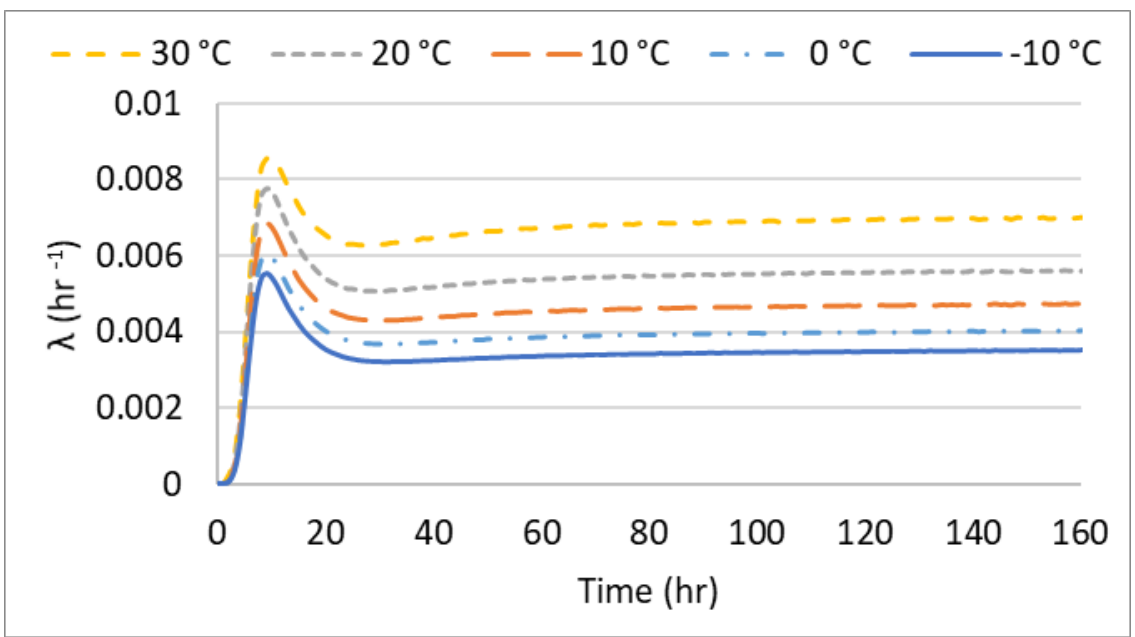

Figure 4-11: Heat loss characteristic comparisons vs. time 


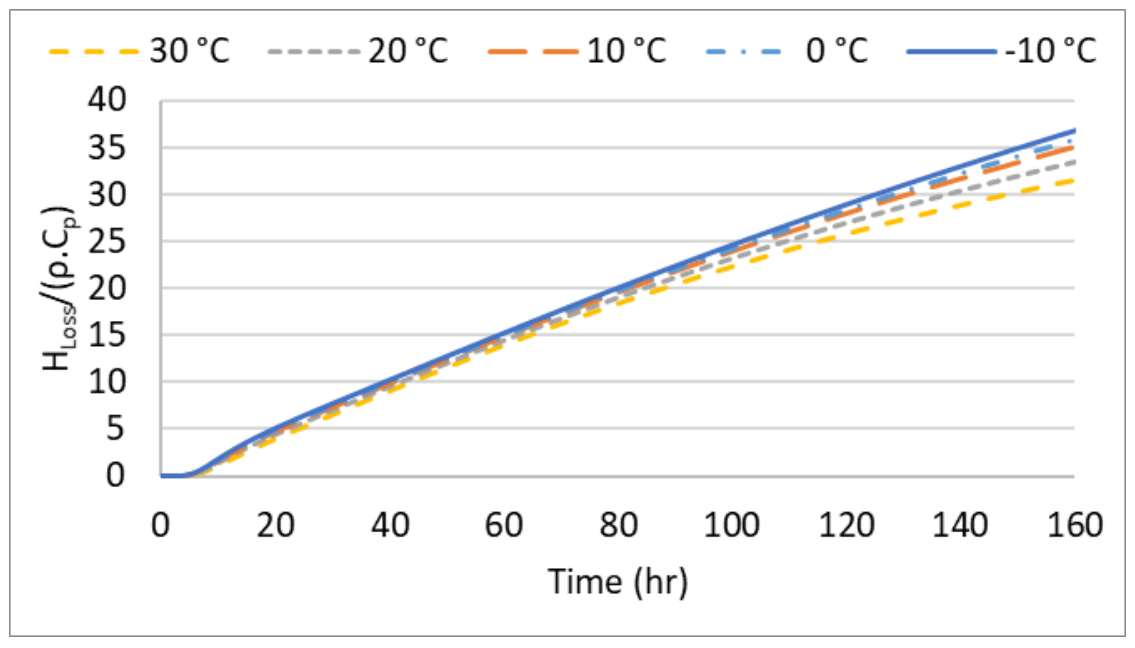

Figure 4-12: Normalized heat loss comparisons

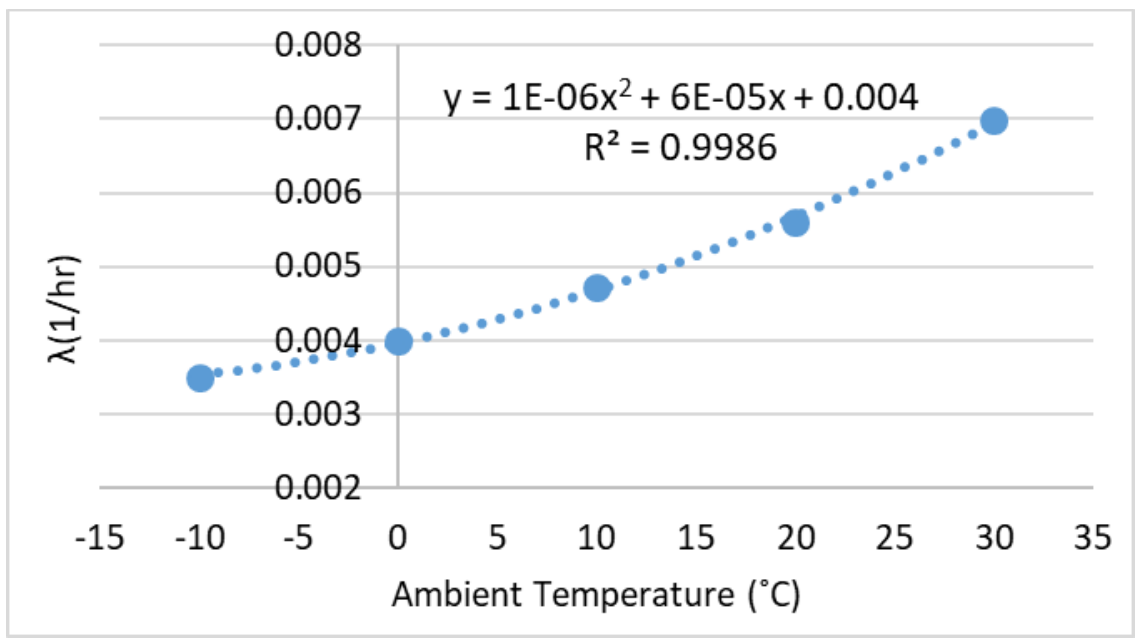

Figure 4-13: Heat loss characteristic coefficient vs. ambient temperature

\subsection{Summary}

A 1-m cube with multiple layers of insulations was chosen to act as an on-site semiadiabatic calorimetry. Since the estimation of the spatial temperature profile within the concrete volume is not simple, a practical method is required to simplify the calculation. It was assumed that both volumetric and surface temperatures are equal to the measured center temperature. Therefore, enough insulation is needed to satisfy this condition for any ambient temperatures. The minimum amount depends on the different ambient environmental conditions. A finite element 
model was used to find the minimum insulation needed for using a one-point measurement to calculate the ATR accurately. A table based on different thermal insulation needed for each ambient condition was provided to be used in building the on-site calorimetry. 


\section{Chapter 5 : On-site testing}

\subsection{Material Properties}

The applicability of the proposed procedures for the on-site measurement of $\mathrm{w} / \mathrm{cm}$ ratio and adiabatic temperature rise were tested in several field situations. Three on-site castings took place in three different district locations (District 4 (D-4), District 5 (D-5), and District 10 (D-10)) in the state of West Virginia. In each district location, two ready-mix concrete batches were delivered to the job site by concrete trucks. Table 5-1 contains the submitted mix designs and the measured SSD values. The absorption rate (SSD) of each individual aggregate was measured using ASTM standards before on-site testing. Slump, air percentage, initial temperature, and unit density were tested for the delivered concrete and are shown in Table 5-2.

Table 5-1: Mix design of on-site testing

\begin{tabular}{|c|c|c|c|}
\hline Material & District-4 & District-5 & District-10 \\
\hline Cement $\left(\mathrm{kg} / \mathrm{m}^{3}\right)$ & 150.6 & 150.6 & 211.2 \\
\hline Slag $\left(\mathrm{kg} / \mathrm{m}^{3}\right)$ & 150.6 & 150.6 & - \\
\hline Fly Ash $\left(\mathrm{kg} / \mathrm{m}^{3}\right)$ & - & - & 90.17 \\
\hline Water $\left(\mathrm{kg} / \mathrm{m}^{3}\right)$ & 120.55 & 127.55 & 120.43 \\
\hline Limestone Aggregate $\left(\mathrm{kg} / \mathbf{m}^{3}\right)$ & 1056.03 & 1066.11 & 1056.03 \\
\hline SSD (Limestone) (\%) & 0.5 & 0.44 & 0.5 \\
\hline Fine Aggregate $\left(\mathrm{kg} / \mathrm{m}^{3}\right)$ & 864.4 & 832.36 & 850.75 \\
\hline SSD (Sand) (\%) & 1.4 & 0.8 & 1.5 \\
\hline $\mathrm{w} / \mathrm{cm}$ ratio & 0.4 & 0.423 & 0.4 \\
\hline Air Entraining, ml/100 kg & 32.6 & 81.6 & 12.4 \\
\hline Retarder, ml/100 kg & 130.5 & 84.8 & 228.4 \\
\hline Water Reducer, $\mathrm{ml} / 100$ kg & 261 & 391.5 & 522 \\
\hline Super Plasticizer, ml/100 kg & 208.8 & 913.6 & 287.1 \\
\hline
\end{tabular}




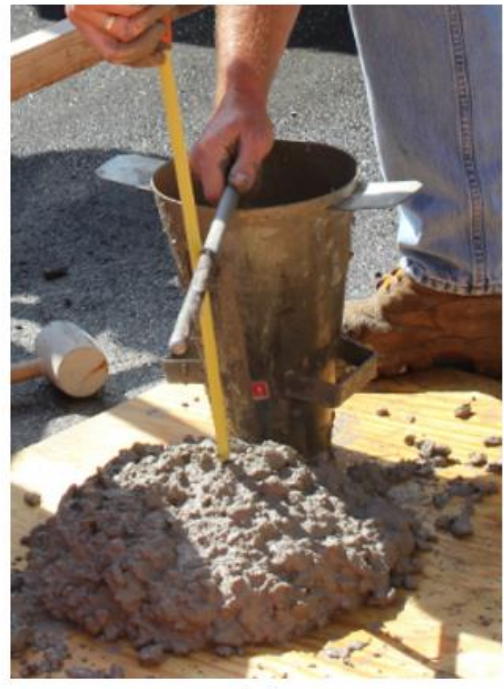

(a)

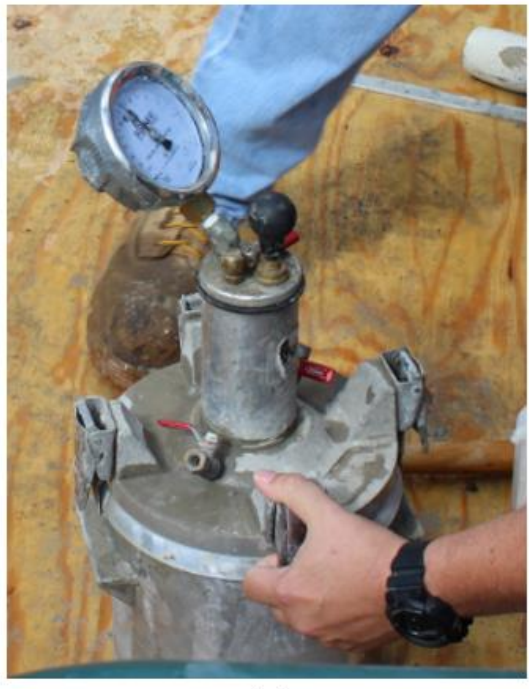

(b)

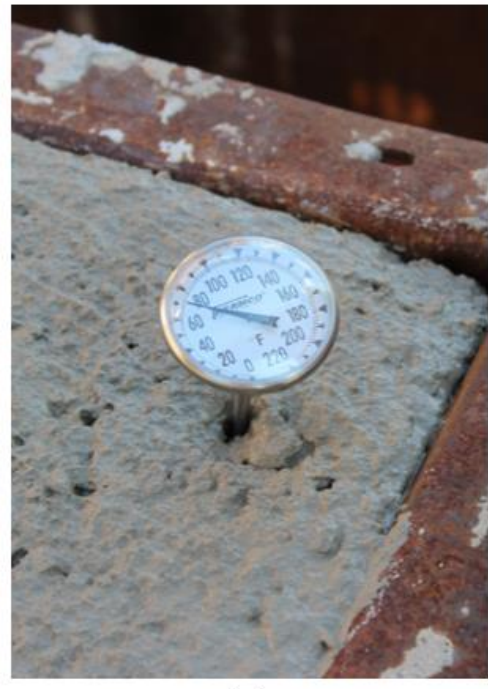

(c)

Figure 5-1: Onsite testing: (a) slump, (b) air content and (c) temperature measurement

Table 5-2: Measured properties

Location Truck \# Slump, cm Air content, \% $\quad$ Initial temperature $\left({ }^{\circ} \mathrm{C}\right) \quad$ Unit density, $\mathrm{kg} / \mathrm{m}^{3}$

\begin{tabular}{llllll}
\hline \multirow{2}{*}{ District-4 } & 1 & 19.7 & 8.5 & 28 & 2322.7 \\
\cline { 2 - 5 } & 2 & 13.2 & 7.0 & 30 & 2338.7 \\
\hline \multirow{2}{*}{ District-5 } & 1 & 12.7 & 7.5 & 21 & 2258.6 \\
\cline { 2 - 5 } & 2 & 17.2 & 7.8 & 22 & 2274.6 \\
\hline District-10 & 1 & 16.5 & 3.6 & 26 & 2316.3 \\
\hline
\end{tabular}

All the necessary tools were brought to the job site, and the on-site w/cm ratio tests were performed. Two samples $(1500 \pm 100-\mathrm{g})$ were taken to measure the w/cm ratio for each batch. The measured w/cm ratios for all the on-site testing, twelve test samples, are shown in Table 5-3. The measured densities were used to calculate the w/cm ratios based on AASHTO equations. The dry limestone mass for each sample was measured on-site. However, even after shaking the dried aggregate on top of a \#4 sieve, powder particles could still be observed around the dried limestone. 
Since the amount of water in these mixes was higher than the laboratory batches, the duration of the heating cycles in the microwave was longer. Thus, the particles had more time to bond around the aggregate. Another reason could be the high chemical admixtures dosage used in these batches to increase the workability of these mixes, which created bonds between the aggregate and the dried powder during the heating cycles. In the laboratory castings, powder particles were not as visible around the aggregate after sieving. To measure the correct amount of coarse aggregate, washing vinegar was used to wash out the particles. The aggregate was saturated in 230 -g of washing vinegar (6\% acetic acid) with the addition of $230 \mathrm{~g}$ of water for $24 \mathrm{hrs}$. The experimental results, as well as the stoichiometry calculation, showed approximately 10-g of limestone was dissolved in the vinegar. Therefore, this amount of limestone in vinegar solution must be added back to the dry limestone mass. After saturation and drying, the aggregate surfaces were clean. Since the aggregate at the time of mixing always contains dust particles, the mass of dust needs to be included in the aggregate mass, which was measured to be approximately 4-g in $600-\mathrm{g}$ of aggregate. An average of $17 \mathrm{~g}$ of bonded particles were collected from the samples. The last column in Table 5-3 shows the results of the w/cm ratio after the washing process. A maximum deviation of 0.041 between the revised method and the revised method after saturation in vinegar was observed. The increment in some results might be due to the underestimation of dust powder in the calculations. The revised method, as well as the T318 method, indicate a higher w/cm ratio for the delivered batches. However, the revised method after saturation showed higher consistency between the two samples tested. 


\section{Table 5-3: w/cm ratio result for different districts casting}

\begin{tabular}{lccccccc} 
Description & $\begin{array}{c}\text { Sample } \\
(\mathbf{g})\end{array}$ & $\begin{array}{c}\text { Evaporated } \\
\text { Water }(\mathbf{g})\end{array}$ & $\begin{array}{c}\text { Limestone } \\
(\mathbf{g})\end{array}$ & $\begin{array}{c}\text { w/cm ratio } \\
\text { (Mix design) }\end{array}$ & $\begin{array}{c}\text { w/cm ratio } \\
\text { (AASHTO } \\
\text { T-318 } \\
\text { method) }\end{array}$ & $\begin{array}{c}\text { w/cm ratio } \\
\text { (Revised } \\
\text { method) }\end{array}$ & $\begin{array}{c}\text { w/cm ratio } \\
\text { (Revised } \\
\text { method - } \\
\text { saturated in } \\
\text { vinegar) }\end{array}$ \\
\hline D-4 (Truck 1-1) & 1520.7 & 95.6 & 673.5 & 0.4 & 0.428 & 0.414 & 0.429 \\
\hline D-4 (Truck 1-2) & 1526.7 & 102.3 & 609.7 & 0.4 & 0.458 & 0.411 & 0.425 \\
\hline D-4 (Truck 2-1) & 1551.2 & 102.2 & 629.1 & 0.4 & 0.453 & 0.407 & 0.417 \\
\hline D-4 (Truck 2-2) & 1560.7 & 96.7 & 691.2 & 0.4 & 0.424 & 0.406 & 0.416 \\
\hline D-5 (Truck 1-1) & 1534.2 & 106.8 & 689 & 0.423 & 0.485 & 0.490 & 0.498 \\
\hline D-5 (Truck 1-2) & 1525.2 & 102.6 & 696 & 0.423 & 0.468 & 0.479 & 0.488 \\
\hline D-5 (Truck 2-1) & 1545.8 & 95.9 & 762.3 & 0.423 & 0.432 & 0.486 & 0.471 \\
\hline D-5 (Truck 2-2) & 1569.4 & 101.1 & 753.2 & 0.423 & 0.45 & 0.494 & 0.475 \\
\hline D-10 (Truck 1-1) & 1573.4 & 110.9 & 736.9 & 0.4 & 0.484 & 0.516 & 0.498 \\
\hline D-10 (Truck 1-2) & 1589.1 & 115.9 & 730 & 0.4 & 0.503 & 0.529 & 0.494 \\
\hline D-10 (Truck 2-1) & 1721.1 & 139.2 & 691 & 0.4 & 0.562 & 0.534 & 0.493 \\
\hline D-10 (Truck 2-2) & 1539.6 & 113.7 & 688.2 & 0.4 & 0.51 & 0.523 & 0.499 \\
\hline
\end{tabular}

\subsection{Compressive Strength Tests}

Standard compressive strength cylinders $(15-\mathrm{cm}$ diameter by $30-\mathrm{cm}$ length) were made during each field casting and cured in a temperature-controlled water bath (at $23{ }^{\circ} \mathrm{C}$ ). The compressive strength was tested at the ages of $1,3,7,14,28$, and 56 days shown in Figure 5-3, Figure 5-4, and Figure 5-5. The measured 1-day and 28-days compressive strength are compared in Table 5-4 for each batch. Table 5-4 shows that the 50\% slag batches have very low one-day compressive strength results but much higher 28-days compressive strength. The very low compressive strength of District 5 batch at one-day testing was a result of overdosing the water reducer/retarder admixture to adjust the slump of the mix. 


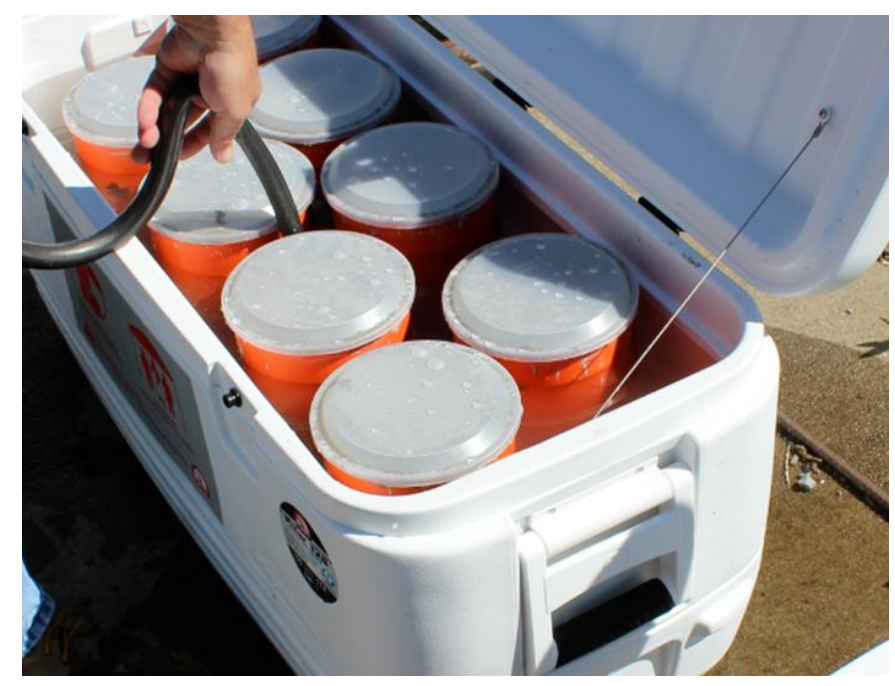

Figure 5-2: On-site curing of compressive strength specimens

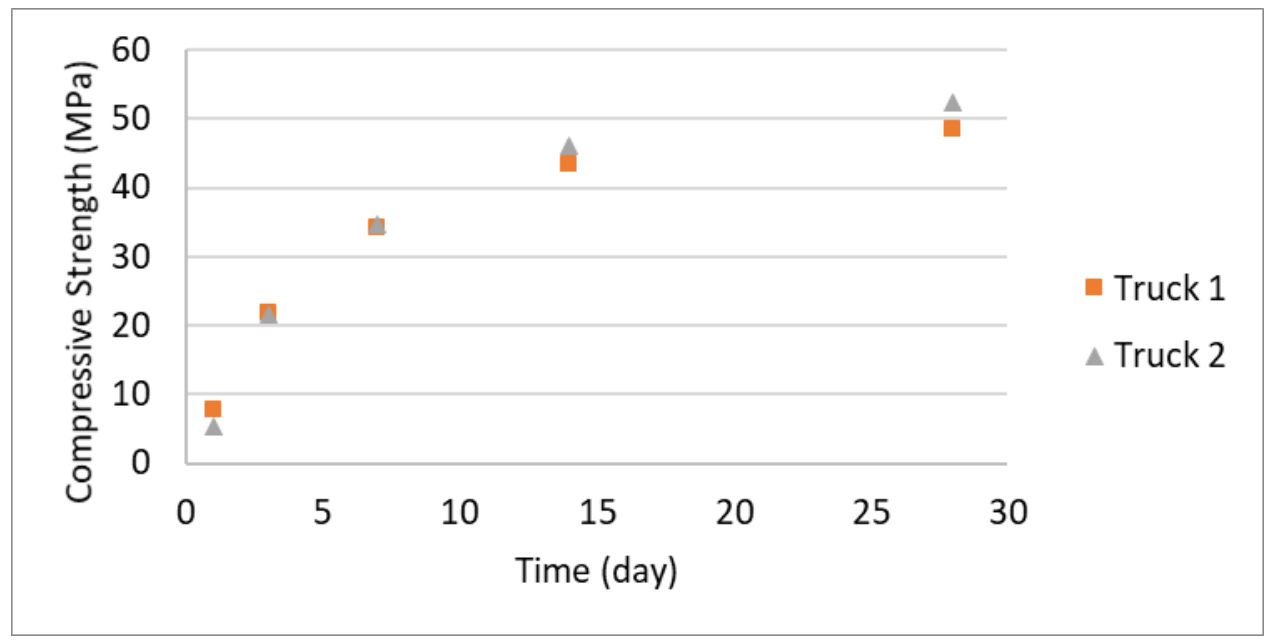

Figure 5-3: Comparison of compressive strength (District-4) 


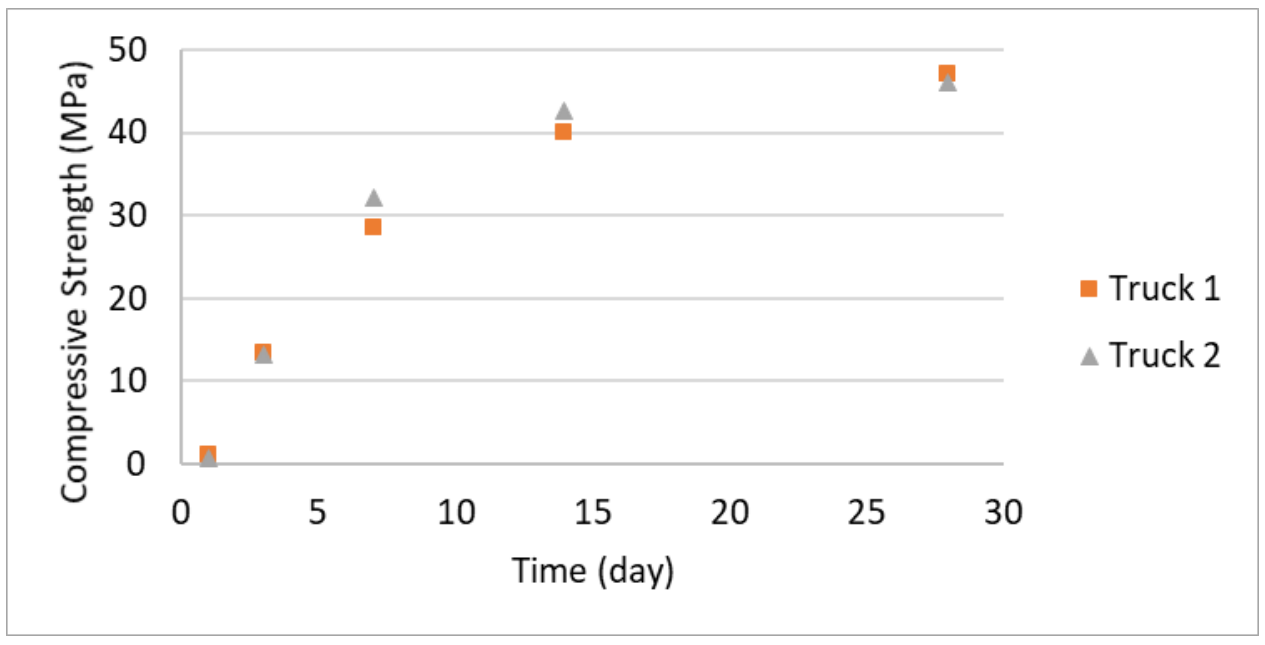

Figure 5-4: Comparison of compressive strength (District-5)

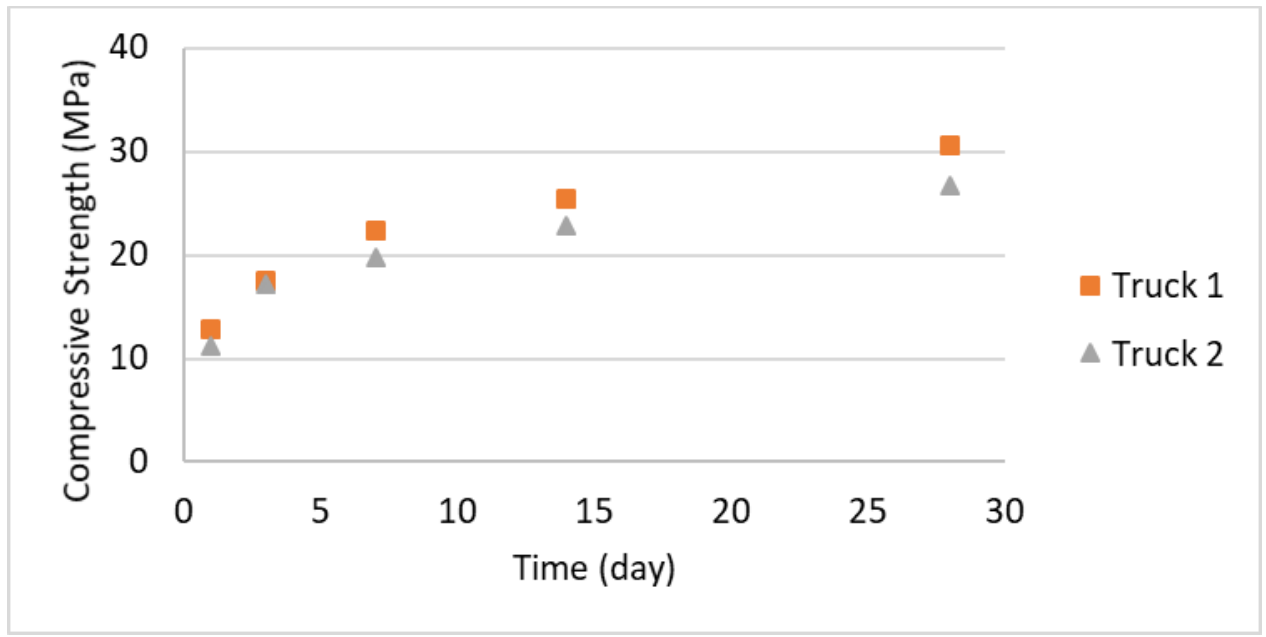

Figure 5-5: Comparison of compressive strength (District-10)

Table 5-4: Comparison of compressive strength 1-day and 28-days

\begin{tabular}{lccc}
\hline District & Batch & 1-Day Compressive Strength (MPa) & 28-Days Compressive Strength (MPa) \\
\hline \multirow{2}{*}{ District-4 } & Truck 1 & 7.83 & 48.37 \\
\cline { 2 - 4 } & Truck 2 & 5.30 & 52.25 \\
\hline \multirow{2}{*}{ District-5 } & Truck 1 & 1.00 & 47.08 \\
\cline { 2 - 4 } & Truck 2 & 0.64 & 46.13 \\
\hline \multirow{2}{*}{ District-10 } & Truck 1 & 12.76 & 30.57 \\
\cline { 2 - 4 } & Truck 2 & 11.26 & 26.78 \\
\hline
\end{tabular}




\subsection{Insulated Cubes}

Each cube was built based on the design that was shown in Chapter 4. Thermal loggers, with the accuracy of $1{ }^{\circ} \mathrm{C}$, were mounted inside the cubes and activated an hour before the concrete delivered. Another temperature logger was also installed on the shaded area to record the ambient environmental temperature, which was directly used to calculate the heat loss of the specimen. As shown in Figure 5-6, each cube was covered with a 5-cm insulation sheet on the top and plastic sheets around the mold after smoothing the top surface. The measured temperature histories for the center, side center ( 5 -cm from the formwork), and the bottom center $(5-\mathrm{cm}$ from the wooden pallet) are shown in Figure 5-7, Figure 5-8, and Figure 5-9. The largest peak temperature difference at the different locations are $3{ }^{\circ} \mathrm{C}, 2{ }^{\circ} \mathrm{C}$ and $2{ }^{\circ} \mathrm{C}$ for District 4,5 , and 10 .

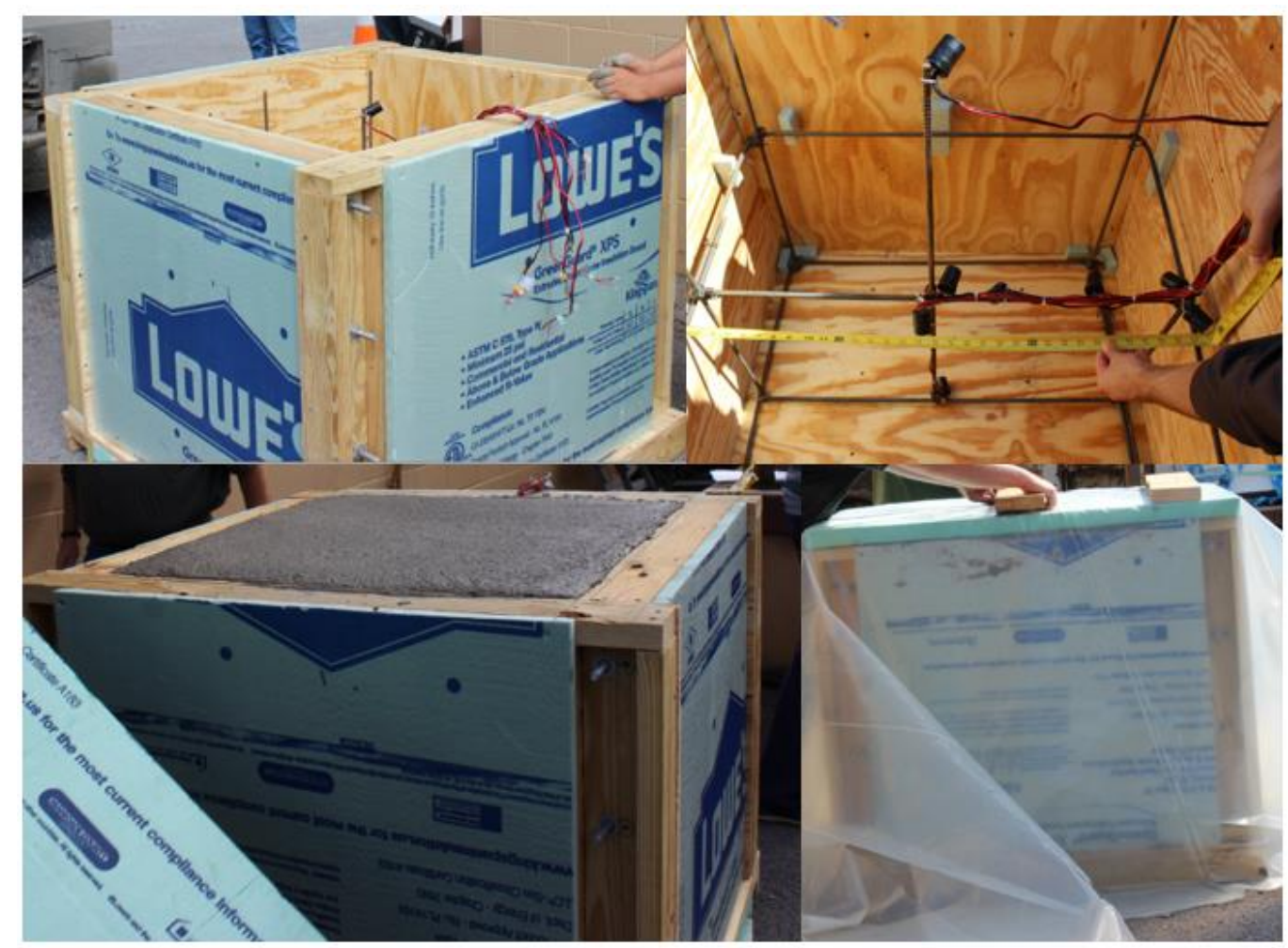

Figure 5-6: Cube casting 


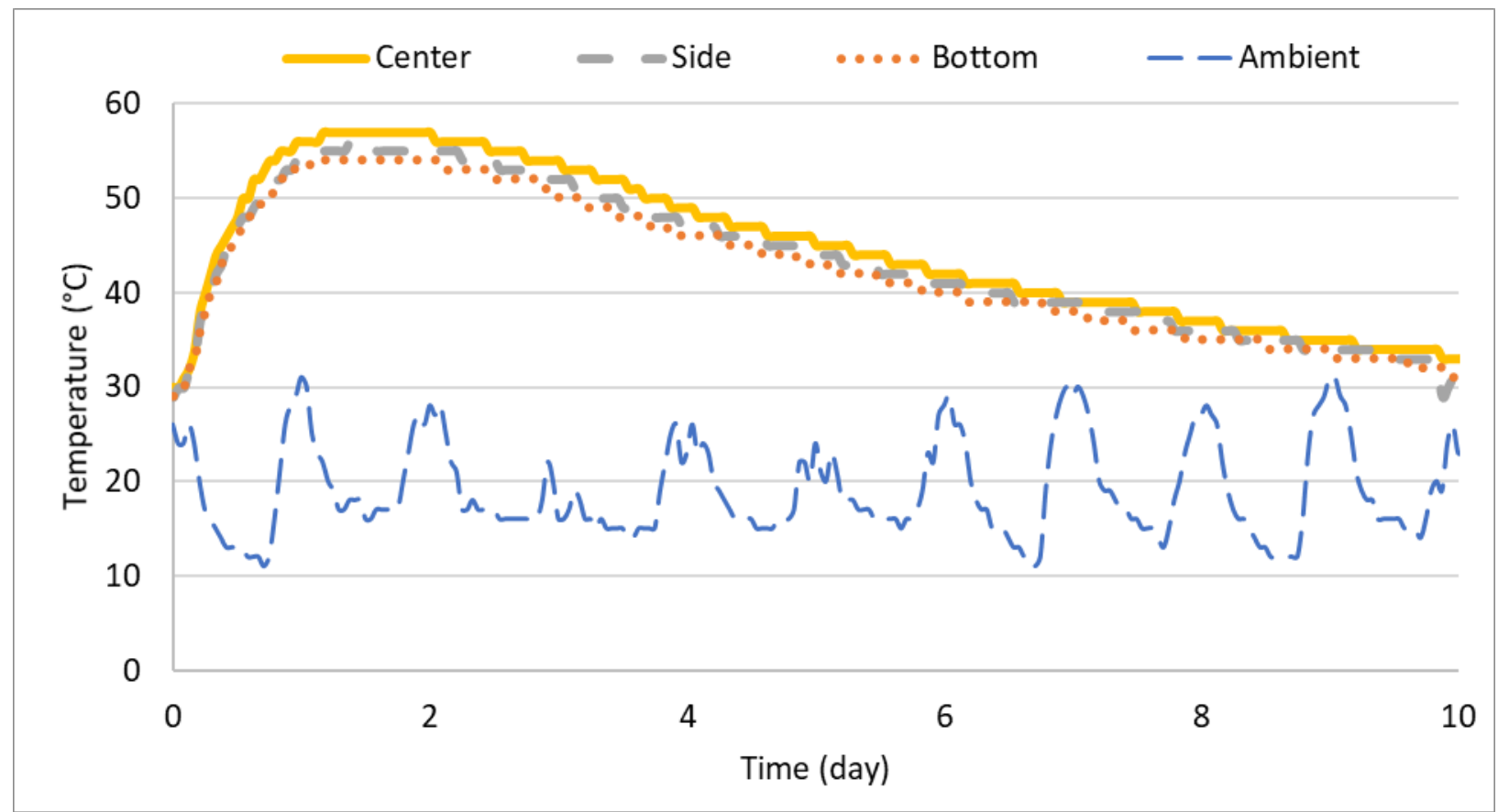

Figure 5-7: District 4 Cube

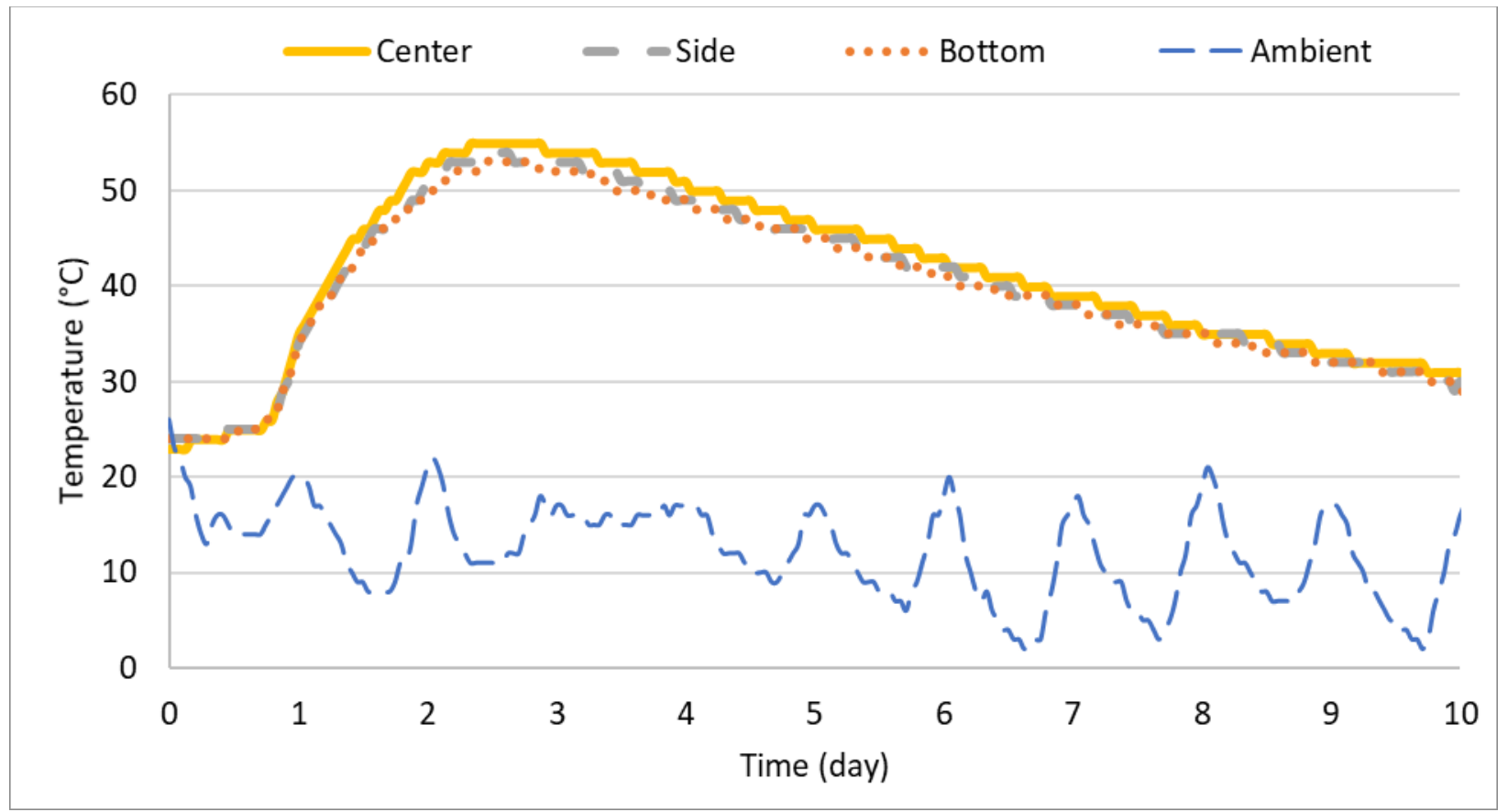

Figure 5-8: District 5 Cube 


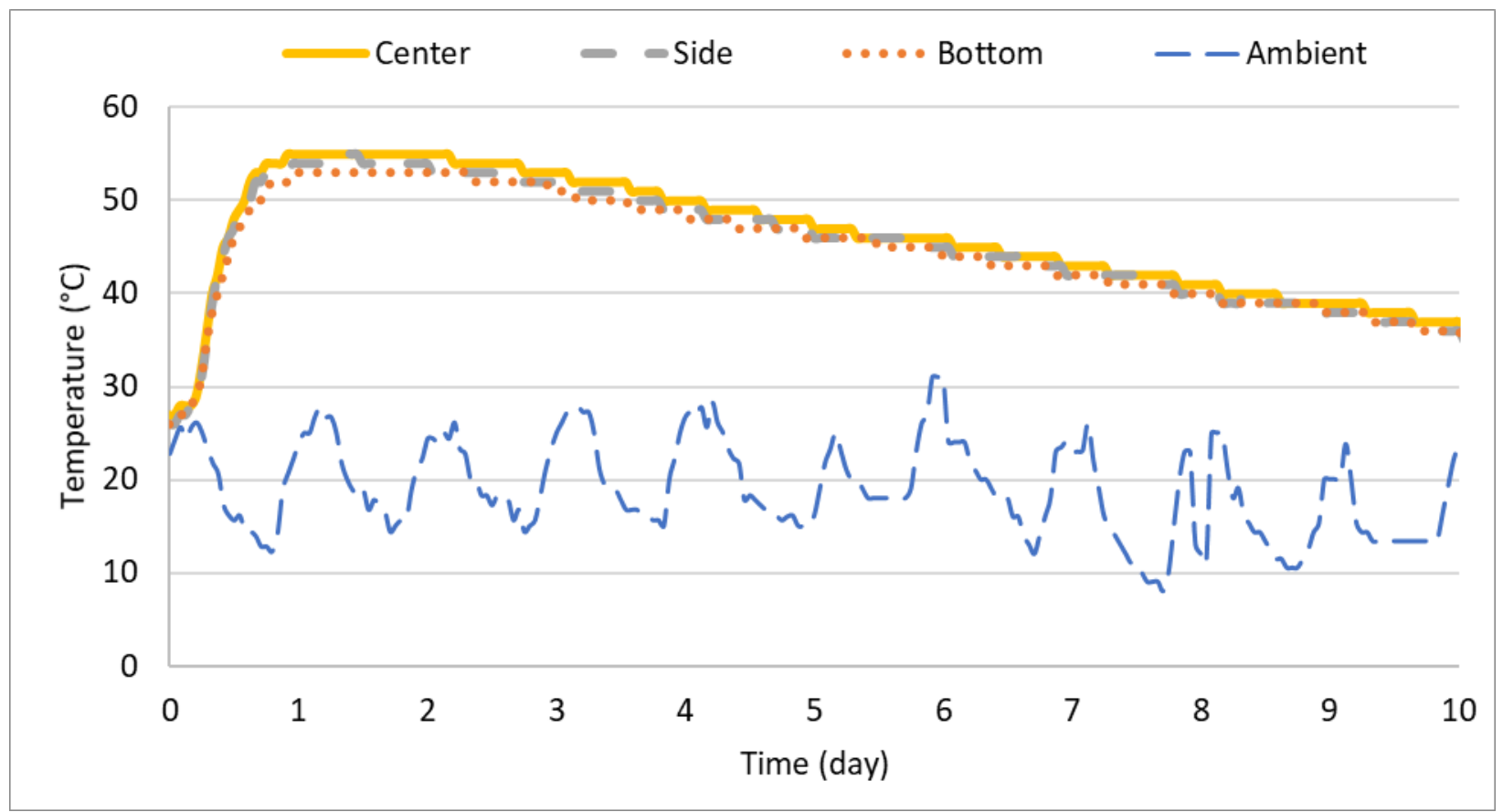

Figure 5-9: District 10 Cube 


\section{Chapter 6 : Laboratory Tests, Analysis and Comparison of}

\section{Results}

\subsection{Compressive Strength Measurement}

The collected material from the district locations was used to produce $10-\mathrm{cm}$ diameter by 20-cm height compressive strength cylinders and tested at the ages of $1,3,7,14$, and 28 days. The measured w/cm ratios of District 4,5 , and 10 laboratory batches were obtained to be $0.4,(0.423$ and 0.47 ), and 0.4 as shown in their mix designs (Table 5-1). To ensure the added water amount, the sand and large aggregates were dried in the $105^{\circ} \mathrm{C}$ oven for 24 hours before the mixing process, and the w/cm ratio was measured using the revised method mentioned in Chapter 3 . The comparison between the measured compressive strength of the laboratory and on-site mixes are shown in Figure 6-1, Figure 6-2, and Figure 6-3. The compressive strength results can reversely confirm that the average measured $w / \mathrm{cm}$ ratio results (shown in Table 6-1) are indeed higher than their mix design ones since the compressive strength results of laboratory batches of both Districts 5 and 10 are much higher than their corresponding on-site batches.

Table 6-1: Summary of w/cm ratio results

\begin{tabular}{|c|c|c|}
\hline Description & w/cm ratio (Mix Design) & w/cm ratio (On-Site) Average \\
\hline D-4 (Truck 1) & \multirow{2}{*}{0.4} & 0.427 \\
\hline D-4 (Truck 2) & & 0.417 \\
\hline D-5 (Truck 1) & \multirow{2}{*}{0.423} & 0.493 \\
\hline D-5 (Truck 2) & & 0.473 \\
\hline D-10 (Truck 1) & \multirow{2}{*}{0.4} & 0.496 \\
\hline D-10 (Truck 2) & & 0.496 \\
\hline
\end{tabular}




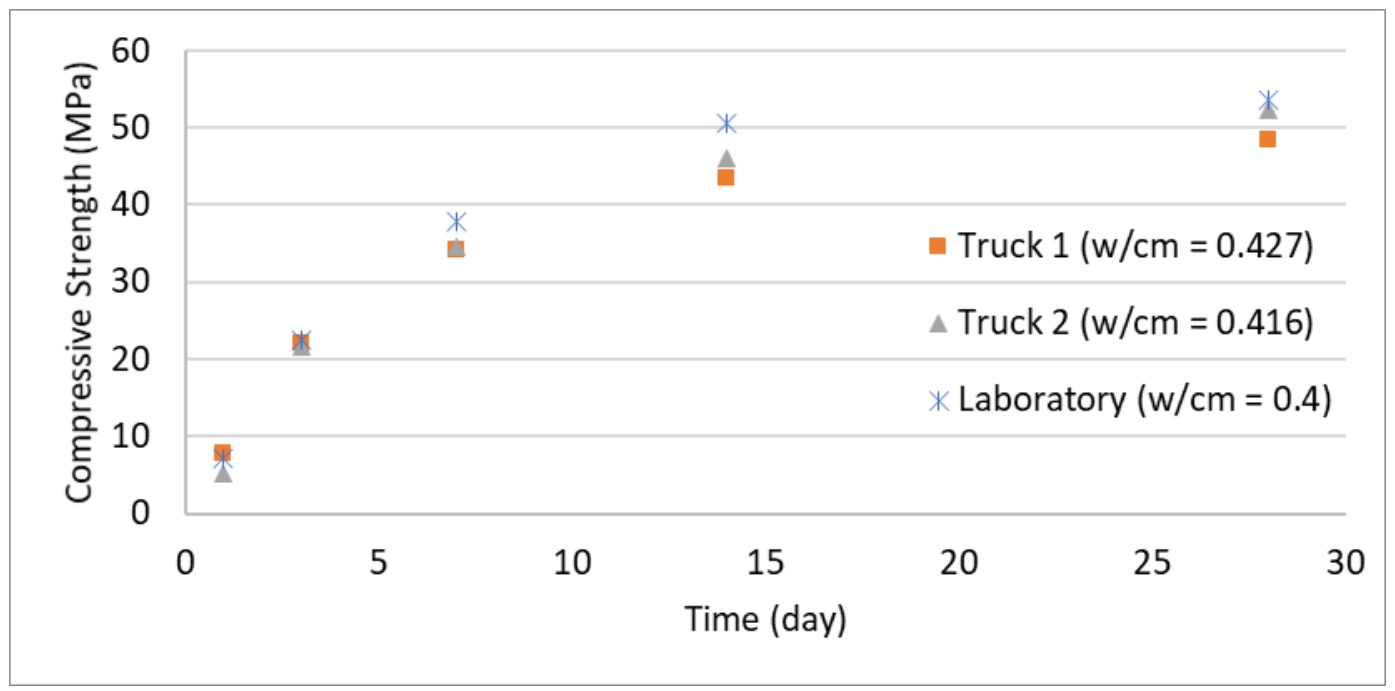

Figure 6-1: The compressive strength comparison of District-4 mix

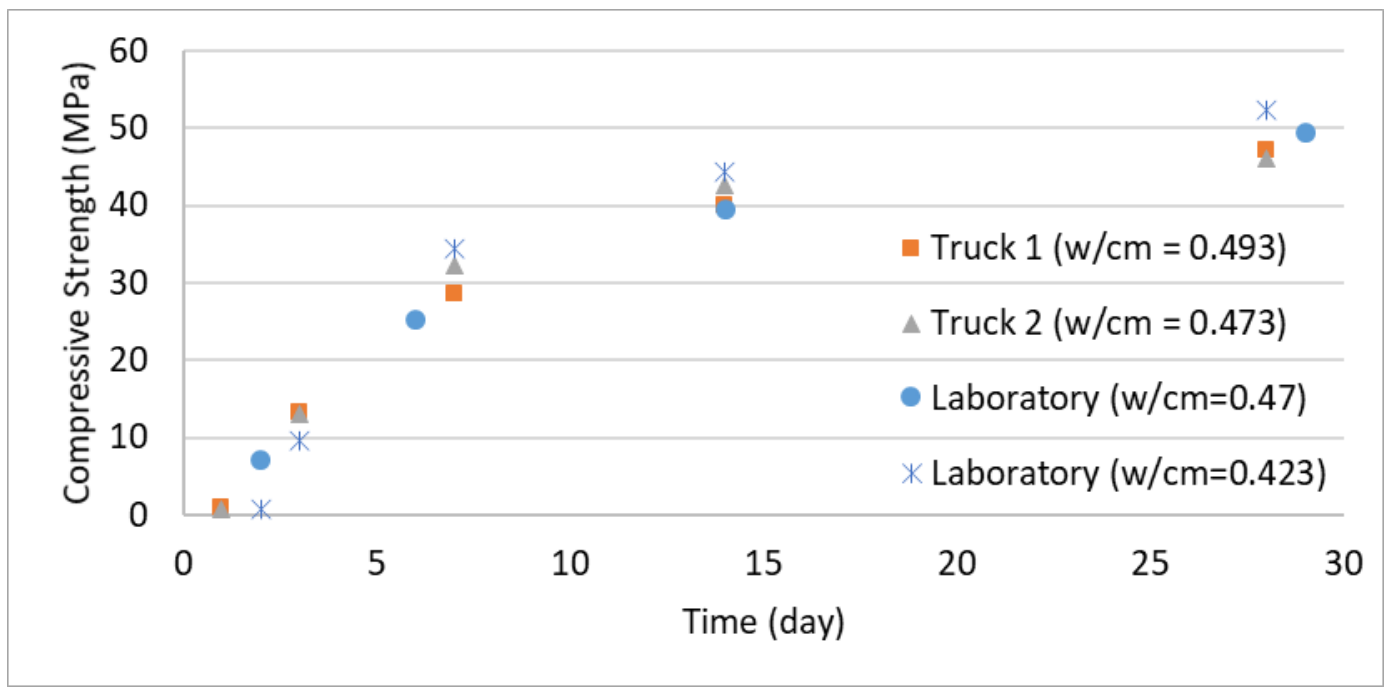

Figure 6-2: The compressive strength comparison of District-5 mix 


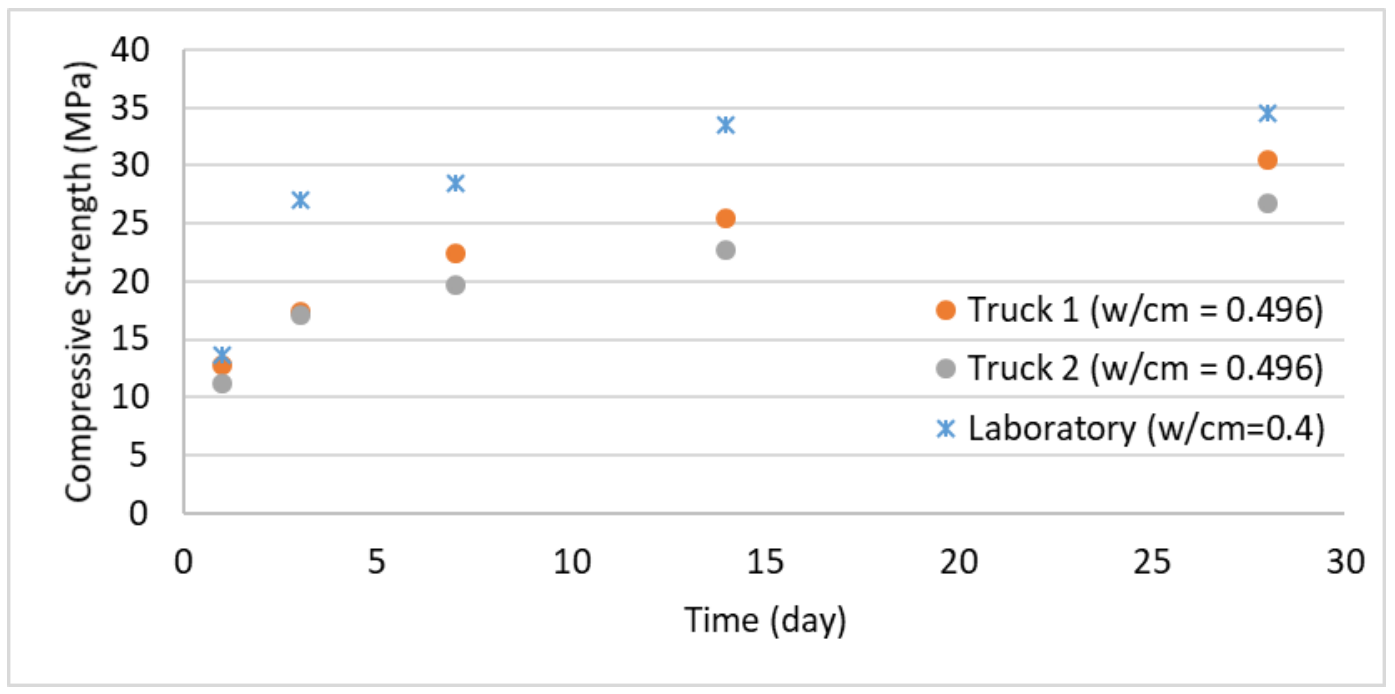

Figure 6-3: The compressive strength comparison of District-10 mix

\subsection{Heat Generation Measurement}

Using the cementitious materials collected from each district location, the heat generation of each blend was measured with the isothermal calorimetry. The heat generation (W/g binder) and accumulated heat (J/g binder) are shown in Figure 6-4, Figure 6-5, and Figure 6-6. The isothermal calorimetry was a commercially available device, TAM Air microcalorimeter (8 channels), which was set at $73.4^{\circ} \mathrm{F}$ constant curing temperature. A total of 20 -gram cementitious materials was mixed with water for each isothermal test, and water was used as the reference material in the calorimetry. 


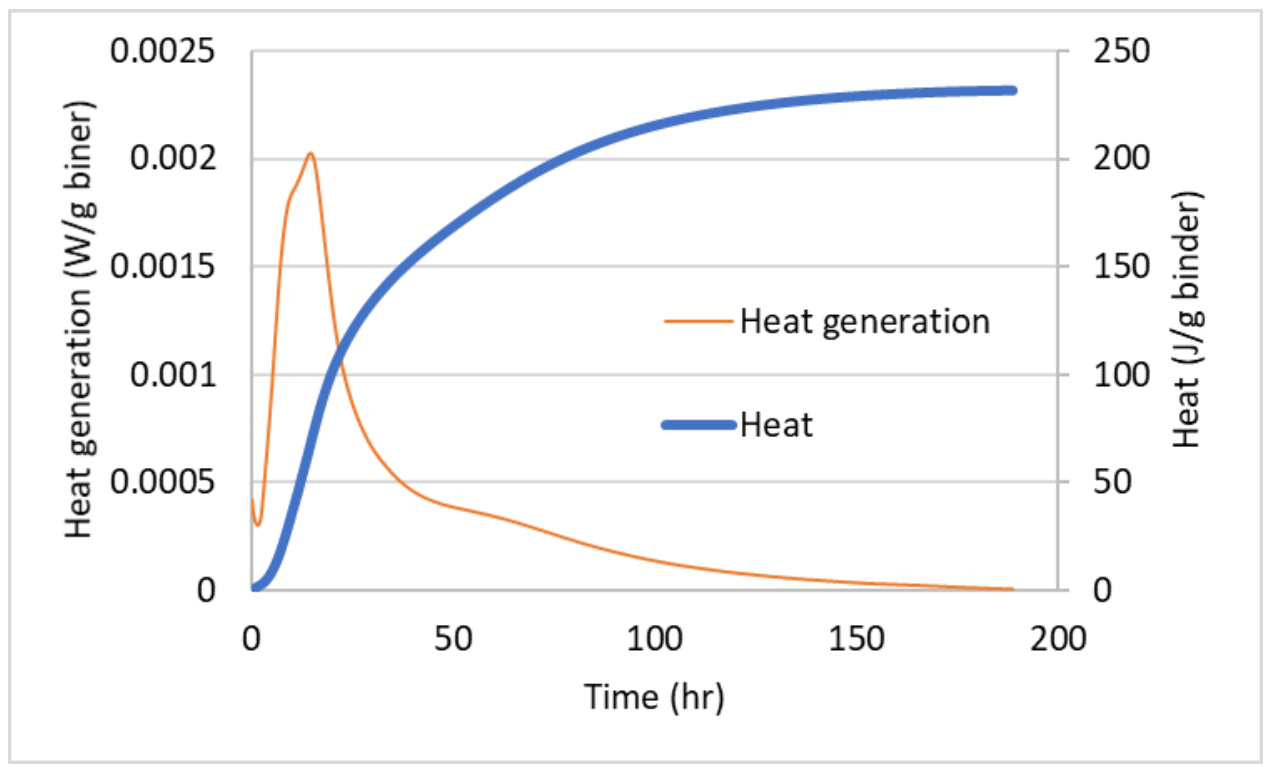

Figure 6-4: Isothermal heat of hydration measurement of District-4 mix

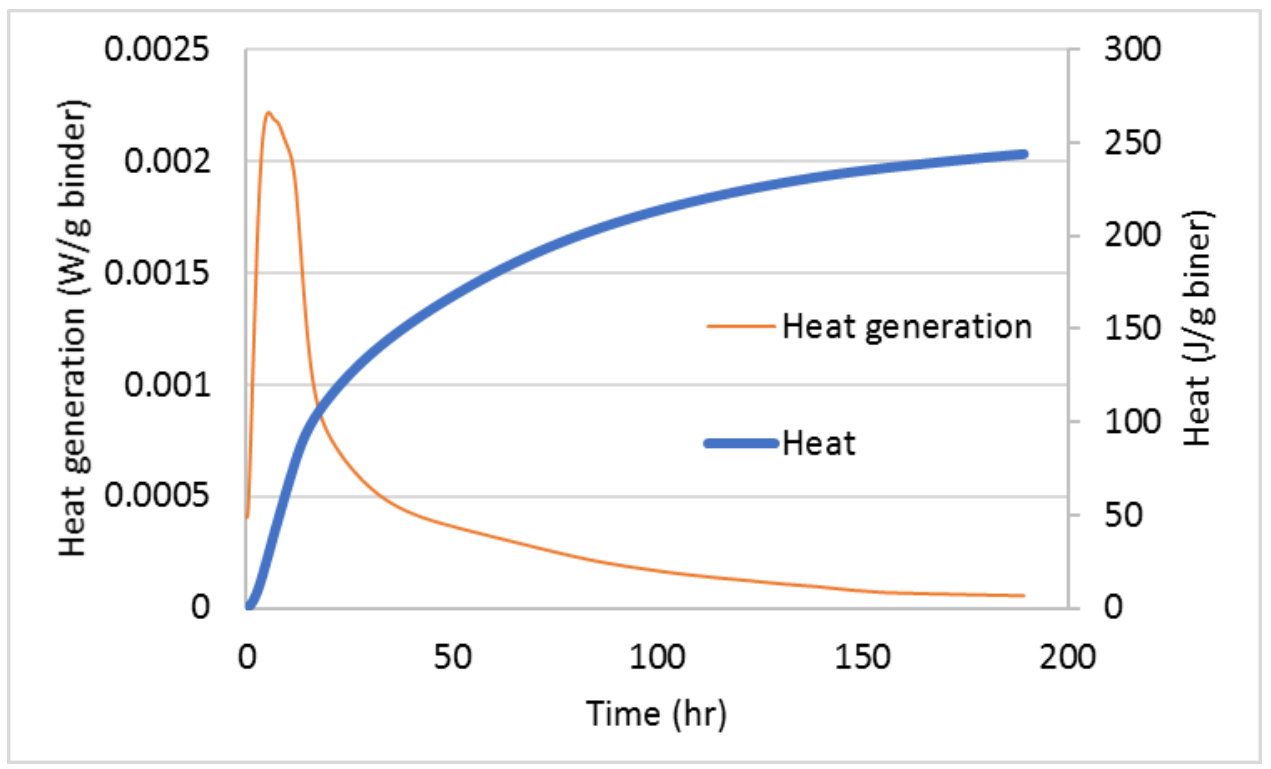

Figure 6-5: Isothermal heat of hydration measurement of District-5 mix 


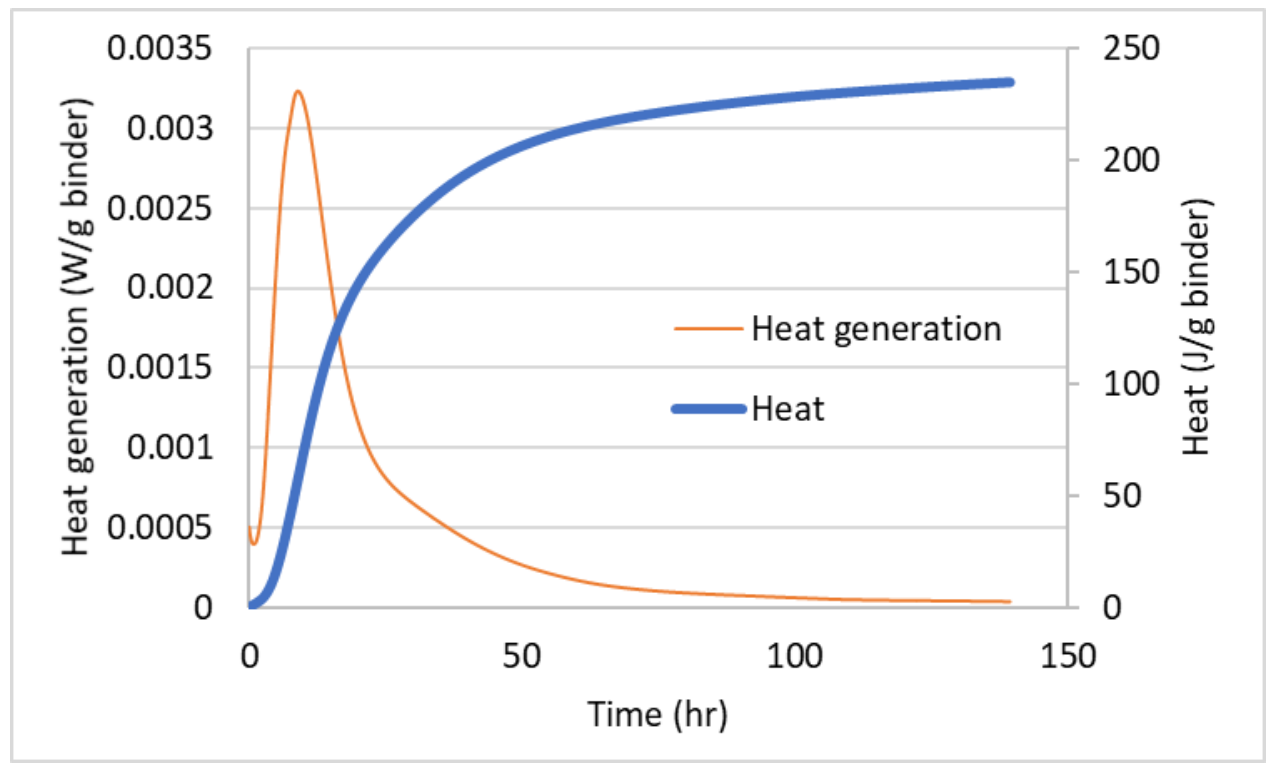

Figure 6-6: Isothermal heat of hydration measurement of District-10 mix

\subsection{Adiabatic Temperature Rise Measurement}

Besides isothermal tests, the adiabatic temperature rise of each blend was also tested in an adiabatic calorimeter developed at WVU (Lin and Chen, 2015). The adiabatic calorimeter was constructed, following Gibbon et al.'s concept (Gibbon, Ballim, and Grieve 1997; Lin and Chen 2015). The heat loss was controlled by keeping the temperature of the concrete sample and surrounding water the same in addition to adding a layer of polystyrene foam around the sample holder. The accuracy of the temperature measurements was between 0.1 to $0.5{ }^{\circ} \mathrm{C}$ using RTD sensors. The measured adiabatic temperature rises are shown in Figure 6-7, Figure 6-8, and Figure 6-9. 


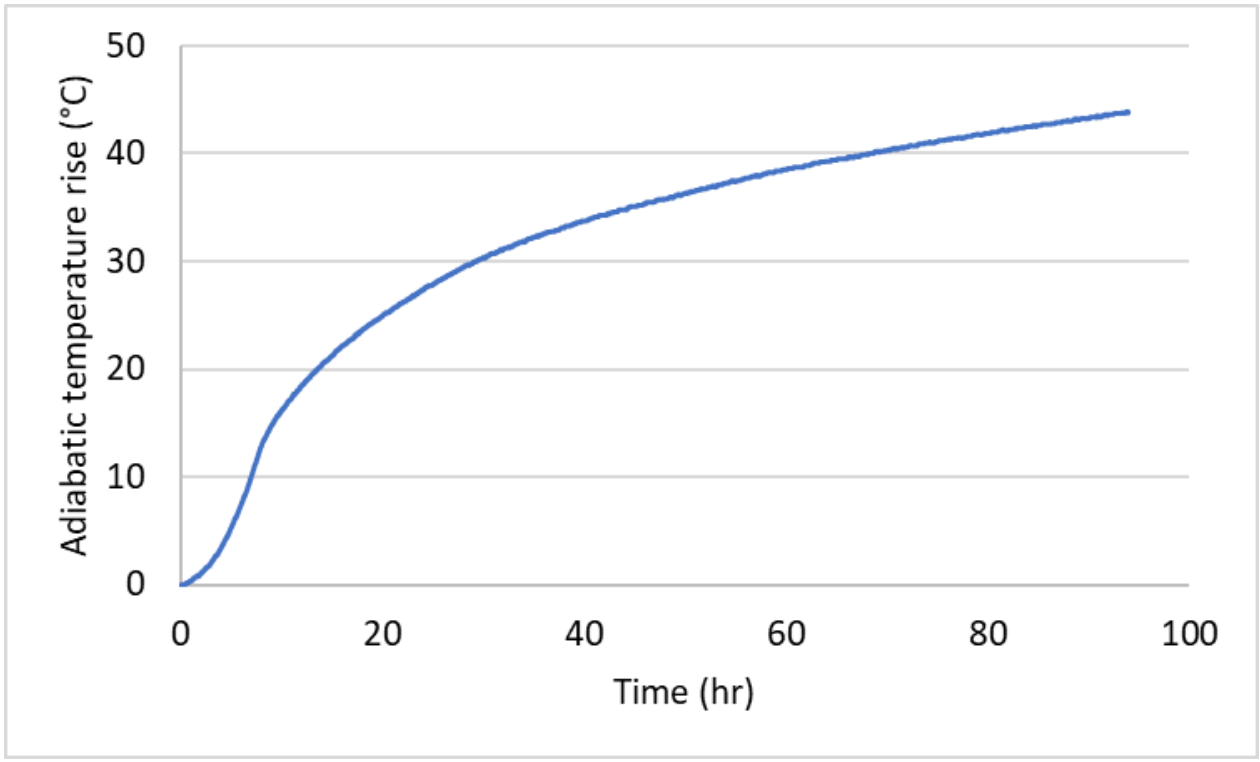

Figure 6-7: ATR of District-4 mix

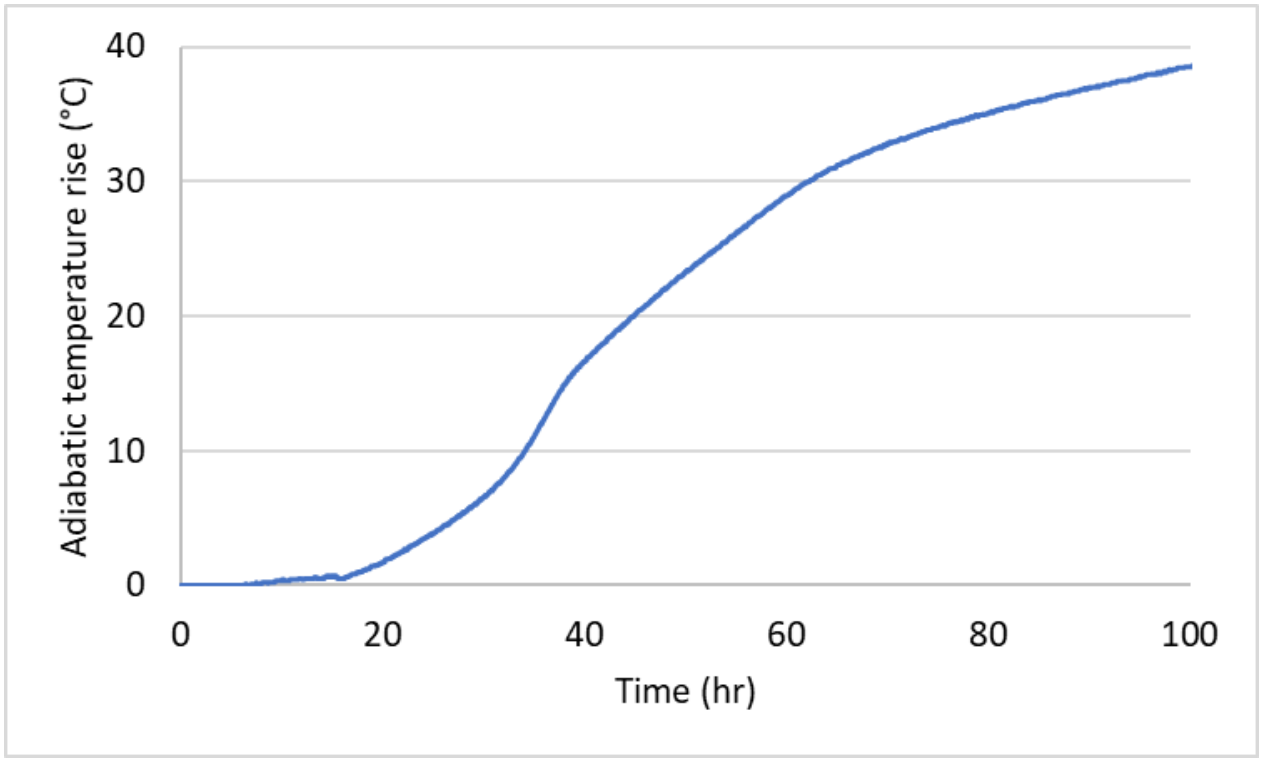

Figure 6-8: ATR of District-5 mix 


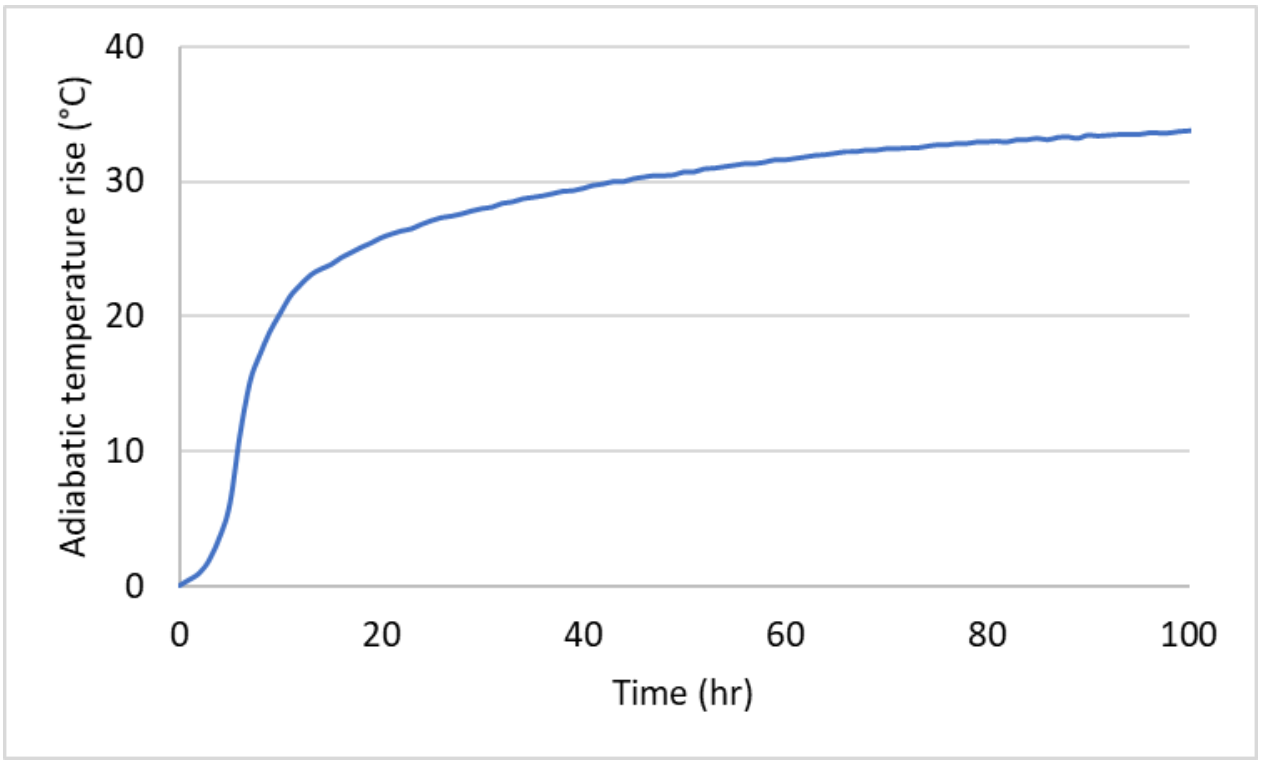

Figure 6-9: ATR of District-10 mix

\subsection{Analysis \& Comparisons of ATR}

The temperature history of each $1-\mathrm{m}$ cube was used to calculate the adiabatic temperature rises based on the method explained in Chapter 4. The average heat loss characteristic coefficients, minimum, maximum and average ambient temperatures of the district cubes are shown in Table 6-2. Based on the average ambient temperature, the heat loss characteristic coefficients were compared to the minimum required $\lambda$ (Figure 4-13) and shown in Figure 6-10. As shown in Figure 6-10 the amount of insulations were enough for all three districts' cubes; therefore, the method of ATR calculation using the cube's center temperature is applicable to these cases. Then, the results of ATR calculated by the compensation of heat loss using cube temperature data were compared to the results obtained from the adiabatic and isothermal calorimetry in Figure 6-11, Figure 6-12, and Figure 6-13. The normalized heat of hydration ( $\mathrm{J} / \mathrm{g}$ binder) measured by the isothermal calorimetry was divided by the density and calculated specific heat of concrete based on mix design proportions. The densities are $2348.13,2348.16$ and $2357.63 \mathrm{~kg} / \mathrm{m}^{3}$ based on the measured on-site w/cm ratios of D-4, D-5 and D-10 delivered batch, respectively. The specific heat was 
considered to be variable and calculated based on Equation (4-7). A weighted average (using the proportions of cement, slag and fly ash in each mix) specific heat of cementitious materials was used to calculate the ATR from the heat of hydration since the district's mixes contained slag and fly ash. Krishnaiah et al (Krishnaiah and Singh 2006) measured the specific heat of supplementary cementitious materials at different compaction levels. The value of 640 and $720 \mathrm{~J} / \mathrm{kg} /{ }^{\circ} \mathrm{C}$ was reported for slag and fly ash, respectively. Therefore, Equation (4-7) was revised to have 690 (D4 and D-5 mix) and 734 (D-10 mix) $\mathrm{J} / \mathrm{kg} /{ }^{\circ} \mathrm{C}$ instead of $740 \mathrm{~J} / \mathrm{kg} /{ }^{\circ} \mathrm{C}$ which was assumed for Portland cement. The degree of hydration in Equation (4-7) was calculated based on the heat release divided by the ultimate heat of hydration, $H_{u}$, for each mix (Shown in Table 6-4). The ultimate degree of hydration, $\alpha_{u}$, is calculated based on a w/cm ratio based equation and shown in Table 6-4. The equivalent age was calculated using the activation energies of 53,000 J/mol for District 4 and District 5 and 47,947 J/mol for District 10 mix. The activation energies obtained using ASTM C1074 (“Standard Practice for Estimating Concrete Strength by the Maturity Method” 2019). At 100 equivalent hours the maximum difference between all three ATR are $0.5,2.1$ and $2.4{ }^{\circ} \mathrm{C}$ for District-4, District-5 and District-10 mixes. The District-5 ATR based on the isothermal calorimetry was shifted to the beginning of the ATR calorimetry and heat compensated ATR heat generation since the isothermal calorimetry samples were not mixed with chemical admixtures and District-5 mix had an excessive amount of superplasticizer.

Table 6-2: Calculated heat loss characteristic coefficient for each cube

\begin{tabular}{ccccc}
\hline Location & $\begin{array}{c}\text { Minimum Ambient } \\
\text { Temperature }\left({ }^{\circ} \mathrm{C}\right)\end{array}$ & $\begin{array}{c}\text { Maximum Ambient } \\
\text { Temperature }\left({ }^{\circ} \mathrm{C}\right)\end{array}$ & $\begin{array}{c}\text { Average Ambient } \\
\text { Temperature }\left({ }^{\circ} \mathrm{C}\right)\end{array}$ & $\boldsymbol{\lambda}\left(\boldsymbol{h r} .^{-\mathbf{1}}\right)$ \\
\hline District 4 & 11 & 31 & 19 & 0.00574 \\
\hline District 5 & 2 & 22 & 12.4 & 0.00485 \\
\hline District 10 & 8 & 31 & 24.4 & 0.00429 \\
\hline
\end{tabular}




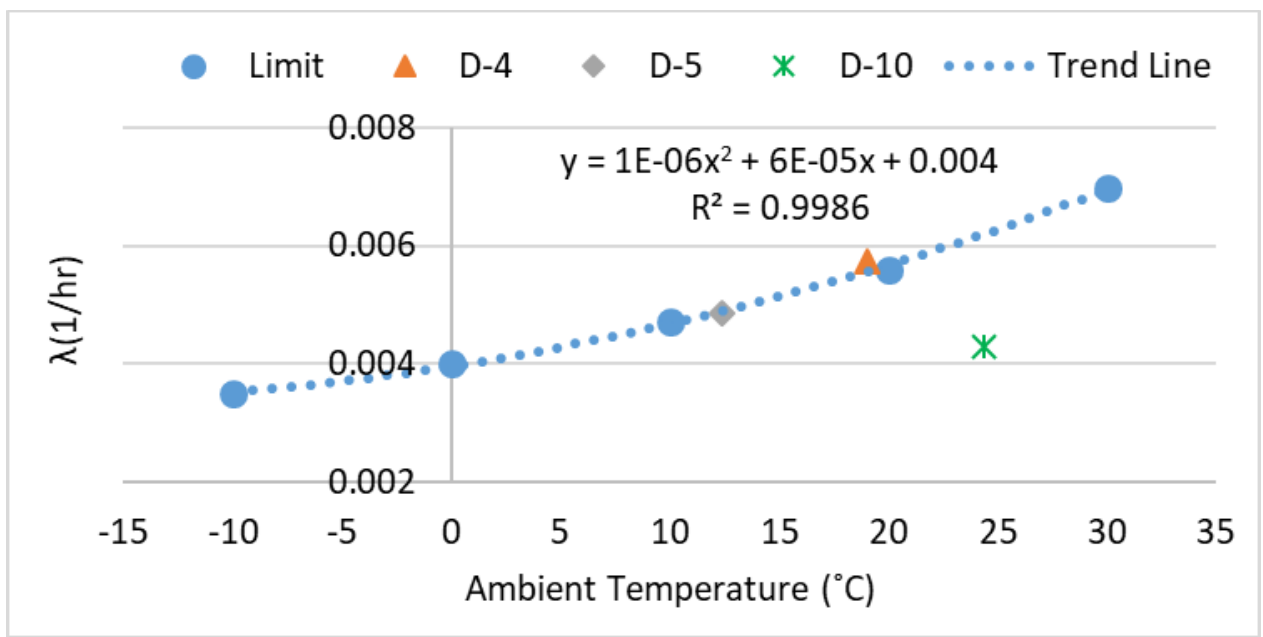

Figure 6-10: Cube's heat loss characteristic coefficients vs. reference

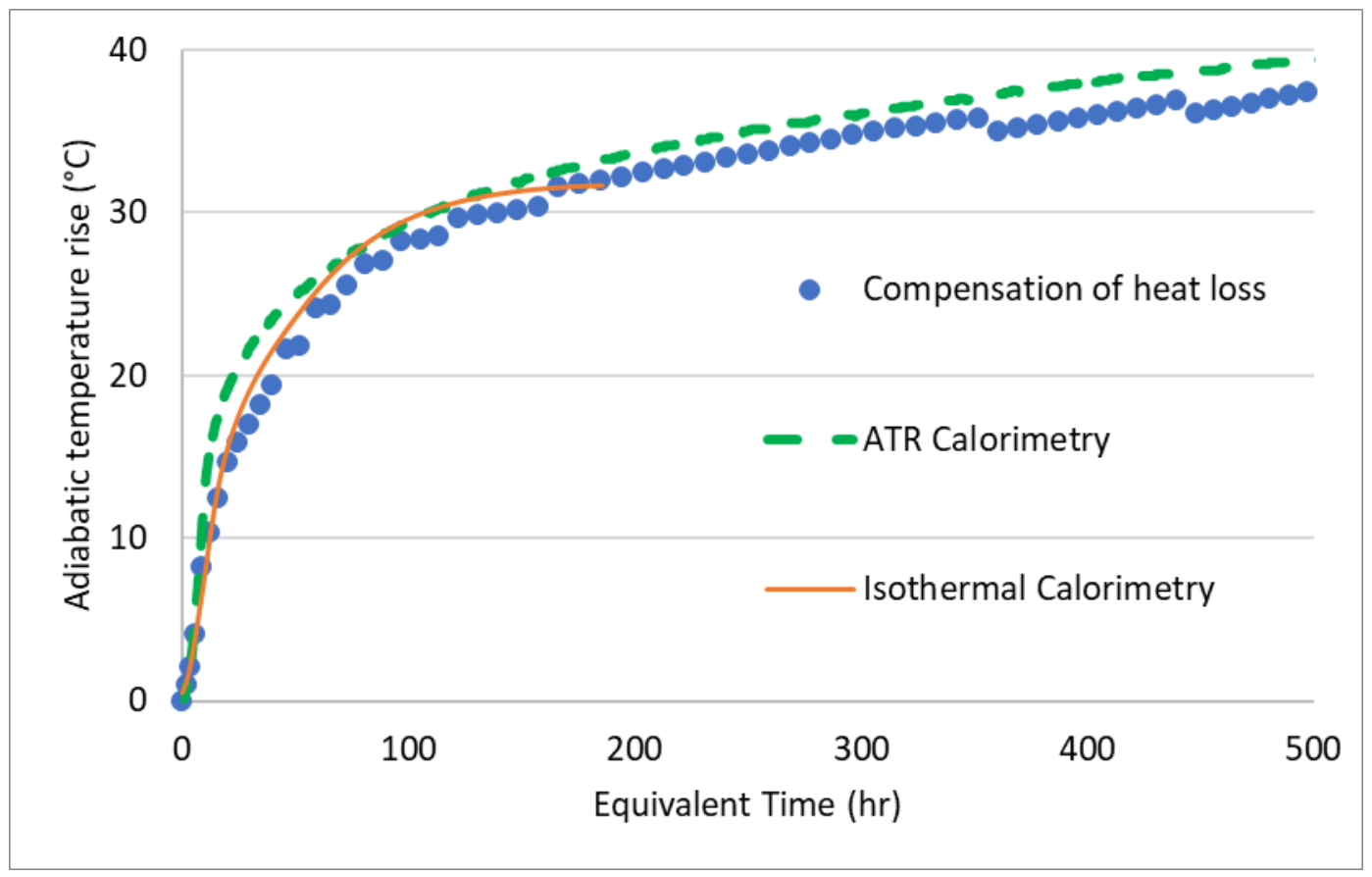

Figure 6-11: District 4 adiabatic temperature rise comparison 


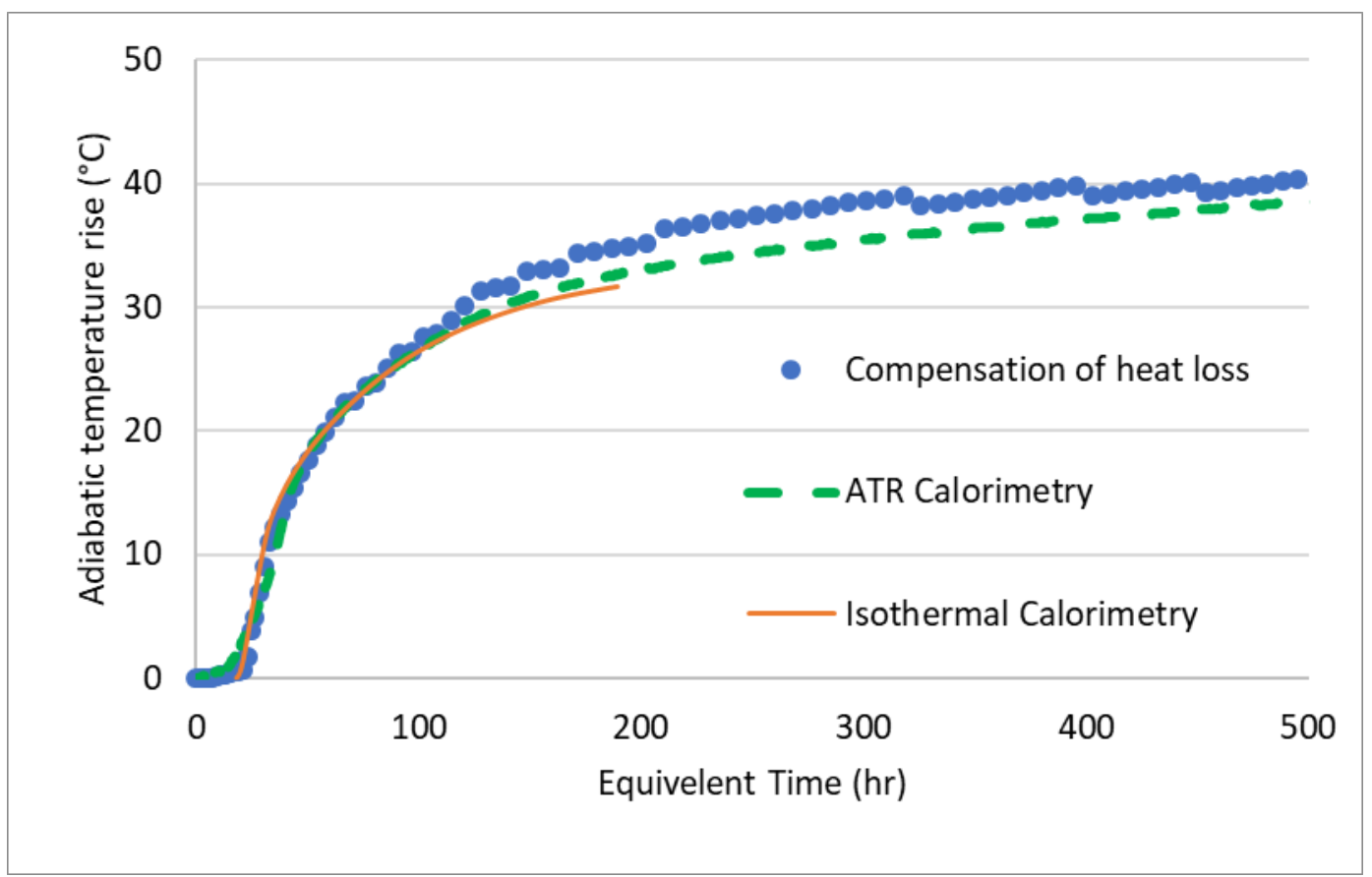

Figure 6-12: District 5 adiabatic temperature rise comparison

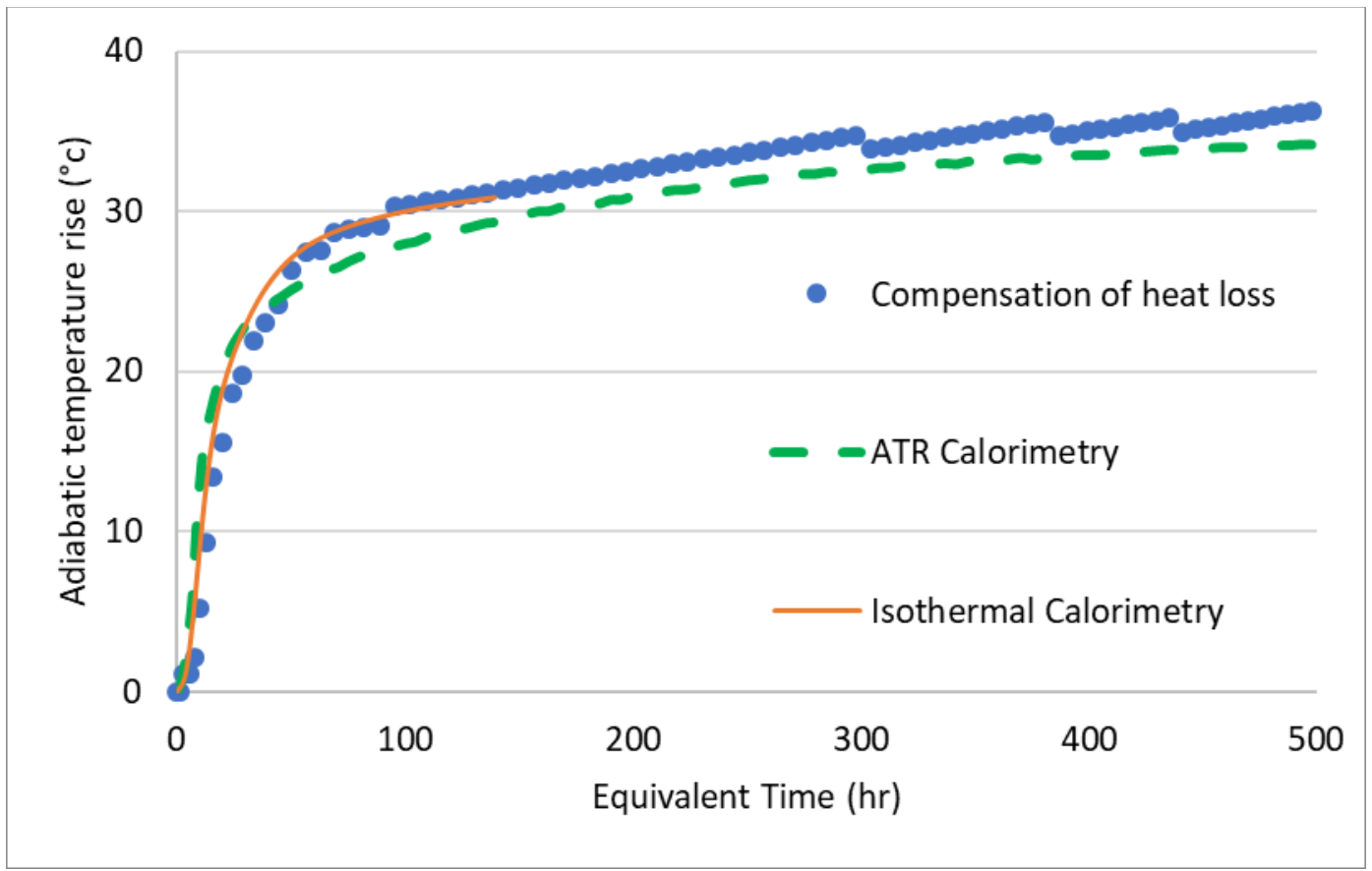

Figure 6-13: District 10 adiabatic temperature rise comparison 
The hydration parameters of the three mixes, defined based on the heat compensated ATR are shown in Figure 6-11, Figure 6-12 and Figure 6-13. The $\tau$ and $\beta$ parameters were decided by the summation of error squares analysis. The ultimate heat of hydration, $H_{u}$ was calculated based on the cement chemical compositions and the proportions of slag and fly ash in the mix design, shown in Equation (6-2) (Schindler and Folliard 2005). In Equation (6-2), the ultimate heat of hydration of Portland cement, $H_{c e m}$, was calculated using Equation (6-1) based on its chemical properties (shown in Table 6-3). The ultimate degree of hydration, $\alpha_{u}$ was calculated using Equation (6-3) which is a w/cm ratio dependent function.

$$
\begin{aligned}
& H_{c e m}=500 P_{C_{3} S}+260 P_{C_{2} S}+866 P_{C_{3} A}+420 P_{C_{4} A F}+624 P_{S_{3}}+1186 P_{\text {freeCaO }}+850 P_{M g O} \\
& H_{u}=H_{c e m} \cdot P_{c e m}+H_{S L} \cdot P_{S L}+1800 P_{F A-C a O} \cdot P_{F A} \\
& \alpha_{u}=\frac{1.031(w / c m)}{0.194+{ }^{W} / \mathrm{cm}}+0.50 P_{F A}+0.30 P_{S L}
\end{aligned}
$$

Where $P_{C_{3} S}, P_{C_{2} S}, P_{C_{3} A}, P_{C_{4} A F}, P_{S_{3}}, P_{\text {freeCao }}$ and $P_{M g o}$ are the mass proportions of cement chemical compounds, $\mathrm{SO}_{3}$, free $\mathrm{CaO}$ (assumed to be $1 \%$ ) and $\mathrm{MgO}$ in Portland cement, $P_{c e m}, P_{S L}$, $P_{F A}$ are the mass fractions of cement, slag and fly ash in total cementitious materials and $P_{F A-C a O}$ is the mass proportions of $\mathrm{CaO}$ in the fly ash. $H_{S L}$ in Equation (6-2) was originally assumed to be $461(\mathrm{~J} / \mathrm{g})$ based on the assumption of Maekawa et al. (Maekawa, Ishida, and Kishi 2009) with the slag major chemical compositions of $\mathrm{CaO}=43.3 \%$ and $\mathrm{SiO}_{2}=31.3 \%$. The $H_{S L}$ for the two types of slag materials were obtained based on the isothermal $\left(23{ }^{\circ} \mathrm{C}\right)$ heat measurement of slag in $25 \%$ hydrated limewater as a source of alkali. The two D-4 and D-5 slag materials were compared to a reference slag with a similar major chemical composition (shown in Table 6-3) as Maekawa et al.'s slag. It can be assumed that the same behavior might be observed using Maekawa et al. slag 
hydrated with the $25 \%$ limewater solution. Therefore, the ultimate heat of slag assumed by Maekawa et al. (461 J/g) was reduced following the heat ratio between the D-4, D-5 slag over the reference slag (shown in Figure 6-15). Based on the assumption, the reductions need to be approximately $70 \%$ and 50\% from the Maekawa et al.'s assumption; therefore, D-4 and D-5 slag's ultimate heat were assumed to be 322.7 and $230.5 \mathrm{~J} / \mathrm{g}$, respectively. Finally, the hydration parameters of these mixes are obtained and shown in Table 6-4.

Table 6-3: Chemical composition of cementitious Materials

\begin{tabular}{|c|c|c|c|c|c|c|c|c|c|}
\hline $\begin{array}{l}\text { Chemical } \\
\text { Properties }\end{array}$ & $\begin{array}{l}\text { LOI } \\
(\%)\end{array}$ & $\begin{array}{l}\mathrm{CaO} \\
(\%)\end{array}$ & $\begin{array}{c}\mathrm{SiO}_{2} \\
(\%)\end{array}$ & $\begin{array}{c}\mathrm{Al}_{2} \mathrm{O}_{3} \\
(\%)\end{array}$ & $\begin{array}{c}\mathrm{Fe}_{2} \mathrm{O}_{3} \\
(\%)\end{array}$ & $\begin{array}{c}\text { MgO } \\
(\%)\end{array}$ & $\begin{array}{l}\mathrm{SO}_{3} \\
(\%)\end{array}$ & $\begin{array}{c}\mathrm{Na}_{2} \mathrm{O} \\
(\%)\end{array}$ & $\begin{array}{l}\mathrm{K}_{2} \mathrm{O} \\
(\%)\end{array}$ \\
\hline Cement (D-4) & 2.93 & 63.41 & 19.91 & 5.17 & 3.48 & 2.55 & 3.25 & 0.08 & 0.84 \\
\hline Cement (D-5) & 2.74 & 63.95 & 19.61 & 5.42 & 4.06 & 1.19 & 3.08 & 0.04 & 0.66 \\
\hline Cement (D-10) & 2.65 & 63.39 & 20.19 & 5.12 & 3.48 & 2.17 & 2.67 & 0.087 & 0.83 \\
\hline Fly ash (D-10) & 1.5 & 6.69 & 43.46 & 21.06 & 17.39 & 0.87 & 1.68 & 1.77 & 1.84 \\
\hline Reference Slag & - & 47.48 & 28.89 & 8.27 & 1.93 & 8.34 & 0.73 & - & - \\
\hline
\end{tabular}

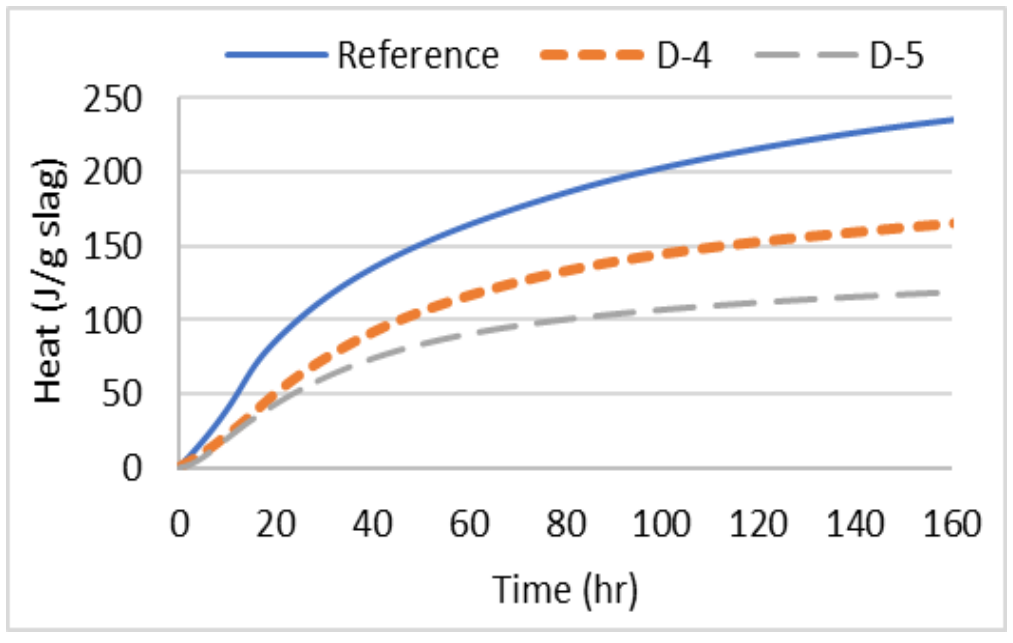

Figure 6-14: Comparison of slag materials heat of hydration 


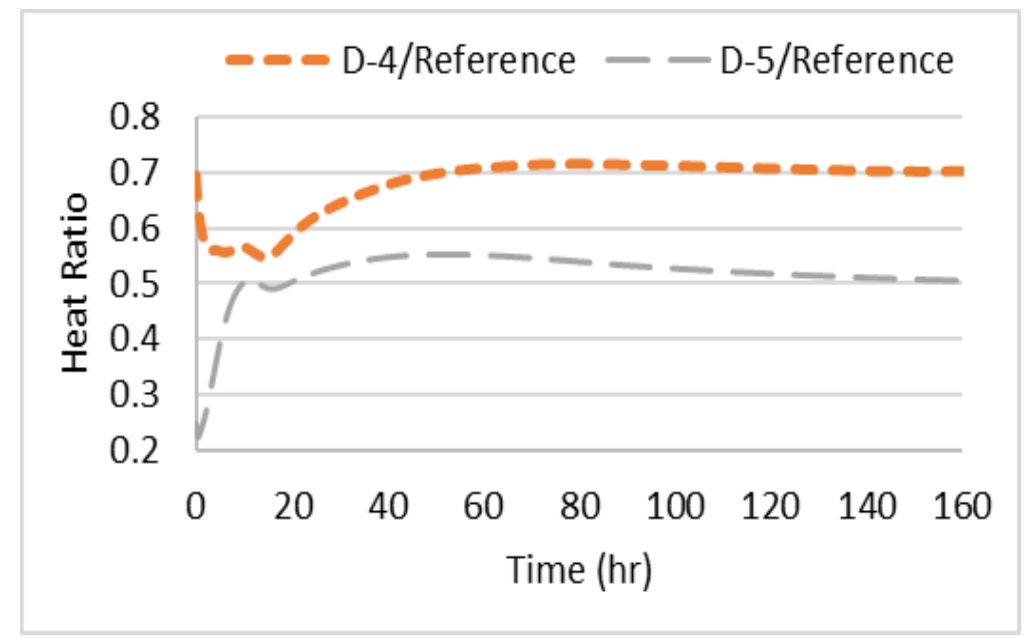

Figure 6-15: Heat ratios of slag materials

Table 6-4: Hydration parameters

\begin{tabular}{ccccccc}
\hline Location & $\boldsymbol{\tau}$ & $\boldsymbol{\beta}$ & $\begin{array}{c}\boldsymbol{H}_{\boldsymbol{c e m}} \\
(\mathbf{J} / \mathbf{g})\end{array}$ & $\begin{array}{c}\boldsymbol{H}_{\boldsymbol{u}} \\
(\mathbf{J} / \mathbf{g})\end{array}$ & $\boldsymbol{\alpha}_{\boldsymbol{u}}$ & $\begin{array}{c}\boldsymbol{E}_{\boldsymbol{a}} \\
(\mathbf{J} / \mathbf{m o l})\end{array}$ \\
\hline District 4 & 28.5 & 0.52 & 492,571 & 407,630 & 0.859 & 53,000 \\
\hline District 5 & 25 & 0.76 & 488,041 & 359,270 & 0.889 & 53,000 \\
\hline District 10 & 21.9 & 0.65 & 483,560 & 374,618 & 0.891 & 47,947 \\
\hline
\end{tabular}

The hydration parameters, shown in Table 6-4, can be used to obtain the ATR for a similar type of mix design and chemical compositions of the cementitious materials. Using Equation (4-7) and Equation (4-11), the following equation can be obtained to calculate ATR with known hydration parameters.

$$
\begin{aligned}
& T_{a d}(t)=\left(\frac{W_{c}}{\rho \cdot C_{p}\left(\alpha_{r}, T(t)\right)}\right) H(t), \quad H(t)=\int_{0}^{t} q(t) d t \\
& T_{a d}(t)=\left(\frac{W_{c} H_{u} \alpha_{u}}{\rho \cdot C_{p}\left(\alpha_{r}, T(t)\right)}\right) \int_{0}^{t} \exp \left(-\left[\frac{\tau}{t_{e}}\right]^{\beta}\right)\left[\frac{\tau}{t_{e}}\right]^{\beta} \frac{\beta}{t_{e}} \exp \left(\frac{E_{a}}{R}\left(\frac{1}{T(t)+273}-\frac{1}{23+273}\right)\right) d t
\end{aligned}
$$


The ATRs obtained using Equation (6-4) in comparison with the experimental results are shown in Figure 6-16, Figure 6-17 and Figure 6-18. In addition, these figures show the comparisons between the district' ATRs versus the ATR obtained by $100 \%$ Portland cement mix (using Table 4-1 hydration parameters). As Figure 6-16, Figure 6-17 and Figure 6-18 represent, $50 \%$ and 30\% replacements of Portland cement by slag and fly ash, respectively, greatly reduced the heat of hydration and ATR of the concrete.

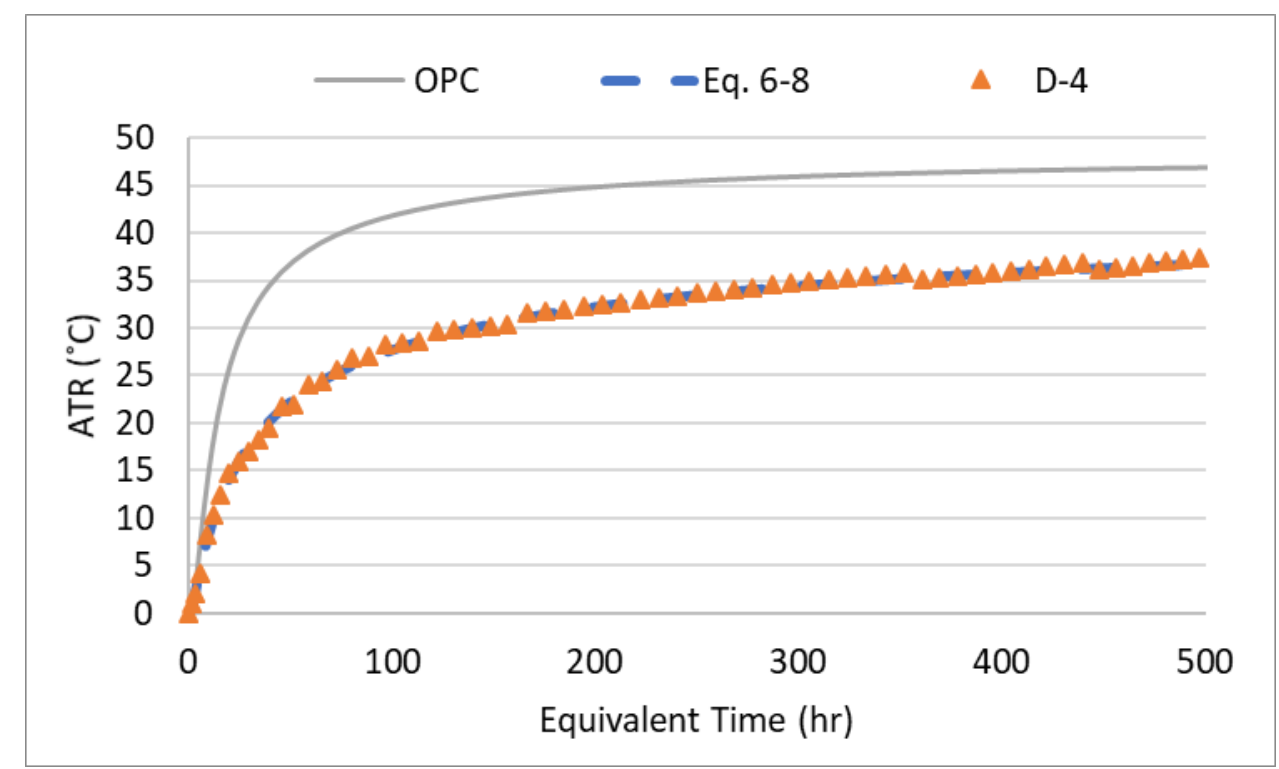

Figure 6-16: Analysis vs. experiment (District-4) 


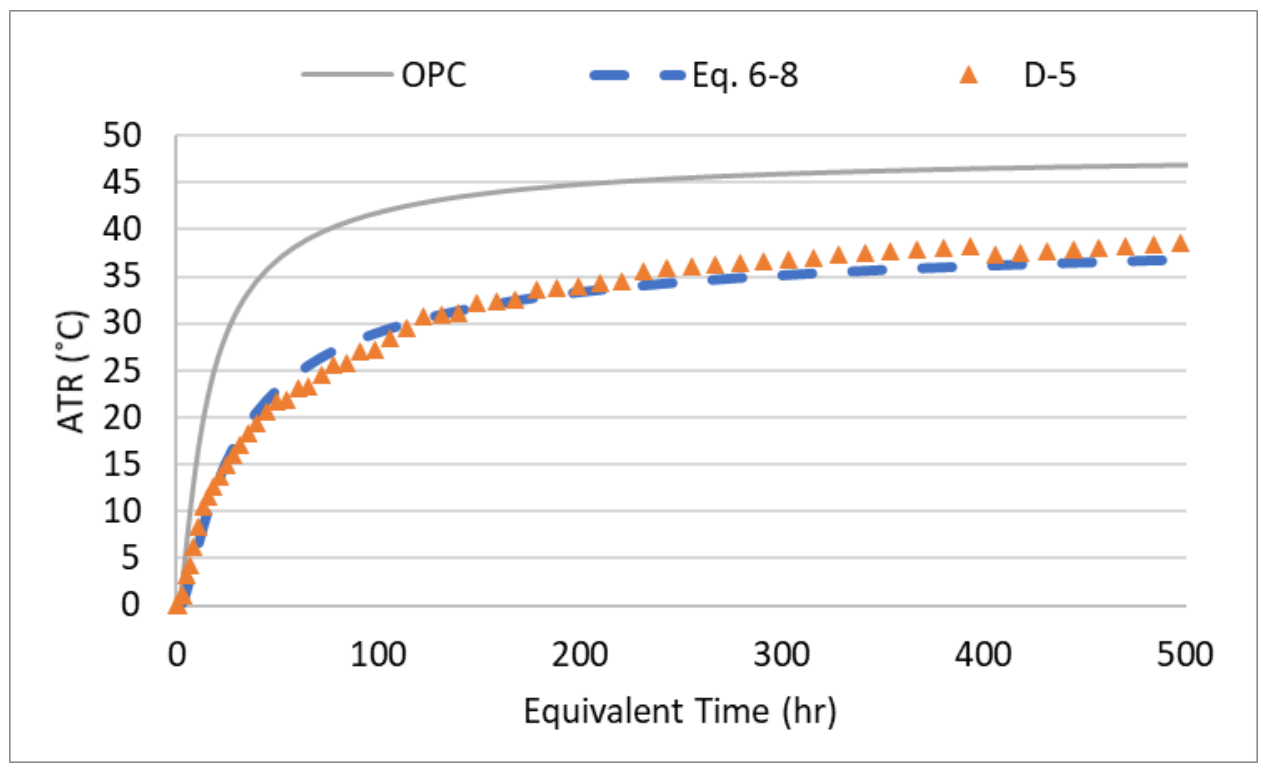

Figure 6-17: Analysis vs. experiment (District-5)

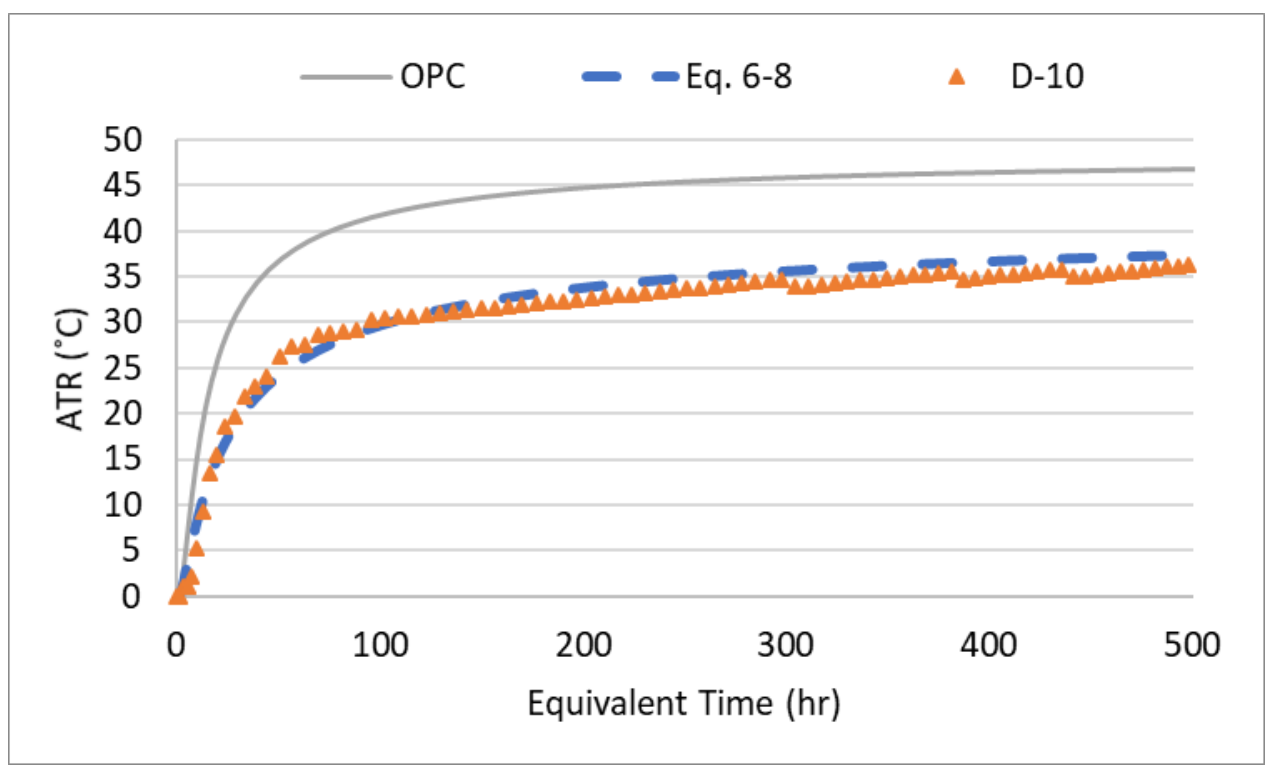

Figure 6-18: Analysis vs. experiment (District-10) 


\section{Chapter 7 : Conclusions \& Recommendations}

\subsection{Conclusions}

In this study, the most recent AASHTO T318-15 guideline was adopted and improved to have better precision in estimating the water amount of an on-site delivered concrete mix. Since the coarse aggregate amount in each sample could vary, the method proposed requires sieving the coarse aggregate from the dried sample and separating the mass of the fine aggregate and cementitious material based on the mix design ratios. The results of the experiments indicated the accuracy of the proposed method was increased to have an average error of about $2.16 \%$ from the actual mix design w/cm ratio whereas the method based on AASHTO calculations had an error of $6.2 \%$. Using the revised method, the results of laboratory tests were consistent among the samples from the same batch which also indicates the accuracy of the revised method when considering the actual mass of coarse aggregate for each sample. In the case of higher amount of chemical admixture in the mixes, washing vinegar was used to wash out the particles around the dried aggregate, which was dissolved by the vinegar's acid, was calculated based on its stoichiometric reaction equation.

Additionally, a 1-meter cube was used as an on-site semi-adiabatic calorimetry. The estimation of the spatial temperature profile within the concrete volume is not simple, therefore, a practical method is required to simplify the calculation. It can be assumed that both volumetric and surface temperatures are equal to the measured center temperature. A minimum amount of insulation should be obtained to satisfy this condition for any ambient temperatures so that calculated ATR has enough accuracy. The on-site semi-adiabatic calorimetry setup can be used in ambient weather conditions with variations more significant than the laboratory conditions. The setup was analyzed in a finite element model, and a table was provided for the required insulations 
in different ambient temperatures ranging from -10 to $30{ }^{\circ} \mathrm{C}$. On-site measurements of heat of hydration using a cube located beside the real structure can be a useful, accurate, and straightforward practice.

The applicability of the proposed procedures for the on-site measurement of $w / \mathrm{cm}$ ratio and adiabatic temperature rise were tested in several field situations. Three on-site castings took place in three different district locations (District 4, District 5, and District 10) in the state of West Virginia. On-site testing of slump, air content and water cementitious ratio were performed. The measured on-site water cement ratio for both District 5 and District 10 mixes were much higher than their corresponding mix design ones. The compressive strength cylinders were made on-site and cured at $23{ }^{\circ} \mathrm{C}$ reference temperature. One-meter concrete cubes were made and placed on-site to measure the heat of hydration of the mixes.

Using all materials collected from each district location, several laboratory mixes were made. The compressive strength and heat of hydration was again measured then compared to the on-site batches. The heat of hydration was measured using the isothermal and adiabatic calorimetry. The compressive strength results can reversely confirm that the average measured w/cm ratio results are indeed higher than their mix design ones since the compressive strength results of laboratory batches of both Districts 5 and 10 are much higher than their corresponding on-site batches. Using the average measured ambient temperatures of the cubes and calculated heat loss characteristic coefficients, the calculation of ATR using the center temperature method is applicable to the district cases. The calculated ATR from the temperature time histories of the onsite 1-m cube using the compensation method was compared well with the ATR measured by the isothermal and adiabatic calorimetry with the maximum difference of $2.4{ }^{\circ} \mathrm{C}$ in 100 equivalent hours related to District 10 batch. Results show that both on-site measurement methods are 
applicable and useful and can accurately measure w/cm ratio and heat of hydration of fresh concrete at the job site.

\subsection{Recommendations for future work}

* It was mentioned that sand and cementitious materials are the two components that are not easy to separate from the dried specimen after sieving the large aggregates which can be addressed to improve the accuracy of the revised w/cm ratio method. In addition, washing the aggregate using vinegar was only studied on Limestone type of aggregate; however, other type of aggregate can be tested.

* The same procedure that was used to develop the required insulation table for the 1-m cube may be obtained for smaller size specimens since it would be easier to dispose a smaller cube after the experiment has ended. To have a more comprehensive approach that can be used to accurately calculate ATR for any type of on-site calorimetry design with any ambient conditions, the author of this study will be working on an inverse threedimensional heat conduction approach using numerical analysis in his $\mathrm{Ph} . \mathrm{D}$. study. 


\section{REFERENCES}

Broda, M., E. Wirquin, and B. Duthoit. 2002. "Conception of an Isothermal Calorimeter for Concrete- Determination of the Apparent Activation Energy." Materials and Structures 35 (7): 389-94. https://doi.org/10.1007/BF02483141.

C. T. Tam, Y. H. Loo, and K. F. Choong. 1994. "Adiabatic Temperature Rise in Concrete With and Without GGBFS." ACI Symposium Publication 149 (October). https://doi.org/10.14359/4116.

Center, H.I.T.E. 1996. Evaluation of the Troxler Model 4430 Water-Cement Gauge. CERF Reports 96-03-F. Civil Engineering Research Foundation. https://books.google.com/books?id=zbj8L10AtB0C.

Chen, Wei, Peiliang Shen, and Zhonghe Shui. 2012. "Determination of Water Content in Fresh Concrete Mix Based on Relative Dielectric Constant Measurement." Construction and Building Materials 34 (Supplement C): 306-12. https://doi.org/10.1016/j.conbuildmat.2012.02.073.

De Schutter, G., and L. Taerwe. 1995. "General Hydration Model for Portland Cement and Blast Furnace Slag Cement.” Cement and Concrete Research 25 (3): 593-604. https://doi.org/10.1016/0008-8846(95)00048-H.

Do, Tu Anh. 2013. "Finite Element Modeling of Behavior of Mass Concrete Placed on Soil." Doctorate (Ph.D.), Gainesville, Florida: University of Florida.

Dowell, A., and S. Cramer. 2002. "Field Measurement of Water-Cement Ratio for Portland Cement Concrete - Phase II Field Evaluation and Development.” \#0092-45-16. Wisconsin Highway Research Program.

Eddhahak, Anissa, Sarra Drissi, Johan Colin, Sabine Caré, and Jamel Neji. 2014. "Effect of Phase Change Materials on the Hydration Reaction and Kinetic of PCM-Mortars." Journal of Thermal Analysis and Calorimetry 117 (2): 537-45. https://doi.org/10.1007/s10973-014-3844-x.

Fox, M., S. Trost, and S. Hellman. 2007. "Evaluation of Novel Methods to Measure Water-toCement Ratio of Fresh Concrete." Final Report for Highway IDEA Project 105.

Gibbon, G., Y. Ballim, and G. Grieve. 1997. "A Low-Cost, Computer-Controlled Adiabatic Calorimeter for Determining the Heat of Hydration of Concrete." Journal of Testing and Evaluation 25 (no.2): 261-66.

Gruyaert, E., N. Robeyst, and N. De Belie. 2010. "Study of the Hydration of Portland Cement Blended with Blast-Furnace Slag by Calorimetry and Thermogravimetry." Journal of Thermal Analysis and Calorimetry 102 (3): 941-51. https://doi.org/10.1007/s10973-0100841-6.

Hershberger, J. 2015. "A Study of Self Consolidating Concrete for Cast in Place Applications: Current Practices, Rapid W/Cm Determination, and Stability Effects of Pumping." M.S. Thesis, Morgantown: West Virginia University.

Hossain, Mustaque, James Koelliker, Hisham Ibrahim, and John Wojakowski. 1996. "Kansas Water-Cement Ratio Meter: Preliminary Results." Transportation Research Record: Journal of the Transportation Research Board 1532 (January): 73-79. https://doi.org/10.3141/1532-11. 
K. A. MacDonald and D. O. Northwood. 1999. "Rapid Estimation of Water-Cementitious Ratio and Chloride Ion Diffusivity in Hardened and Plastic Concrete by Resistivity Measurement." Special Publication 191 (December). https://doi.org/10.14359/5734.

Klemczak, Barbara, and Maciej Batog. 2016. "Heat of Hydration of Low-Clinker Cements." Journal of Thermal Analysis and Calorimetry 123 (2): 1351-60. https://doi.org/10.1007/s10973-015-4782-y.

Krishnaiah, S., and D.N. Singh. 2006. "Determination of Thermal Properties of Some Supplementary Cementing Materials Used in Cement and Concrete." Construction and Building Materials 20 (3): 193-98. https://doi.org/10.1016/j.conbuildmat.2004.10.001.

Kyle A. Riding, Jonathan L. Poole, Anton K. Schindler, Maria C. G. Juenger, and Kevin J. Folliard. 2006. "Evaluation of Temperature Prediction Methods for Mass Concrete Members." ACI Materials Journal 103 (5). https://doi.org/10.14359/18158.

L. Poole, Jonathan, Kyle Riding, Kevin Folliard, Maria C.G. Juenger, and Anton Schindler. 2007. Methods for Calculating Activation Energy for Portland Cement. Vol. 104.

Leung, Christopher K.Y., and Thanakorn Pheeraphan. 1995. "Very High Early Strength of Microwave Cured Concrete." Cement and Concrete Research 25 (1): 136-46. https://doi.org/10.1016/0008-8846(94)00121-E.

Lin, Yun, and Hung-Liang Chen. 2015. "Thermal Analysis and Adiabatic Calorimetry for EarlyAge Concrete Members." Journal of Thermal Analysis and Calorimetry 122 (2): 937-45. https://doi.org/10.1007/s10973-015-4843-2.

Maekawa, Koichi, Tetsuya Ishida, and Toshiharu Kishi. 2009. Multi-Scale Modeling of Structural Concrete. 1 edition. London; New York: CRC Press.

Mancio, Mauricio, J R. Moore, Z Brooks, P Monteiro, and S D. Glaser. 2010. Instantaneous InSitu Determination of Water-Cement Ratio of Fresh Concrete. Vol. 107.

Meeks, Corey, and Kevin Folliard. 2013. "ConcreteWorks Implementation: Final Report." University of Texas at Austin. Center for Transportation Research (CTR).

N. T. Ali, K. Mubarak, N. McEwan, K. A. Mezher, A. Kulaib, and A. Al-Zarouni. 2010. "Reflectometer Apparatus for Rapid Determination of Water-Cement Ratio." In 2010 17th IEEE International Conference on Electronics, Circuits and Systems, 1061-63. https://doi.org/10.1109/ICECS.2010.5724698.

Nägele, E., and H.K. Hilsdorf. 1980. "A New Method for Cement Content Determination of Fresh Concrete." Cement and Concrete Research 10 (1): 23-34. https://doi.org/10.1016/0008-8846(80)90048-4.

Nagi, M., and D. Whiting. 1994. "Determination of Water Content of Fresh Concrete Using a Microwave Oven." Determination of Water Content of Fresh Concrete Using a Microwave Oven.

Naik, Tarun R., and Bruce W. Ramme. 1987. "Determination of the Water Content of Concrete by the Microwave Method." Cement and Concrete Research 17 (6): 927-38. https://doi.org/10.1016/0008-8846(87)90081-0.

Nantung, T. 1998. "Determination of Water-to-Cement Ratio.” Interim Report for Indiana Department of Transportation. Indiana Department of Transportation.

Neville, A.M. 2011. Properties of Concrete. Pearson. https://books.google.com/books?id=TdfewmQ-cMIC.

Ng, P L, and A K H Kwan. 2012. "Semi-Adiabatic Curing Test with Heat Loss Compensation for Evaluation of Adiabatic Temperature Rise of Concrete." HKIE Transactions 19 (4): 11-19. https://doi.org/10.1080/1023697X.2012.10669000. 
P. L. Ng, I. Y. T. Ng, and A. K. H. Kwan. 2008. "Heat Loss Compensation in Semi-Adiabatic Curing Test of Concrete.” ACI Materials Journal 105 (1). https://doi.org/10.14359/19207.

Pane, Ivindra, and Will Hansen. 2005. "Investigation of Blended Cement Hydration by Isothermal Calorimetry and Thermal Analysis." Cement and Concrete Research 35 (6): 1155-64. https://doi.org/10.1016/j.cemconres.2004.10.027.

Pang, Xueyu, Walmy Cuello Jimenez, and Benjamin J. Iverson. 2013. "Hydration Kinetics Modeling of the Effect of Curing Temperature and Pressure on the Heat Evolution of Oil Well Cement." Cement and Concrete Research 54 (December): 69-76. https://doi.org/10.1016/j.cemconres.2013.08.014.

Pang, Xueyu, Christian Meyer, Robert Darbe, and Gary p. Funkhouser. 2013. "Modeling the Effect of Curing Temperature and Pressure on Cement Hydration Kinetics." ACI Materials Journal 110 (2). https://doi.org/10.14359/51685528.

Poole Jonathan L., Riding Kyle A., Juenger Maria C. G., Folliard Kevin J., and Schindler Anton K. 2011. "Effect of Chemical Admixtures on Apparent Activation Energy of Cementitious Systems.” Journal of Materials in Civil Engineering 23 (12): 1654-61. https://doi.org/10.1061/(ASCE)MT.1943-5533.0000345.

Roshore, E.C. 1973. "Use of Microwave Oven to Determine Water Content of Fresh Concrete." U.S. Army Engineer Waterways Experiment Station Report.

Schindler, Anton K., and Kevin J. Folliard. 2005. "Heat of Hydration Models for Cementitious Materials.” Materials Journal 102 (1). https://doi.org/10.14359/14246.

"Standard Method of Test for Water Content of Freshly Mixed Concrete Using Microwave Oven Drying." 2015. AASHTO T318. Washington, D.C: AASHTO The Voice of Transportation.

"Standard Practice for Estimating Concrete Strength by the Maturity Method." 2019. ASTM C1074.

"Standard Test Method for Relative Density (Specific Gravity) and Absorption of Coarse Aggregate." 15.

"Standard Test Method for Relative Density (Specific Gravity) and Absorption of Fine Aggregate." 15.

Tarun R. Naik and Bruce W. Ramme. 1989. "Determination of the Water-Cement Ratio of Concrete by the Buoyancy Principle." Materials Journal 86 (1). https://doi.org/10.14359/1796.

TC Members. 1997. "TCE1: Adiabatic and Semi-Adiabatic Calorimetry to Determine the Temperature Increase in Concrete Due to Hydration Heat of the Cement." Rilem.

Tia, Mang, Christopher Ferraro, Adrian Lawrence, Samuel Smith, and Eiji Ochiai. 2010. "Development of Design Parameters for Mass Concrete Using Finite Element Analysis." FDOT.

US Army Corps of Engineers. 1973. "CRD-C36-73 Method of Test for Thermal Diffusivity of Concrete." CRD-C36-73.

Van Breugel, K. 1980. "Artificial Cooling of Hardening Concrete.” Delft University of Technology.

Williamson, R. 1985. "Methods for Determining the Water and Cement Content of Fresh Concrete." Materials and Structures 18 (4): 269-78. https://doi.org/10.1007/BF02472915. 
Yikici, Tahsin Alper, and Hung-Liang (Roger) Chen. 2015. "Use of Maturity Method to Estimate Compressive Strength of Mass Concrete." Construction and Building Materials 95 (October): 802-12. https://doi.org/10.1016/j.conbuildmat.2015.07.026.

Yikici, Tahsin, and Hung-Liang Chen. 2015. Numerical Prediction Model for Temperature Development in Mass Concrete Structures. Vol. 2508. https://doi.org/10.3141/2508.

Zhang, Yunsheng, Wei Sun, and Sifeng Liu. 2002. "Study on the Hydration Heat of Binder Paste in High-Performance Concrete." Cement and Concrete Research 32 (9): 1483-88. https://doi.org/10.1016/S0008-8846(02)00810-4. 


\section{VITA}

Seyednavid Mardmomen was born in Gorgan, Iran, on August 31, 1990. He was a member of the National Organization for Development of Exceptional Talents (NODET) in middle and high school. He received a B.S. in Civil Engineering from Islamic Azad University-South Tehran Branch in Tehran, Iran, in the Spring of 2013. After finishing a semester in the Intensive English Program (IEP) at West Virginia University, he began graduate school in the fall of 2015 under the supervision of Dr. Roger Chen. In the fall of 2017, he was accepted into the Ph.D. program at West Virginia University. Up to this date, he has finished all the required $\mathrm{Ph} . \mathrm{D}$. course works and currently is working on his Ph.D. dissertation topic. The following peer-reviewed article was presented in the 2019 Transportation Research Board (TRB) annual meeting in Washington DC from his master's thesis. This article was accepted and published in the journal of Transportation Research Record (TRR) with the following citation:

Mardmomen, S., Chen, H.-L. (Roger), \& Leon, G. (2019). Revised Method for Rapid Determination of On-Site Water-Cement Ratio using Microwave Oven. Transportation Research Record, 2673(8), 1-10. https://doi.org/10.1177/0361198119849408 